\title{
Major cold-season precipitation events at Iqaluit, Nunavut
}

\author{
Gabrielle Gascon \\ Master of Science \\ Department of Atmospheric and Oceanic Sciences \\ McGill University \\ Montreal, Quebec, Canada \\ 23-07-2008 \\ A thesis submitted to McGill University \\ in partial fulfilment of the requirements \\ of the degree Master of Science
}

CGabrielle Gascon 2008 


\section{DEDICATION}

To my grand-father, Marcel Brisebois. 


\section{ACKNOWLEDGMENTS}

I would first like to express my thanks to my supervisor, Prof. Ronald Stewart for his guidance and enthusiasm throughout this research project. I gained tremendous knowledge and experience from him. He always generously gave of his time and offered me with the opportunity to participate to the Storm Studies in the Arctic field project. I am grateful to Dr. William Henson for his precious help with my thesis, from the methodology settings to the redaction. I am grateful to Shawn Milrad for his help with Gempak and to the members of the Extreme Weather group for their constructive comments. A special thanks to Maria, my officemate. I would like to thank Daniel Nadeau who continued helping me even abroad in Switzerland. I would also like to thank Rodica Nitu from the Environment Canada Weather and Environment Monitoring Division and Bob Kochtubajda from the Environment Canada Hydrometeorology and Arctic Lab for their help in providing archived precipitation data. I would also like to thank the Histoire-Geographie Departement of the Academie d'Aix-Marseille for the background map of North America. Finally, I would like to thank my parents, Pierre and Mance and their respective partners, Sylvie and Maurice, as well as my sisters Camille and Élise and my partner Guillaume for their constant love and support; a special thanks to my dog. This research has been carried out with the financial support of the Natural Sciences and Engineering Research Council of Canada, the Canadian Foundation for Climate and Atmospheric Sciences and ArcticNet. 


\begin{abstract}
This study focuses on cold-season (October-April) precipitation events at Iqaluit, Nunavut that exceed the $97^{\text {th }}$ percentile of daily corrected precipitation accumulation. The characteristics of 194 major precipitation events are described for the 1955-1996 period; four events were examined in great detail as well. Based on NCEP-NCAR and NARR reanalysis data, the low pressure systems that led to these events came from the South $(40 \%)$, the West $(29 \%)$, the Atlantic Ocean $(23 \%)$, or were triggered by short-wave troughs $(8 \%)$. The duration and precipitation rate of the events, rather than the speed of motion, were critical factors influencing on precipitation accumulation. High atmospheric moisture content and surface warm fronts were the common tropospheric features of these events. Snow was the dominant precipitation type and topography was important in terms of wind direction. The NAO index tends to influence the occurrence of major precipitation events, but is not a determining factor.
\end{abstract}




\begin{abstract}
ABRÉGÉ
Ce travail traite des évènements de précipitation qui sont supérieurs au $97^{\mathrm{e}}$ rang centile des précipitation quotidiennes à Iqaluit, Nunavut, durant la saison froide, soit d'octobre à avril. Nous décrivons les caractéristiques de 194 évènements de précipitation majeures qui se sont déroulés entre 1955 et 1996; quatre d'entre eux font l'objet d'une explication détaillée. Selon les données traitées par $N C E P-N C A R$ et $N A R R$, les systèmes dépressionnaires responsables de ces évènements provenaient du sud (40\%), de l'ouest (29\%), de l'océan Atlantique (23\%) ou étaient associés à des creux barométriques dans $8 \%$ des cas. Plus que la vitesse des systèmes dépressionnaires, la durée et le niveau de précipitation ont été des facteurs déterminant sur les accumulations. Le haut taux d'humidité atmosphérique et la présence de fronts chands en surface furent les caractéristiques troposphériques de ces évènements. La neige fut le principal type de précipitation et la topographie influença de manière importante la direction $\mathrm{du}$ vent. L'Oscillation Nord-Atlantique a certes une influence sur les évènements de précipitation majeures, mais ne peut être considéré comme un facteur déterminant.
\end{abstract}




\section{TABLE OF CONTENTS}

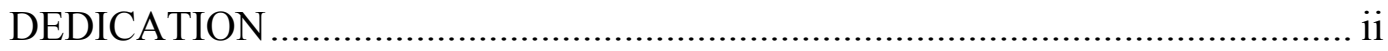

ACKLOWLEDGMENTS .............................................................................. ii

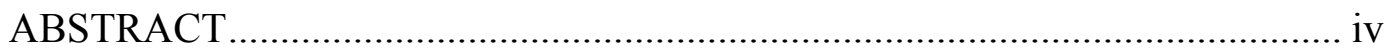

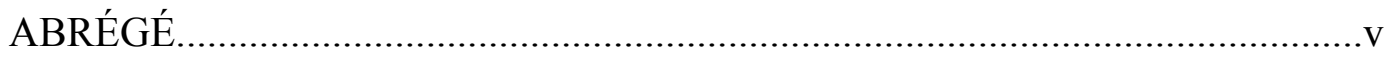

TABLE OF CONTENTS ............................................................................ vi

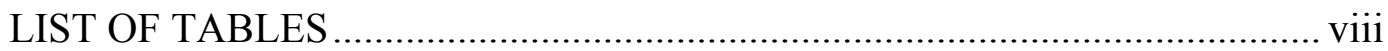

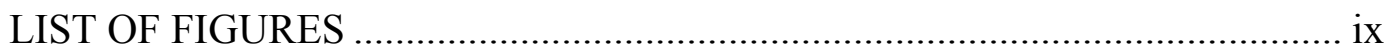

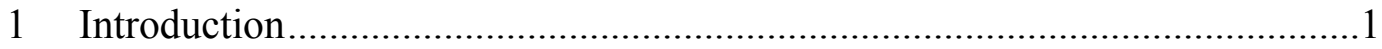

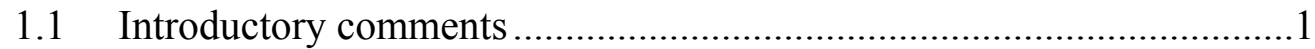

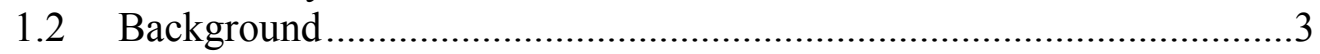

1.2.1 Cyclonic activity in the Arctic....................................................

1.2.2 Precipitation distribution and trends..........................................5

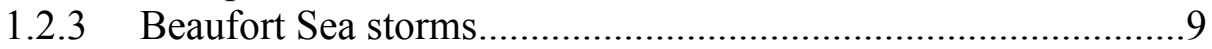

1.2.4 Canadian Archipelago storms ………………….......................11

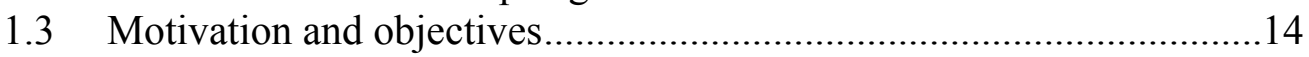

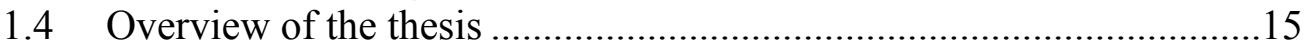

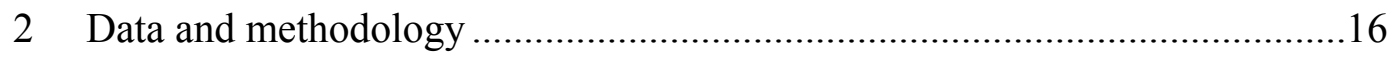

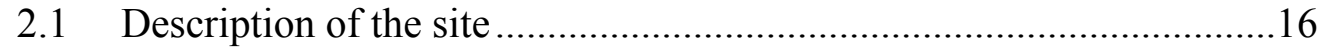

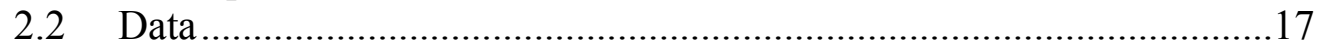

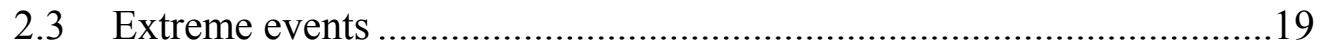

2.3.1 Background on extreme events ...........................................19

2.3.2 Definition of extreme events ...................................................20

2.4 Determination of the cyclone tracks and synoptic evolution.................22

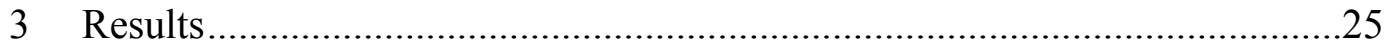

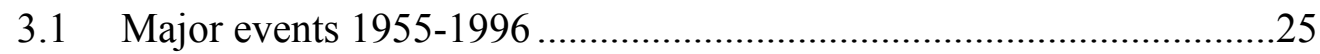

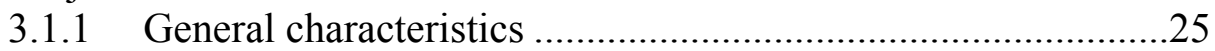

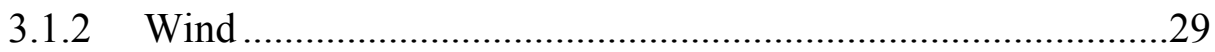

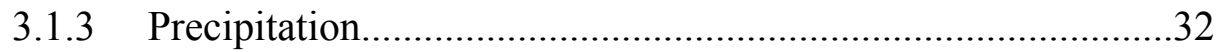

3.1.3 Regions of origin and storm tracks...........................................

3.1.4.1 Storm track characteristics...........................................36

3.1.4.2 Evolution and synoptic stage .......................................39

3.1.4.3 Monthly variability ......................................................41

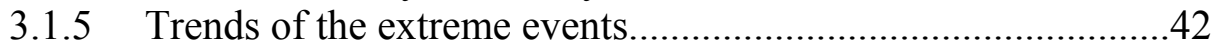

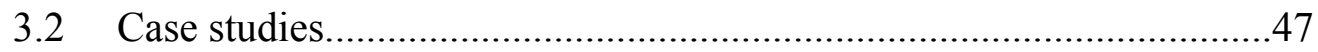

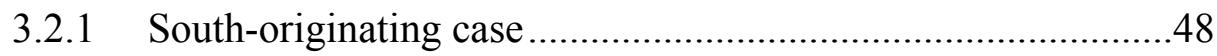


3.2.1.1 Synoptic evolution.....................................................49

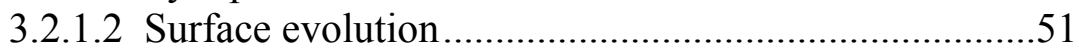

3.2.1.3 Precipitation type and atmospheric profiles ................53

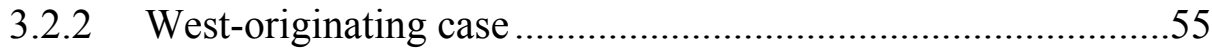

3.2.2.1 Synoptic evolution....................................................56

3.2.2.2 Surface variables ......................................................58

3.2.2.3 Precipitation type and atmospheric profile...................60

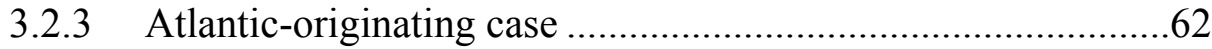

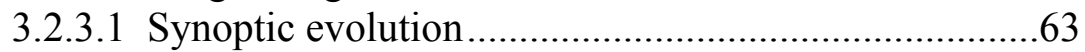

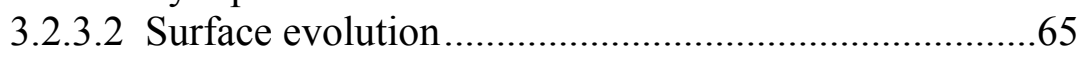

3.2.3.3 Precipitation type and atmospheric profile...................67

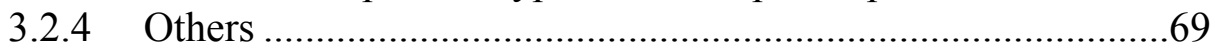

3.2.4.1 Synoptic evolution.....................................................69

3.2.4.2 Surface evolution..........................................................

3.2.4.3 Precipitation type and atmospheric profile...................72

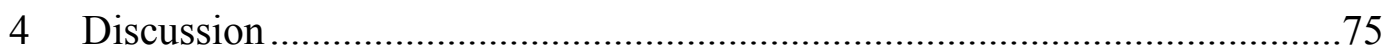

4.1 Factors influencing precipitation accumulation....................................75

4.2 Severity variability ........................................................................

4.3 Origin groups and synoptic characteristics ............................................

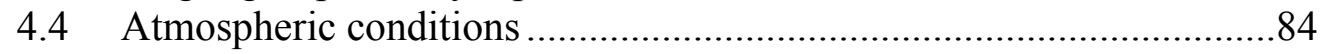

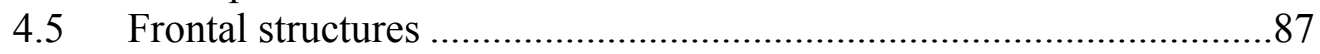

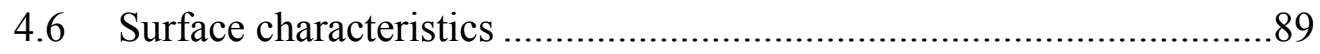

$4.7 \quad 41$-year tendency of occurrence .............................................................94

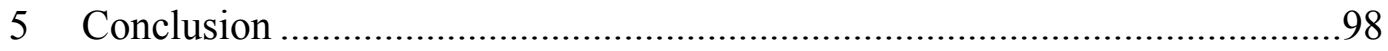

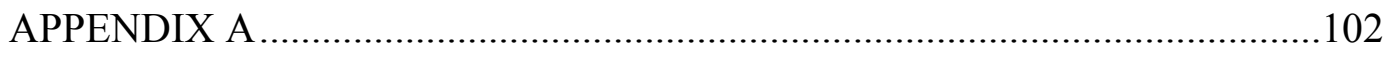

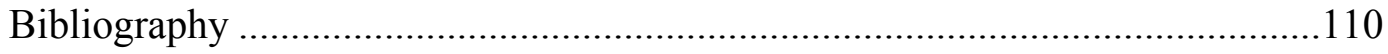




\section{LIST OF TABLES}

Table page

3-1: Statistics of the major precipitation events at Iqaluit................................25

3-2: Definition of the different precipitation types observed during the major

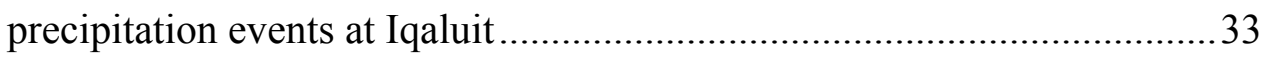

3-3: Occurrence and speed of motion of each origin group and their sub-storm

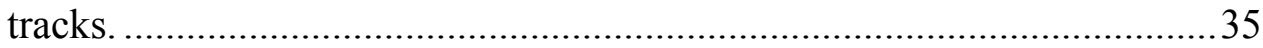

3-4: Monthly precipitation accumulation statistics during the case studies. ........49

3-5: Precipitation types during the selected case studies...................................53

4-1: Position of the systems with respect to Iqaluit during the 194 major precipitation events at Iqaluit ........................................................... 82

4-2: Atmospheric characteristics during the 73 major events following $1978 \ldots . . .85$

4-3: Atmospheric characteristics during the four case studies.

4-4: Frontal structures observed during the 194 major cold-season precipitation events, as well as during the 4 case studies. ...................... 88

4-5: Number of occurrences of major events per precipitation type ....................90

4-6: Number of occurrences of events associated with winds $\geq 40 \mathrm{~km} / \mathrm{h}$ and

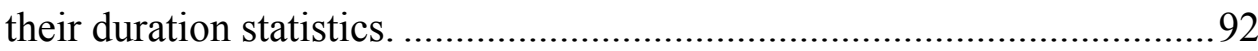

4-7: Summary of the surface characteristics of the four case studies ...................93

A-1: Detailed list of the 194 major precipitation events and their atmospheric and surface characteristics. 


\section{LIST OF FIGURES}

$\underline{\text { Figure }}$

page

1-1: The Arctic region and its main water basins 2

1-2: Snowfall distribution and duration of the 1948-1997 heavy snowfall events in the Canadian Archipelago........................................................ 7

1-3: Main storm tracks of systems entering the Canadian Archipelago .................11

2-1: Geographical location of Iqaluit, Nunavut

2-2: Occurrence of daily accumulation events at Iqaluit between October 1954 and April 1996 over the cold-season months .................................22

2-3: Example of a mean-sea-level pressure and $500 \mathrm{mb}$ thickness map................23

2-4: Example of mature stage, cut-off low, and closed-low systems ...................24

3-1: Number of occurrences accumulationduring the 194 major precipitation

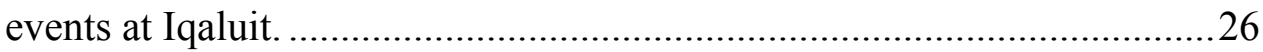

3-2: Monthly and annual number of occurrences of the 194 major events. ..........28

3-3: Wind rose of the ercent-frequency of surface wind direction during major events

3-4: Frequency of occurrence of wind speed during the 194 major events...........30

3-5: 1955-1996 monthly hours of precipitation of each precipitation type during the 194 major precipitation events.............................................33

3-6: Cyclone tracks and sub-tracks associated with the major cold-season precipitation events at Iqaluit

3-7: Main regions of decay of storms leading to major precipitation events at Iqaluit .

3-8: Cumulative monthly occurrence of each origin group over the 1955-1996 period.

3-9: 1955-2006 Cold-season occurrences of major precipitation events.

3-10: Major precipitation events anomaly and winter NAO index between 1955 and 2003. 45

3-11: Synoptic conditions of the February 12, 1981 event 
3-12: Evolution of the 6-hourly accumulation, surface temperature and surface pressure during the February 12, 1981 event ...........................52

3-13: Skew T- $\log (\mathrm{p})$ plot of the February 121981 event..................................54

3-14: Synoptic conditions of the October 24-25, 1985 event ..............................57

3-15: Evolution of the 6-hourly accumulation, surface temperature and surface pressure during the October $24-25,1985$ event........................59

3-16: Skew T-log(p) plot of the October 24-25 1985 event ...............................61

3-17: Synoptic conditions of the November 25-27, 1989 event ...........................64

3-18: Evolution of the 6-hourly accumulation, surface temperature and surface pressure during the November 25-27, 1989 event......................66

3-19: Skew T-log(p) plot of the November 25-27 1989, event. ..........................67

3-20: Synoptic conditions of the April 20, 1981 event .......................................70

3-21: Evolution of the 6-hourly accumulation, surface temperature and surface pressure during the April 20, 1981 event .................................71

3-22: Skew T-log(p) plot of the April 20, 1981 event ........................................ 73

4-1: Number of events per speed of motion for each origin group during the 194 major precipitation events at Iqaluit........................................... 76

4-2: Duration, precipitation rate, and speed of motion as a function of precipitation accumulation for the 194 major precipitation events at Iqaluit per origin group

4-3: Cumulative fraction of occurrence of major events for each origin group as a function of the rank.

4-4: Atlantic-originating major precipitation events anomaly and winter NAO index between 1955 and 1996

A-1: Wind rose of the ercent-frequency of surface wind direction of (a) South-originating events, (b) West-originating events, (c) Atlanticoriginating events, and (d) the Others events 


\section{CHAPTER 1}

Introduction

\subsection{Introductory comments}

When produced in large quantities or at high rates, precipitation can have significant effects on cities and communities. For example, heavy rain can result in damaging floods such as the 1993 Mississippi River Basin (Kunkel et al., 1994) and the 1996 Quebec floods (Milbrandt and Yau, 2001). Heavy rainfall can also trigger snowmelt-generated floods during spring thaw like the 1997 Red River flood (Bell and Halpert, 1998). Freezing rain paralyzed the Montreal region in 1998 (Roebber and Gyakum, 2003; Henson et al., 2007) whereas the 1993 Superstorm affected the East Coast of the United States, producing widespread heavy snowfall and causing coastal flooding (Kocin et al., 1995; Bosart et al., 1996).

In the Arctic, freezing rain, snowfall or mixed-precipitation events can be hazardous for communities (Hudson et al., 2001; Roberts and Stewart, 2008), paralysing transport, affecting hunting and recreation industries, and impacting the economy of the region. It is normally very difficult to predict such events and so this only adds to their impact on Northern Communities (e.g. Ford et al., 2006).

Several geographical features are known to influence precipitation patterns in the Arctic. Convection over open water (e.g. Gryschka and Raasch, 2005), orographic forcing (e.g. Bryazing, 1976; Bromwich, 1997) and extratropicalcyclones (e.g. Serreze et al., 1993) are the most important ones.

In the Section 1.2, we present an overview of the weather in the Arctic (Figure 1-1) with an emphasis on the Canadian Arctic. The focus is on cyclonic 
activity in the Arctic, precipitation distribution and trends, as well as characteristics of storms affecting the Beaufort Sea region and the Canadian Archipelago.

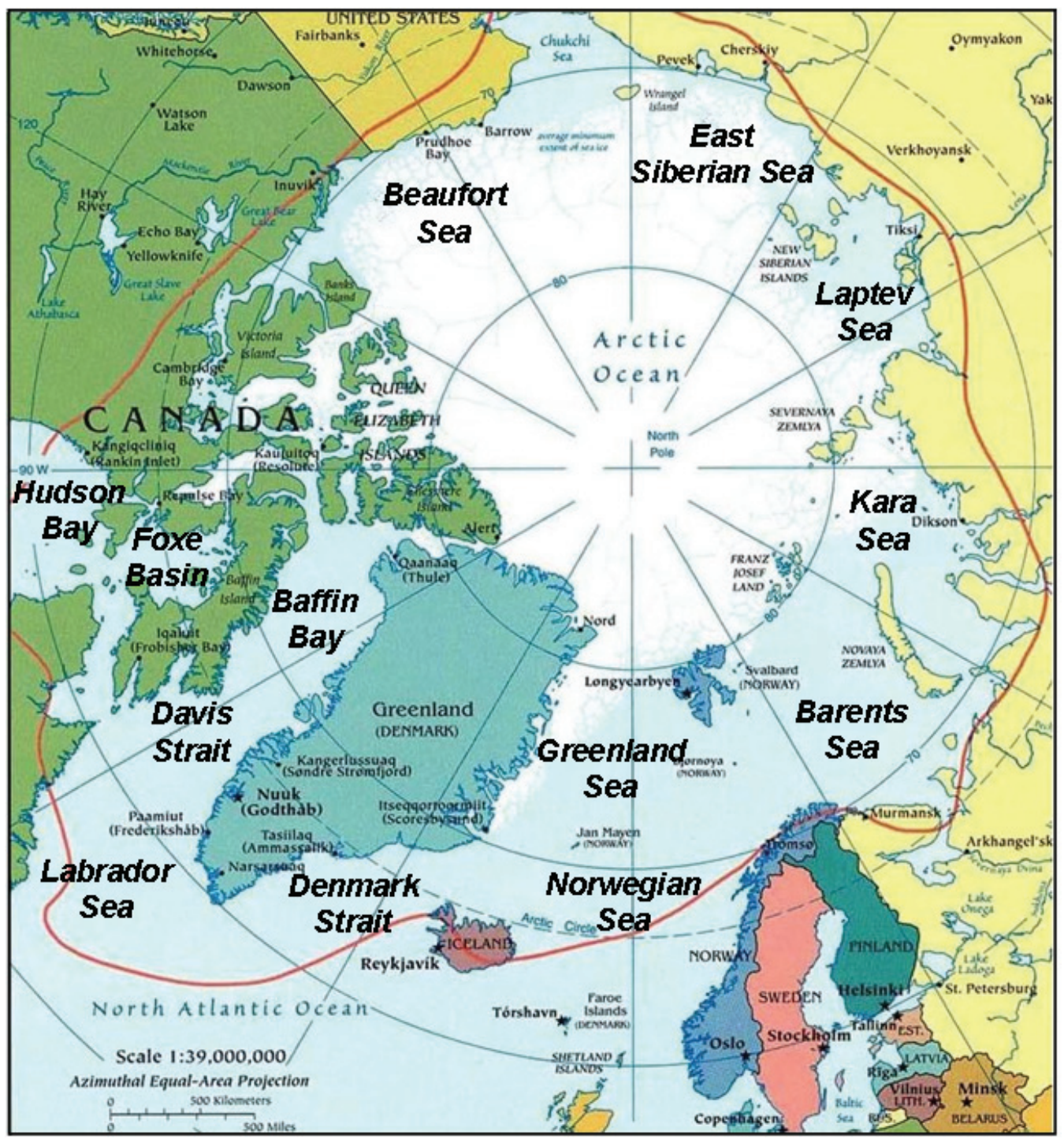

Figure 1-1: The Arctic region and its main water basins. The average temperature of the warmest month is below $10^{\circ} \mathrm{C}$ for the region north of the red line (Adapted from the Perry-Castaneda Library map collection, 2008). 


\subsection{Background}

\subsubsection{Cyclonic activity in the Arctic}

Extra-tropical cyclonic activity is the main factor responsible for some of the most significant storms impacting Arctic communities. It also plays a major role in the water budget of the region (Newton, 1969). Extra-tropical cyclones are also the main mechanism for the transport of heat and moisture into the Arctic, making extra-tropical cyclonic activity in the Arctic one of the most fundamental aspects of high-latitude weather and climate.

Whittaker and Horn $(1981,1984)$ investigated the 1958-1977 cyclonic activity over North America. They incorporated the northern regions in their analysis unlike most of the previous work carried out on the same topic. They showed that many low-pressure systems observed around the eastern shores of Greenland originated in the eastern coast of the United States, whereas a large portion of the cyclones reaching Baffin Island and the Canadian Archipelago were initiated east of the Rocky Mountains, converged in the Great Lakes region and then moved northward. On some occasions, cyclones originated from the northern part of the Pacific Ocean.

Serreze et al. (1993) examined the climatological patterns of Arctic synoptic activity for the period 1952-1989. The authors found that, since 1952, significant positive trends in cyclone numbers over the Arctic have been observed during winter, spring and summer. In fact, the number of observed Arctic cyclones rose by approximately $25 \%$ in each season (Serreze et al., 1993). Peaks in cyclonic activity were observed between the months of May and June due to 
the weakening and migration of the persistent wintertime anticyclonic circulation over Siberia. In a later study, Serreze (1995) confirmed his previous findings and added that the entire Atlantic side of the Arctic was the most synoptically active area of the Arctic. He showed that wintertime synoptic activity in this region of the Arctic is characterised by both frequent cyclogenesis and cyclolysis, whereas summertime is almost entirely dominated by cyclolysis of North Atlantic and Eurasian cyclones.

More recently, studies have investigated the trends and variations of cyclonic activity in the Arctic. Chang and Fu (2002) analysed cyclonic trends over the entire Arctic during 51 winters using the NCEP-NCAR reanalysis data. They used the high-pass-filtered 300-hPa meridional velocity variable to denote storm track intensity. They showed that the mean storm track intensity was approximately $30 \%$ stronger during the 1990 s that it was during the 1960 s. Zhang et al. (2004) found similar results, showing that cyclone activity in the Arctic was in a negative phase in the 1960s and entered a positive phase in the 1990s. Moreover, Zhang et al. (2004) found an increase in the intensity and number of cyclones entering the Arctic between 1948 and 2002, suggesting a northward shift of storm tracks from the mid-latitudes into the Arctic.

According to past studies (e.g. Serreze and Barry, 1988; Serreze et al., 1993), the strongest Arctic systems are found in the Icelandic and Norwegian Seas due to the proximity of the persistent Icelandic low. Cyclonic activity is also common in the Barents and the Kara Seas, Baffin Bay and the Canadian Arctic Archipelago. Indeed, cyclogenesis primarily occurs east of Greenland, over the 
Barents Sea and in Baffin Bay during the cold-season (October-April) (Zhang et al., 2004). In addition, Tsukernik et al. (2007) showed that the Greenland topography has positive impacts on the rapid deepening of cyclones in the region.

\subsubsection{Precipitation distribution and trends}

Precipitation is associated with extratropical cyclones. With extratropical cyclonic activity changing in the Arctic, precipitation distribution may change as well. The following describes the trends in precipitation in the Arctic, with a focus on snowfall and freezing rain events (hazardous cold-season Arctic weather).

Taken as a whole, the Arctic region is subject to an increase in heavy precipitation and hazardous weather. This was first shown for heavy precipitation events (Groisman et al., 2003; ACIA, 2005; Zhang et al., 2001). As well, Hanesiak and Wang (2005) used the frequency of no-weather periods to assess changes in freezing rain and snowfall frequencies over the last 55 years. Their increase (decrease) would indicate a decrease (increase) in adverse weather. Yearly, all stations except two (Whitehorse and Watson Lake) showed a significant downward tendency in no-weather events. Going down to the seasonal scale, the decrease was most significant in autumn with a statistically significant downward trend at 11 stations. Overall, this general tendency of decrease in noweather events is more likely explained by the increase in the frequency of freezing rain and snow events as Hanesiak and Wang (2005) found no significant increase in other precipitation types in the Canadian Arctic. 
An increase in precipitation events in the Arctic is in agreement with the northward of the winter storm tracks in Canada (Wang et al, 2004) and the increase in cyclonic activity in the Canadian Arctic (Zhang et al., 2004). It is also in agreement with several studies observing an increase in annual precipitation at higher northern latitudes other that the Canadian Arctic (e.g. Hulme, 1995; Førland and Hanssen-Bauer, 2000).

Przybylak (2002) results, on the other hand, do not entirely agree with the idea of a monotonic positive trend in precipitation for the Arctic region. Instead, he noted that significant drops in precipitation occur in the south-eastern part of the Canadian Arctic during the positive phase of the North Atlantic Oscillation (NAO) index. Similarly, Mosley-Thompson et al. (2005) showed that Greenland precipitation is modulated by the NAO index. During a positive NAO phase, south-westerly flows bringing moisture to the Arctic are reduced because of increased westerlies. Consequently, an overall average reduction of precipitation accumulation is observed in the northern regions (e.g., Hurrell, 1995; Bromwich et al., 1999). In contrast, an increase of precipitation accumulation in the northern regions is observed during a negative NAO period.

Intihar and Stewart (2005) investigated the heavy snowfall-event distribution pattern in the Canadian Archipelago between 1948 and 1997. They found a geographical pattern that characterises snowfall distribution in the analysed region. The occurrence of individual extreme-snowfall events increases from the northeast to the southeast of the Canadian Archipelago; the extremesnowfall event duration follows the same pattern (Figure 1-2). The Alert station 
was the one exception to this pattern, recording average precipitation and event duration values larger than for the surrounding stations.

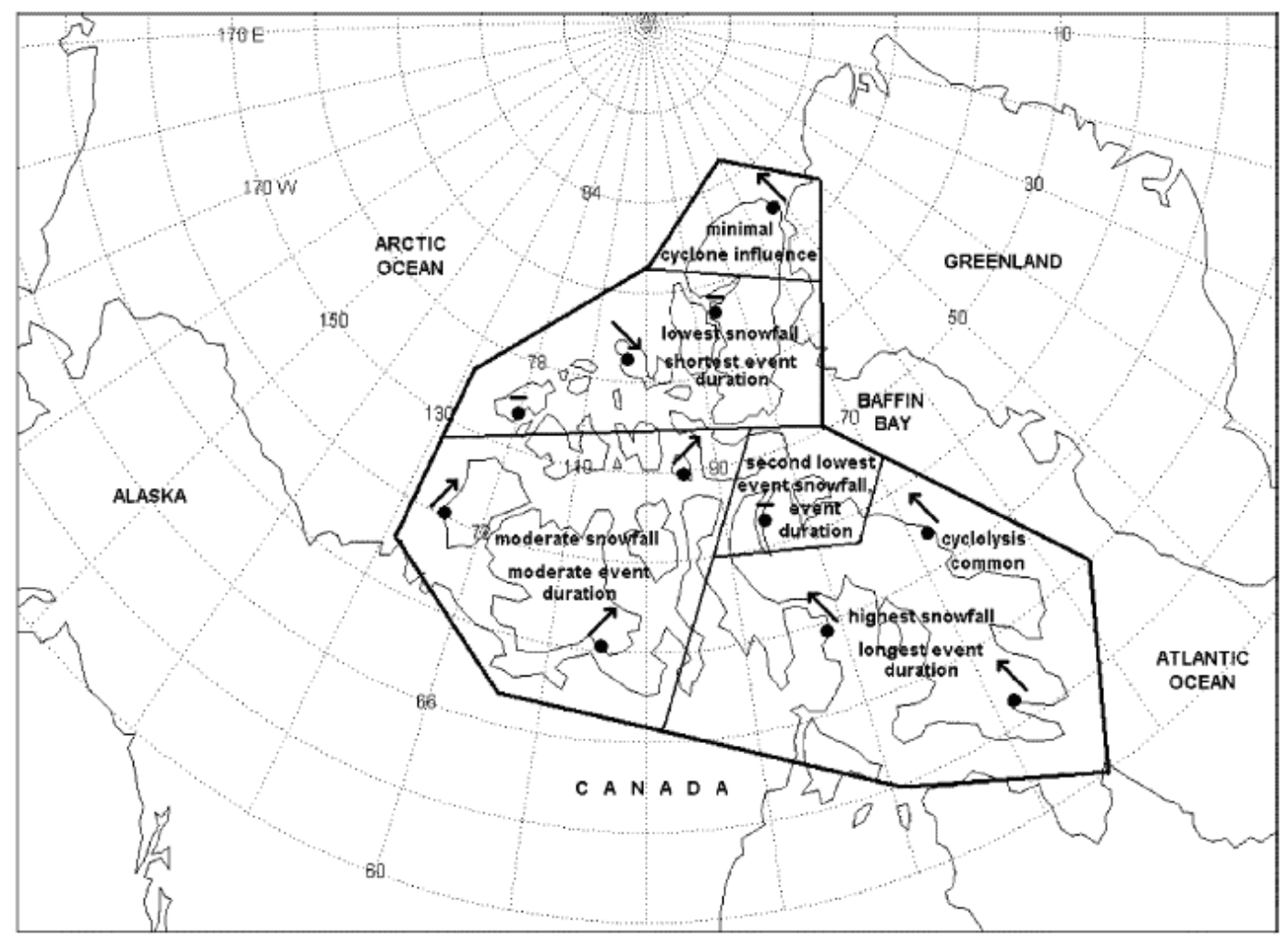

Figure 1-2: Schematics of the snowfall distribution and duration of the 1948-1997 heavy snowfall events in the Canadian Archipelago. Arrows indicate the preferential entrance region for event (from Intihar and Stewart, 2005).

A study published by Zhang et al. (2001) suggested that snowfall events showed an increasing trend since the middle of the $20^{\text {th }}$ century. The authors observed a significant upward trend with strong decadal variability for heavy snow events (defined as the $90^{\text {th }}$ percentiles, the annual maxima, and the 20 -year return values) for the Canadian Arctic, especially during fall and winter. The south-eastern part of the Canadian Arctic experienced this upward trend in autumn, winter and spring. Yellowknife trends were significantly positive for spring and winter whereas the Canadian Archipelago region experienced an 
upward trend in the autumn season only. In all, a significant increase in heavy snowfall events has been observed for the central part of the Canadian Arctic and as far north as the Eureka station for the 1950-1998 period.

Freezing rain events were most often observed during two time periods: a primary period during September-November over the entire Northern Canada and a secondary maximum exclusively for the Canadian Archipelago for the MayJune period (Hanesiak and Wang, 2005). However, the mean-monthly occurrence frequency of such events is less than $2.5 \%$ of the total precipitation accumulation at all stations, indicating that it is not the main type of event affecting the area. As stated earlier, Hanesiak and Wang (2005) showed that freezing rain events in the Canadian Arctic showed a statistically significant upward trend in event frequency over the last 55 years. Of all seasons, spring experienced the most statically significant upward trend. In general, the pattern of freezing rain events from Hanesiak and Wang (2005) matched the pattern of temperature change observed by Zhang et al. (2000). Indeed, the areas of increasing temperature correspond to the areas of increasing freezing rain events, exposing a possible consequence of global warming in the Canadian Arctic.

Air temperature has an effect on the atmospheric relative humidity and may influence on the amount of precipitation produced. Isaac and Stuart (1992) investigated on the temperature-precipitation relationships in Canada, but did not find any relationships for the Canadian Arctic. Przybylak (2002) came to the same conclusion when he analysed the trend in precipitation in the Canadian Arctic for the 1950-1995 period. He observed a statistically significant increase 
of solid precipitation, but no significant changes in air temperature were observed. However, some climate models (e.g. Ye and Mather, 1997) have considered an increase in air temperature during the cold season in the Arctic, resulting in an increase of snow accumulation in the Arctic region. Such results can be explained by the fact that warmer air is leading to more moisture available for precipitation events and that the anticipated warming still allows precipitation to be in the form of snow. These discrepancies between models and observations suggest that a change in temperature in the northern regions might not be the main forcing influencing precipitation and that other factors such as cyclonic activity and atmospheric circulation should also be considered.

\subsubsection{Beaufort Sea storms}

The Beaufort Sea region is the Canadian Arctic region that has been the most examined by scientists. With the exception of the June-October period, the region is characterised by ice cover. Open water conditions enhance the oceanatmosphere heat exchange, triggering or enhancing major storms which are particularly hazardous for the area. Such storms are associated with low visibility and strong winds, with the potential of leading to high storm surge affecting the coastal local communities (Harper et al., 1988). Because of their important socioecological impacts, these storms have been extensively analysed during several field experiments (e.g. Fett et al., 1994; Hudak et al., 1995; Asuma et al., 1998).

The Beaufort and Arctic Storms Experiment (BASE) was carried out during the 1994-1995 winter at Inuvik and Tuktoyaktuk (Hudak et al., 1995). A warm-frontal precipitation band associated with a low-pressure system passing 
over Beaufort Sea was analyzed by Hanesiak et al. (1997). Using research aircraft observations, the authors studied the internal structure and evolution of the system and identified the mesoscale frontogenetic forcing associated with it. Hudak and Young (2002) focused on the major storms lasting at least 24 hours and monitored during the BASE experiment. Using wind speed as the threshold variable to determine the major events, they identified 281 storms for the June-November period between 1970 and 1995. The storms were classified in three storm-track groups: Arctic storm (58\%), Pacific storm (27\%) and Irregular (15\%) (no distinct pattern) storm types. No yearly trend for the Arctic and Irregular types was established. On the other hand, a significant monotonic decrease of the Pacific storm frequency was identified through the 1970-1995 period. Even though the 1976-1982 period was the stormiest (with 19 storms), no trend in storm frequency (all types merged) over the period investigated was observed by Hudak and Young (2002), suggesting that the Beaufort Sea region is unaffected by the increasing cyclonic activity tendency in the Arctic predicted by Zhang et al.'s (2004) study.

Following BASE, the Arctic WANTS (Water vapor, Aerosol and Nuclei Transportation and Snow crystals) project primarily examined the microphysics of storms around Inuvik between December 1995 and January 1996 (Asuma et al., 1998; Asuma et al., 2000), focusing more specifically on case studies of storms originating from the Pacific Ocean. Such storms are characterized by a conditionally unstable atmosphere at low-levels due to warm air advection from the Pacific Ocean at upper-levels and was enhanced by the surrounding 
topography (the northern tip of the Rocky Mountains). During each case, rimed dendrites and graupel was observed at the ground, whereas an abundance of supercooled water droplets in the convective updraft was observed according to the X-band Doppler radar (Asuma et al., 1998), leading the authors to conclude that collision and coalescence of supercooled cloud droplets were the primary growth processes for the Pacific storm type.

\subsubsection{Canadian Archipelago storms}

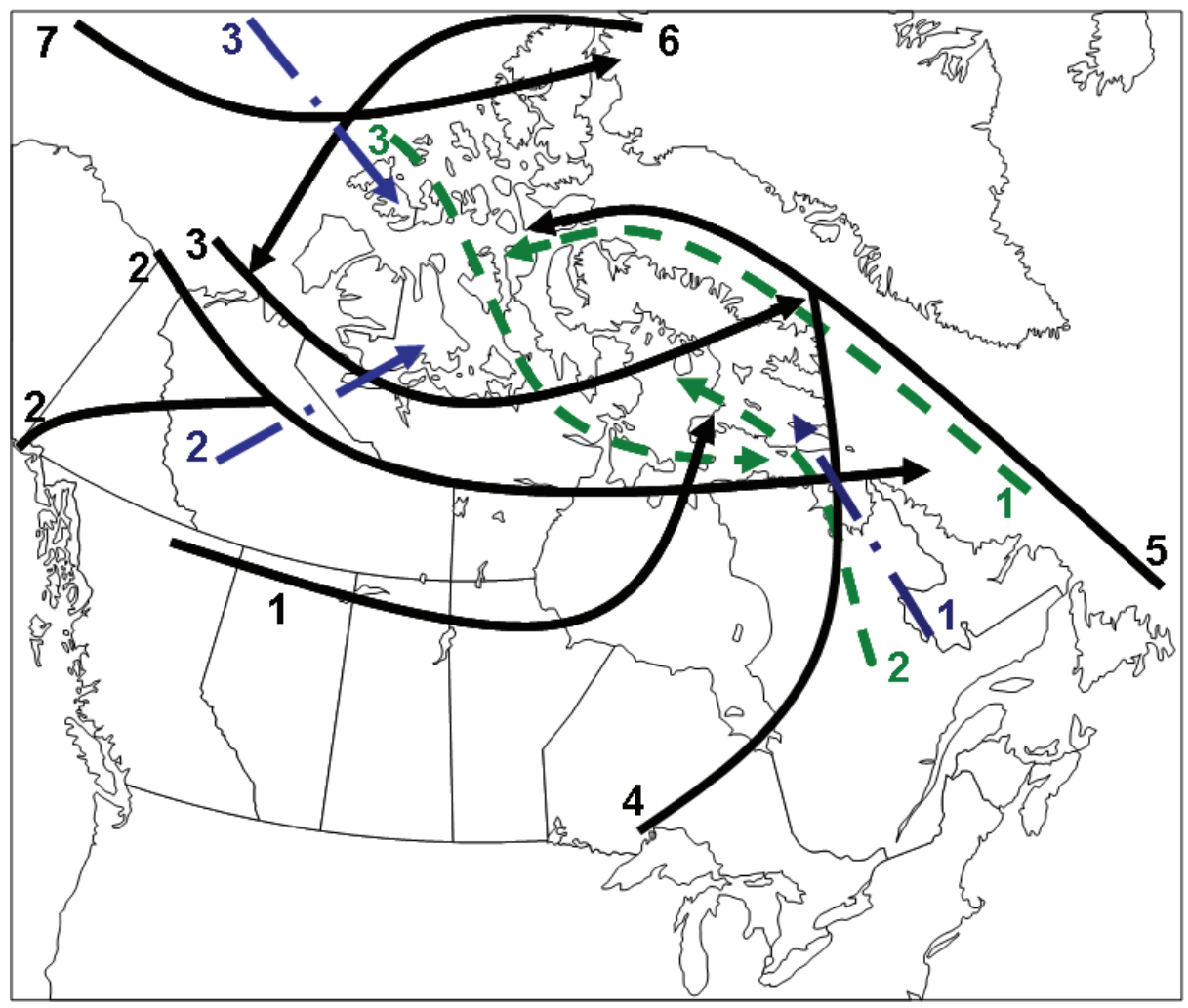

Figure 1-3: Main storm tracks of systems entering the Canadian Archipelago from Stewart et al. (1995) (green dashed line); Hudson et al. (2001) (black solid line); and Intihar and Stewart (2005) (blue long dashed dots).

Previous studies (Stewart et al., 1995; Hudson et al., 2001; Intihar and Stewart, 2005) have identified the main storm tracks of systems affecting the 
Canadian Archipelago. Each track is summarized in Figure 1-3 and will be described below.

Stewart et al. (1995) conducted a study of winter storms over Canada and investigated storms causing Arctic blizzards. The authors found three distinct storm tracks across the Arctic affecting the Canadian Archipelago, identified in green on Figure 1-3: 1) cyclones originating from the Atlantic Ocean, moving northwards though Davis Strait, and decaying over northern Baffin Island, 2) cyclones moving through northern Quebec and into Foxe Basin and 3) cyclones forming over the Arctic Ocean, moving south-eastward and decaying over Hudson Bay. Stewart et al. (1995) also showed that with the exception of storms originating from the Atlantic Ocean, little moisture is imported in the northern regions, explaining the small precipitation amounts received in the Arctic.

Hudson et al. (2001) reported seven main storm tracks affecting the Canadian Arctic, regardless of any event's severity threshold. The tracks are identified by the black lines on Figure 1-3. Five of them directly impact the southern Canadian Archipelago. Cyclones following track 1 originate over the northern Prairies, moving northward and deepen over Hudson Bay. Cyclones moving along track 2 originate either over the Gulf of Alaska or the Beaufort Sea and travel eastward. Track 3 is similar to track 2, but shifted northward; cyclones following this track are generally not as intense as the ones of track 2 . Track 4 is the classical blizzard track for Iqaluit. Lows originate over the Midwest of United States or southern Ontario/Quebec, moving northward. Cyclones following track 5 start out over the east coast of the United States, moving north along the coast 
of the Atlantic Provinces and the Labrador. Northern Ellesmere Island, on the other hand, is affected by storms originating from northern Greenland (track 6) or the Arctic Ocean (track 7).

A more detailed study on Canadian Archipelago storms was later carried out by Intihar and Stewart (2005), focusing on 110 major cold-season snowfall events that affected 11 station in the Canadian Archipelago for the 1948-1997 period. The authors found three main entrance regions of storms in the Archipelago, identified in blue on Figure 1-3: 1) from the southeast, 2) from the southwest and 3) from the north/northeast. Additionally, cyclones showed greater influences on precipitation at the stations in the vicinity of their entering point in the Archipelago. For example, Hall Beach, Clyde River and Iqaluit were mainly affected by storms entering the Archipelago by the southeast. Moreover, the authors believed that the Canadian Archipelago is a region of cyclolysis. They found that out of 120 cyclones entering the region, only 96 of them exited the region. Out of the 24 cyclolysis events, 9 occurred over Baffin Bay, 7 over the central Archipelago, 6 over the Arctic Ocean and 2 over the south-western land mass.

More recently, Roberts et al. (2008) analyzed 6 storms passing over Iqaluit. Half of them originated from Great Lakes cyclones and moved through northern Quebec and into Foxe Basin; two were initiated over the Atlantic Ocean; and one developed over the Northwest Territories, moving eastward.

In addition to analysing storm tracks, Intihar and Stewart (2005) also highlighted mechanisms responsible for major precipitation events at different 
surface stations of the Canadian Archipelago. The Alert station is believed to be more sensitive to orographically enhanced precipitation as the station showed little storm activity in its vicinity, although several high snowfall events of long duration were recorded. Clyde River, on the other hand, receives most of its precipitation during cyclolysis. If the dying system (implying it is quasistationary) is in the vicinity of the station, high amounts of precipitation will be produced; otherwise, little precipitation will fall. Finally, the authors showed that cyclonic activity was more intense at Iqaluit than at any other communities in the Canadian Archipelago. The station is geographically more southerly than the other stations in the Archipelago and thus closer to the jet stream and open water, allowing it to be influenced by a greater number of cyclones.

\subsection{Motivation and objectives}

Despite their importance, storms in the Arctic producing snow and mixed phase precipitation with significant accumulation have received little attention in general. Some studies, as discussed above, have been carried out, but much more needs to be done. Given the importance of these extreme forms of weather to communities in the Canadian Arctic, it is critical to better understand the processes controlling them in order to eventually improve forecasting capabilities.

To analyze the problem in greater detail than ever before, this study concentrates its analysis on events at one site, Iqaluit, Nunavut. Moreover, only cold-season (October-April) (e.g. Zhang et al., 2004; Intihar and Stewart, 2005) events are investigated as snow, freezing rain and mixed-phase precipitation are unlikely to be observed during the warm season. 
Consequently, the objective of this study is to advance our understanding of the mechanisms through which major precipitation events occur in the cold season at Iqaluit.

This objective is achieved though a 3-step strategy. First, the main characteristics and climatology of the 1955-1996 major cold-season precipitation events at Iqaluit are described. Second, in-depth analyses of selected cases are carried out. Third, the information is synthesized to address some of the key factors responsible for heavy precipitation events.

Achieving these will provide a better understanding of the synoptic, mesoscale and surface features leading to, and associated with, major precipitation events at Iqaluit. In the long run, this research is expected to assist in improving the simulation and prediction of the cold-season precipitation events at Iqaluit, as well as to better assess how they will change in the future at this and other Arctic locations.

\subsection{Overview of the thesis}

Chapter 2 describes the geographical situation of Iqaluit, the thresholds used to characterize extreme precipitation events during the cold season at Iqaluit, as well as the data used in this present research. The main climatological and meteorological characteristics of the extreme precipitation events at Iqaluit, followed by in-depth case-study analyses of selected events are discussed in Chapter 3. The results will be synthesized and discussed in Chapter 4. Finally, Chapter 5 provides a summary and synthesis of the results and suggestions for future work. 


\section{CHAPTER 2 \\ Data and methodology}

\subsection{Description of the site}

The community of Iqaluit is the capital of the youngest Canadian Territory, Nunavut. It is situated north of the tree line, at latitude $63.8^{\circ} \mathrm{N}$ and longitude $58.6^{\circ} \mathrm{W}$ in the Canadian Archipelago (Figure 2-1).

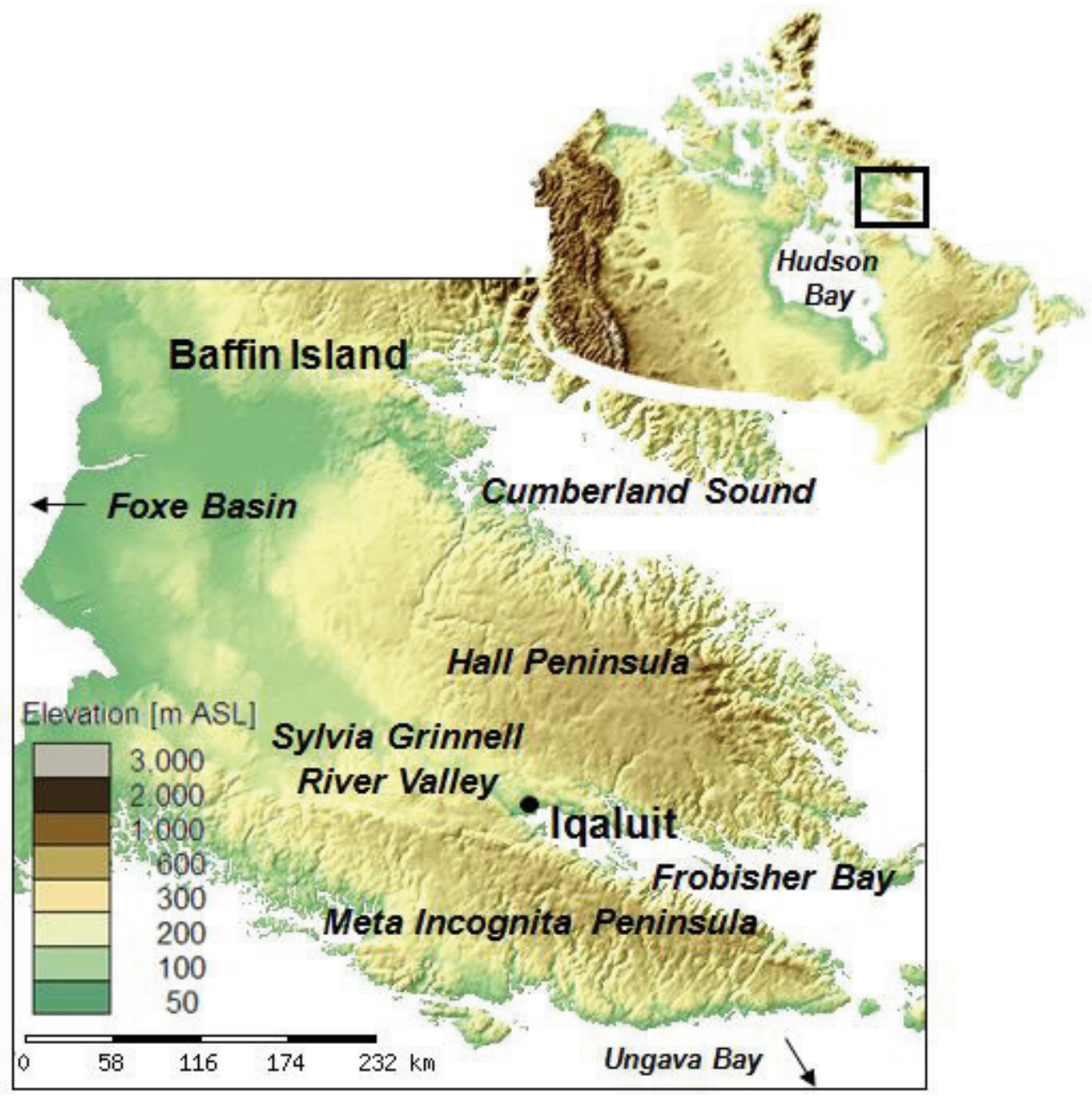

Figure 2-1: Geographical location of Iqaluit, Nunavut (adapted from the Atlas of Canada, 2008).

More precisely, Iqaluit is located on the south-eastern part of Baffin Island, in the north-western end of Frobisher Bay. Several bodies of water are 
situated in close proximity of the community: Foxe Basin to the west, Ungava Bay to the south, Cumberland Sound just north of Iqaluit and Hudson Bay, southwest of the community. Although Iqaluit is situated in the Sylvia Grinnell River Valley at an average altitude of $33.5 \mathrm{~m}$ above mean-sea-level, it is surrounded by major topographic landscapes. Two mountain ranges are present in its vicinity. The ridges of the Meta Incognita Peninsula, west-southwest of Iqaluit, are on average $600 \mathrm{~m}$ high, with some peaks reaching $750 \mathrm{~m}$, whereas peaks as high as $1000 \mathrm{~m}$ are found northeast of the community, on Hall Peninsula. Thus, Iqaluit is in the middle of the valley-fjord formed by the two described mountain ranges. The valley is oriented northwest-southeast, favouring wind channelling (Nawri and Stewart, 2006) or local orographic precipitation bands (Maxwell, 1981) when winds blow perpendicular to the mountains.

\subsection{Data}

Daily corrected precipitation data (Mekis and Hong, 1999) for the Iqaluit operational meteorological weather station site was used to select major precipitation events. Corrections were made to account for gauge catchment errors due to wind effects, snow-water equivalence variations (i.e. not always 10:1 in case of wet snow) and human error. Since continuous corrected precipitation data is only available until up 1996 for Iqaluit ${ }^{1}$, the analysis was not extended to the following years. Precipitation data between 1954 and 1996, with discontinuities in 1993 and the early 1994, is used in this study. Daily

\footnotetext{
${ }^{1}$ Although corrected precipitation data is available until 2006 for other stations in Canada, only corrected precipitation data during seven months in 2001-2002 is available after 1996 at Iqaluit.
} 
precipitation data is measured from $12 \mathrm{UTC}$ to $12 \mathrm{UTC}$, that is, 7a.m. to 7a.m. local Standard Time. For example, March 2 daily precipitation is from 12 UTC (7 a.m.) March 2 to 12 UTC (7 a.m.) March 3.

Six-hourly precipitation for the 1954-1996 period was provided by the Environment Canada Hydrometeorology and Arctic Laboratory, providing information on the beginning and end of the events. Hourly weather observation data of the operational meteorological weather station at Iqaluit for the 1954-2006 period is available through the Environment Canada public archive. The analysis of this information provided insight on the precipitation type, pressure and wind; the temperature evolution was used to detect frontal disturbances.

Cyclone tracks and synoptic evolution are described in this study using the National Centers for Environmental Prediction-National Center for the Atmospheric Research (NCEP-NCAR) reanalysis data and the North American Regional Reanalysis (NARR) data. The NCEP-NCAR dataset provides 6-hourly data for 28 layers of the atmosphere with a resolution of $208 \mathrm{~km}(205 \mathrm{~km}$ in the region of Iqaluit) since 1948 (Kalnay et al., 1996). Note that NCEP precipitation data products were discarded because of their inability to adequately represent observed precipitation accumulation in the Arctic (Serreze and Hurst, 2000). NARR data, on the other hand, is a product of higher resolution, with data available from 1979. It has a resolution of $32 \mathrm{~km}$ and outputs 3-hourly data for 29 distinct layers (Mesinger et al., 2006). NARR precipitation data products, however, were discarded for the same aforementioned reason than for the NCEP data. 
Atmospheric soundings were obtained through the University of Wyoming on-line meteorological database administered by the Department of Atmospheric Science (University of Wyoming, 2008). This dataset contains information on vertical profiles of temperature, humidity and wind and is available from 1978 at the Iqaluit station.

Finally, monthly NAO indices between 1955 and 2003 (Hurrell et al., 2003) have been used to investigate on the possible relation between the winter NAO index and major precipitation event anomalies.

\subsection{Extreme events}

\subsubsection{Background on extreme events}

There is no uniform world-wide definition of an extreme precipitation event. In general, data for high-intensity extreme events are specified by three variables, namely: frequency, duration and precipitation accumulation or mean precipitation intensity (Dalezios et al., 2000; Beniston et al., 2007). The frequency variable accounts for the rarity of an event, i.e. high recurrence interval, whereas the severity of an event in terms of duration usually implies a longlasting event. Events responsible for significant precipitation accumulation are also considered severe.

Extreme events analysis can be based on either percentile values or fixed thresholds. According to the Intergovernmental Panel on Climate Change (IPCC, 2001), "an extreme weather event is an event that is rare within its statistical reference distribution at a particular place. Definitions of rare vary, but an

extreme weather event would normally be as rare as or rarer than the $10^{\text {th }}$ or $90^{\text {th }}$ 
percentile". Groisman et al. (2003) investigated climate changes in high latitudes of the northern hemisphere and considered extreme precipitation accumulation greater than 2 standard deviations above the average of precipitation events with accumulation greater than $0.5 \mathrm{~mm}$. Beniston et al. (2007) and Frich et al. (2002) investigated the $95^{\text {th }}$ percentile of the one-day winter precipitation events and 5 day precipitation total over Europe and the Northern Hemisphere, respectively. Finally, Jones (2000) examined precipitation events in California exceeding the $90^{\text {th }}, 95^{\text {th }}$ and $97^{\text {th }}$ percentile.

Other studies based their extreme-event threshold on a recurrence interval. Changnon and Kunkel (1995) focused on short duration (1-7 days) events over the Midwest United States that have a recurrence interval of 1 year or longer. Konrad's (2001) work over the eastern United States is based on the same definition, but focused on one-day events. Kunkel et al. (2003) used more than one threshold, investigating events with return periods of 1,5 , and 20 years to better analyze different scales of severity. Schumacher and Johnson's (2006) definition of extreme precipitation events consists of the $24-\mathrm{h}$ precipitation total exceeding the 50-year recurrence amount.

\subsubsection{Definition of extreme events}

In this study, the events that exceed the $97^{\text {th }}$ percentile of daily corrected precipitation accumulation are considered to be major precipitation events. The approach is similar to the ones of Jones (2000), Beniston et al. (2007), Frich at al. (2002) and it is also within the range of the IPCC (2001). 
Between October 1954 and April 1996, water-equivalent precipitation of at least $0.2 \mathrm{~mm}$ was recorded during 7289 days. The daily accumulation average of these events is of $1.5 \mathrm{~mm}$, with a standard deviation of $3.1 \mathrm{~mm}$. Daily precipitation accumulation representing the $97^{\text {th }}$ percentile has a value of $9.5 \mathrm{~mm}$, setting the threshold for major precipitation events at Iqaluit for this present research. Multi-day events were considered as long as the daily accumulation threshold was respected.

It should be noted that this study classified major precipitation occurrence based on cold seasons rather than on a yearly basis. As an example, the 1955 cold season consists of events that took place between October 1954 and April 1955. The same process is applied for the other seasons.

Figure 2-2 shows the frequency distribution and cumulative fraction of daily precipitation events at Iqaluit between 1954 and 1996 over the cold season. The occurrence of daily precipitation accumulation is characterized by a positively-skewed distribution (Kotz and Nadarajah, 2001). The different thresholds used in previous studies, as well as the one used in this particular research are superimposed onto Figure 2-2.

The recurrence intervals of 1-year, 5-years and 20-years have been computed using the Weibull Equation (Lundgren, 1986),

$$
R=\frac{(N+1)}{M}
$$

where $R$ is the recurrence interval, $N$ is the number of years examined (in this case 
41) and $M$ is the rank of each given precipitation event. In this study, the event producing the largest amount of precipitation is ranked first.

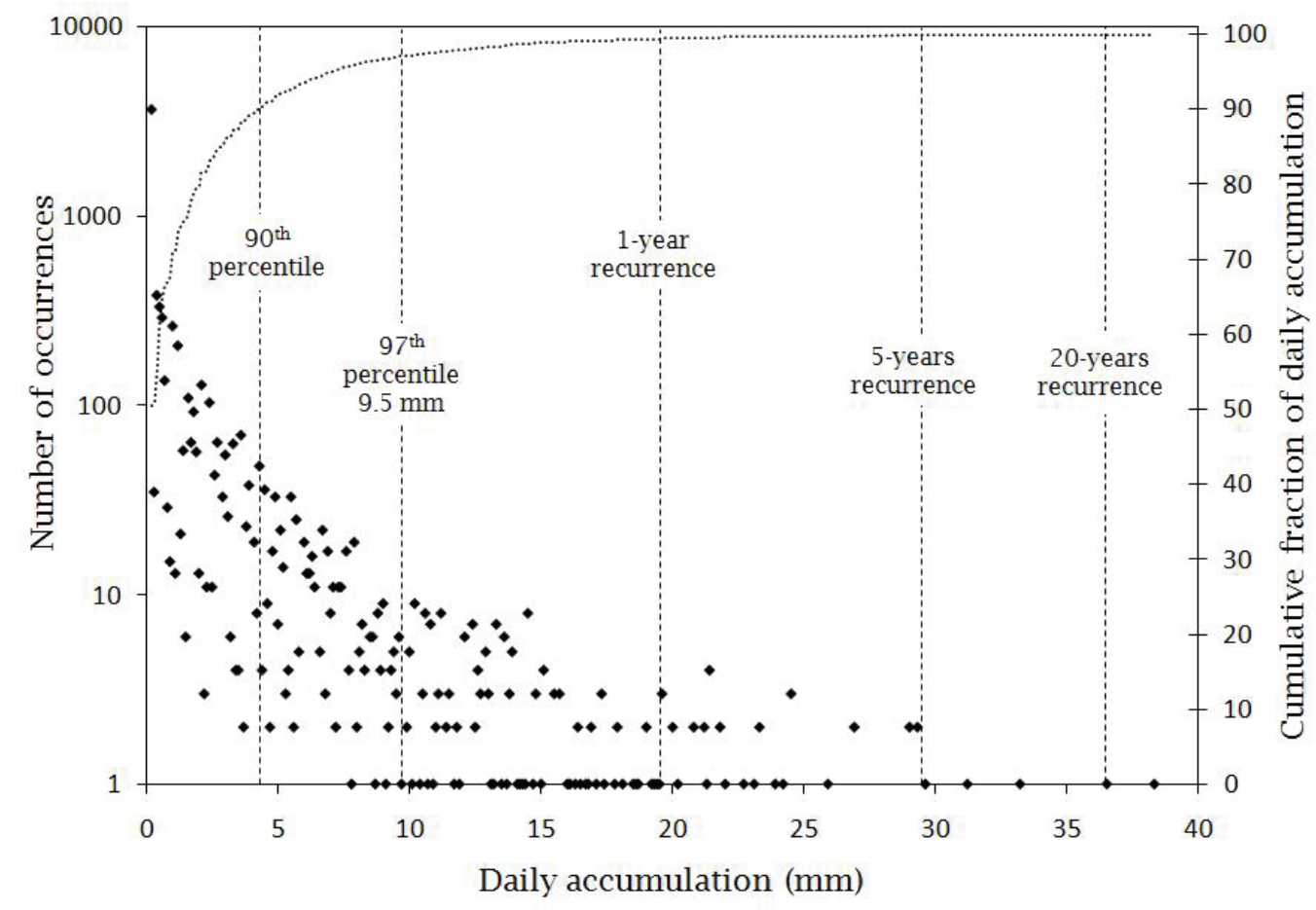

Figure 2-2: Occurrence of daily accumulation events at Iqaluit between October 1954 and April 1996 over the cold-season months. The $97^{\text {th }}$ percentile is identified, as well as other key distribution characteristics $\left(90^{\text {th }}\right.$ percentile and 1year, 5-year and 20-year recurrence interval events). The cumulative fraction of daily accumulation is represented by the thin dotted line.

\subsection{Determination of the cyclone tracks and synoptic evolution}

Cyclone tracks and synoptic evolution of the selected events were manually retrieved using reanalysis data. For the events taking place prior to 1979, the NCEP-NCAR reanalysis data was used. The higher-resolution reanalysis data from NARR is used for the analysis of the events of the subsequent years. Maps of the mean-sea-level pressure in $\mathrm{mb}$ and the $500 \mathrm{mb}$ thickness (the subtraction of the $1000 \mathrm{mb}$ height from the $500 \mathrm{mb}$ height) were generated using the meteorological data analysis software GEMPAK (Koch et al., 1983). The 
overlaying of these two fields every $3 \mathrm{~h}$ (with NARR) or $12 \mathrm{~h}$ (with NCEPNCAR) allowed the tracking the evolution of the surface and upper-level lowpressure centers.

Figure 2-3 illustrates an example of this product using the NARR data, where a surface low-pressure system located north of the Great Lakes is positioned east of the upper-level trough.

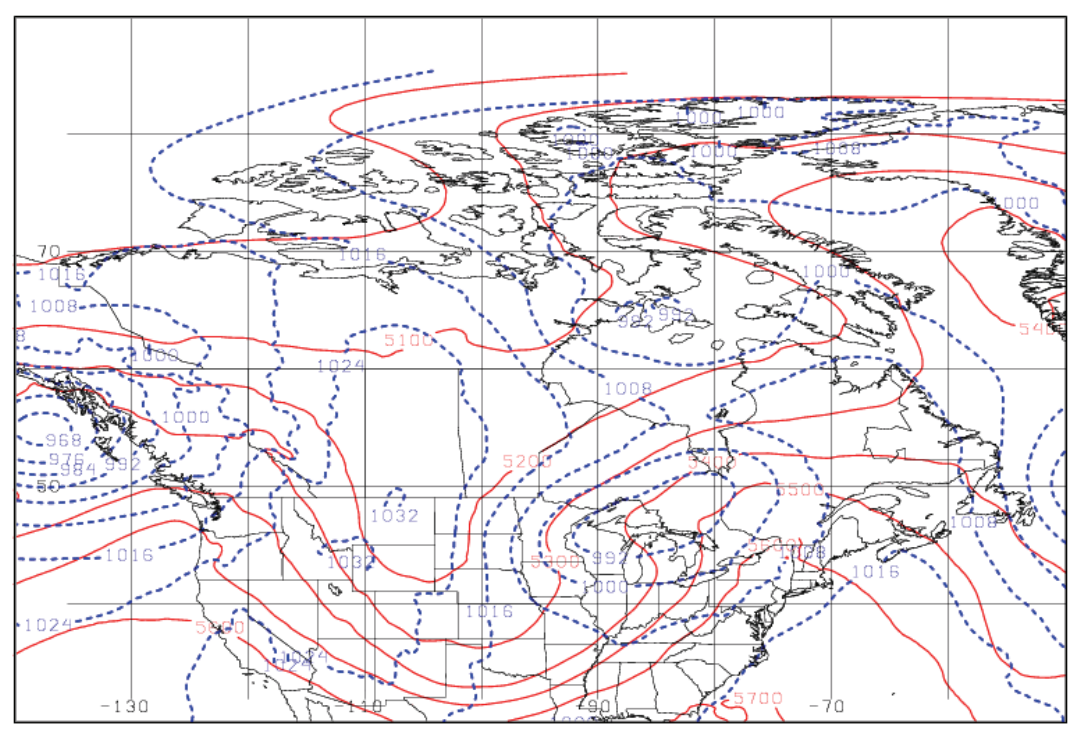

Figure 2-3: Mean-sea-level pressure (blue-dotted lines) and $500 \mathrm{mb}$ thickness (red-solid lines) at 12 UTC on November 27, 1988.

The same product also provided information about the synoptic stage (mature, cut-off, closed low) of each event, by analysing the position on the surface low-pressure center with respect to the $500 \mathrm{mb}$ thickness field. An example of these synoptic stages is presented in Figure 2-4.

A cyclone is said to be mature when the surface low-pressure center is located east of the upper-level trough, in the strongest region for upper-level forcing (Bluestein, 1992) (Figure 2-4a). A cyclone becomes a cut-off or a closed low in its decaying stage. Cut-off lows are defined to be surface lows that are 
completely detached from the main upper-level westerly flow (Bluestein, 1992) (Figure 2-4b); they usually move slowly or remain stationary for several days. Finally, a surface low is said to be closed when it is encircled by one or more isobar at upper-level, inhibiting the forcing to maintain the surface cyclone (Bluestein, 1992) (Figure 2-4c).

(a)

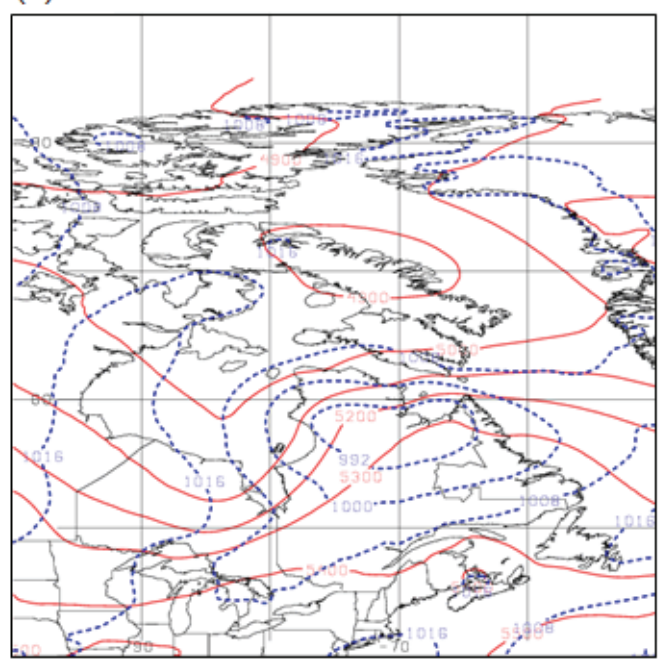

(b)

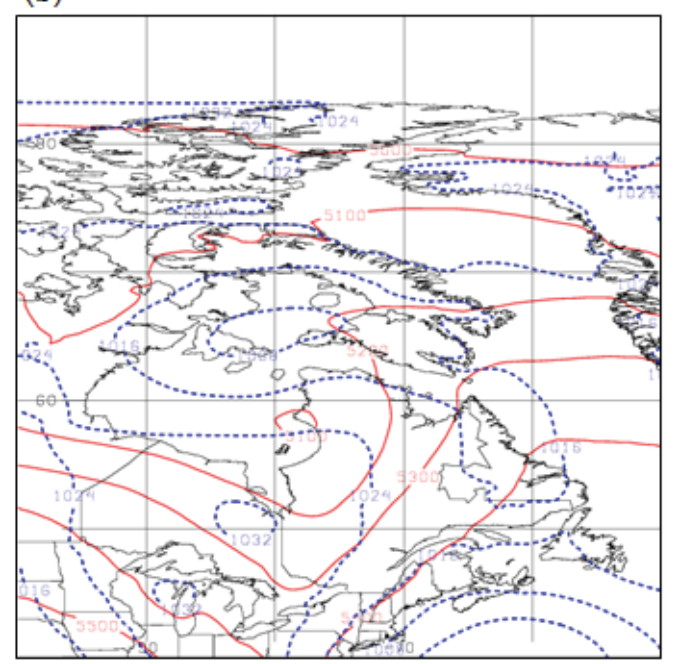

(c)

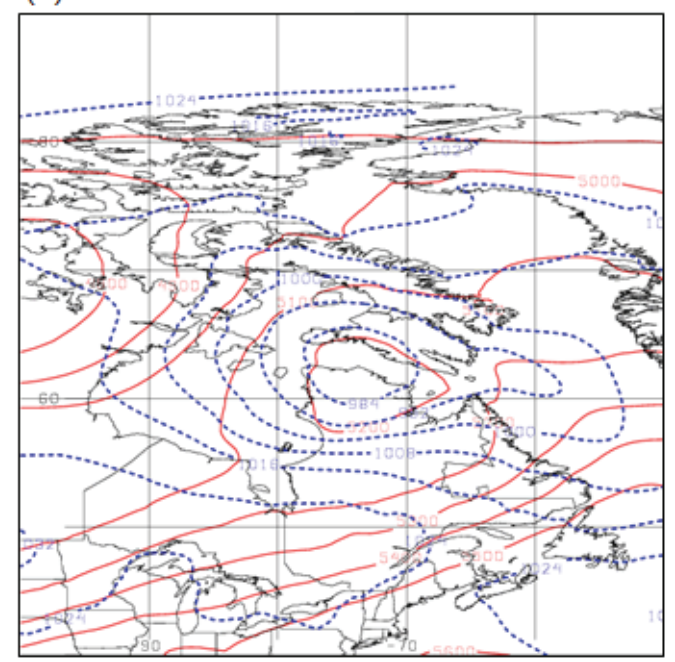

Figure 2-4: Mean-sea-level pressure (blue-dotted lines) and $500 \mathrm{mb}$ thickness (red-solid lines) for (a) mature stage over Northern Quebec (15 UTC March 14, 1996), (b) cut-off low over Foxe Basin (21 UTC Feb. 26, 1981), and (c) closedlow over Hudson Strait (15 UTC Nov. 22, 1982). 


\section{CHAPTER 3}

Results

This Chapter presents the results of the study and is organized into two Sections. Section 3.1 focuses on the 1955-1996 major cold-season precipitation events at Iqaluit. Their general characteristics, including their basic statistics and their seasonal and yearly occurrence will first be discussed, followed by the description of their wind pattern and precipitation types. The analysis of the main regions of origin and storm tracks of systems leading to major precipitation events at Iqaluit, as well as the specific characteristics of each origin group will then be described. Section 3.1 will end with a discussion of the trend and variation of such events over the last half-century. In Section 3.2, the detailed analysis of four cases is performed. The events were chosen according to their severity and their point of origin. The synoptic evolution, the surface variables, precipitation type and atmospheric profiles characterising each event are discussed.

\subsection{Major events 1955-1996}

\subsubsection{General characteristics}

A total of 194 events $\geq 9.5 \mathrm{~mm}$ in total precipitation were observed at Iqaluit between October 1954 and April 1996. Table 3-1 describes the accumulation and duration of these events.

Table 3-1: Accumulation (mm) and duration (day) statistics of the major precipitation events at Iqaluit. Statistics of the duration is expressed by the number of events.

\begin{tabular}{||c|c|c||c|c|c||}
\hline \hline \multicolumn{3}{||c||}{ ACCUMULATION (mm) } & \multicolumn{3}{c||}{ DURATION } \\
\hline Maximum & Minimum & Average & 1 day & 2 days & 3 days \\
\hline 55.9 & 9.5 & 16.7 & 177 & 15 & 2 \\
\hline
\end{tabular}


Figure 3-1 is an enlargement map of Figure 2-2, focusing on the occurrence of precipitation accumulation during major precipitation events at Iqaluit.

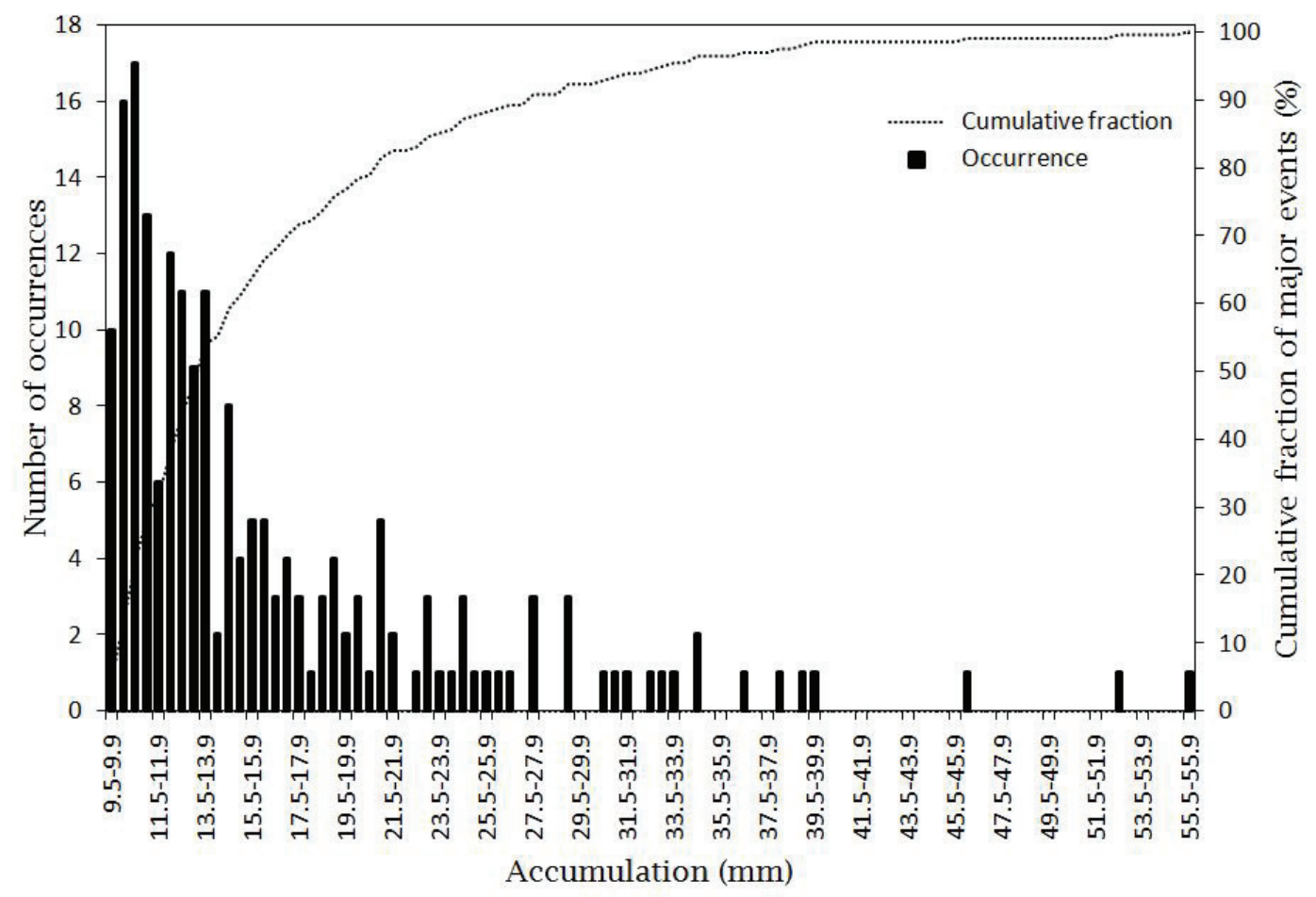

Figure 3-1: Over the 1955-1996 cold-season period, the figure shows number of occurrences and the cumulative fraction (\%) of accumulation ( $\mathrm{mm}$ ) during the 194 major precipitation events at Iqaluit.

On average, major events produced $16.7 \mathrm{~mm}$ of precipitation. The maximum and minimum accumulations were $55.9 \mathrm{~mm}$ and $9.5 \mathrm{~mm}$, respectively (Table 3-1). Here again, accumulation distribution is positively skewed. More than $50 \%$ of the major events consist of accumulation $<13.5 \mathrm{~mm}$ and only $8 \%$ of the major events produced $>30 \mathrm{~mm}$ of precipitation (Figure $3-1$ ).

Since the events were based on a daily precipitation threshold, their duration is better expressed in days. A total of 177 events (90\%) were single-day events, lasting $\leq 24 \mathrm{~h}$ (Table 3-1). Fifteen events consisted of 2-day events, 
representing $9 \%$ of the major events. Two events lasted for three consecutive days; these events represent $1 \%$ of the major precipitation events. No event lasted longer than three days.

Figure 3-2a presents the monthly occurrence of major precipitation events at Iqaluit. Major events are more frequent at the beginning (October-November) and end of the cold season (April) rather than during the colder months of winter. October is the month experiencing the highest number of major events with a total of 41 . The minimum monthly occurrence of 17 events is observed during the coldest climatological month, February (Environment Canada, 2008). During the cold season, the atmosphere is usually moister during the months of October, November and April, while wintertime (December-March) is often considered to be the driest period of the year in the Arctic (Stewart et al., 1995).

Figure 3-2b illustrates the number of occurrences of major precipitation at Iqaluit per cold-season over the 1955-1996 period. On average, 5 major events are observed every cold-season. The highest number of major precipitation events during a single cold-season was 12 events. It occurred twice during the period investigated, during the cold-seasons of 1958 and 1968. Five cold seasons experienced a single major precipitation event: 1957, 1961, 1991, 1993 and 1994. The absence of major events observed during the 1995 cold-season was due to missing precipitation data. Trends and tendency of major precipitation events since 1955 will be further discussed in Section 3.1.5. 

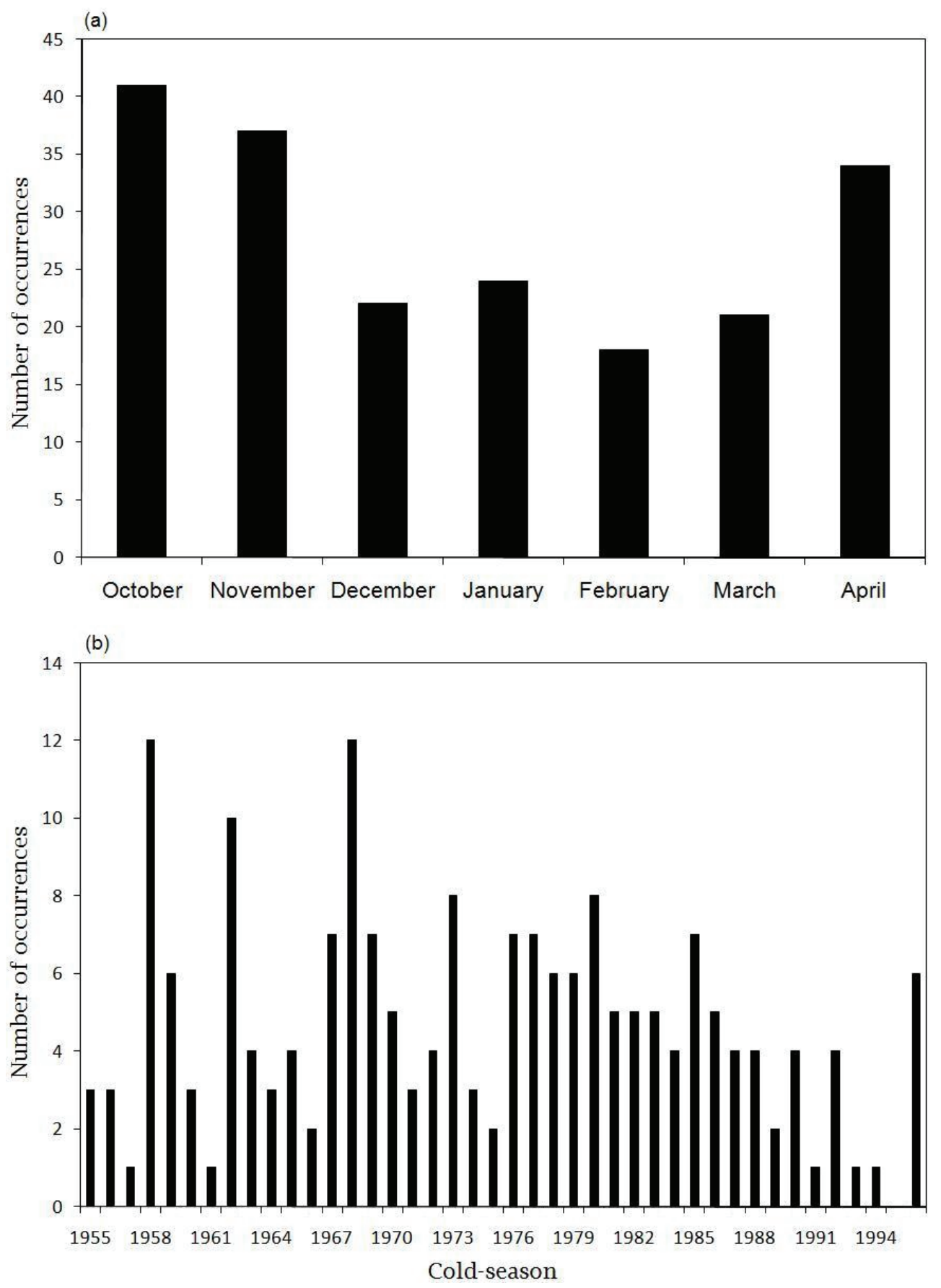

Figure 3-2: Over the 1955-1996 cold-season period, (a) shows the monthly number of occurrences and (b) shows the annual number of occurrences of the 194 major events. 


\subsubsection{Wind}

The important mountain ridges in close proximity of Iqaluit often affect its wind regime (Nawri and Stewart, 2006). The percent frequency of occurrence of hourly surface wind direction recorded during the 194 cold-season major precipitation events is summarized in a wind rose (Figure 3-3). A total of 4266 surface hourly wind observations from Environment Canada were classified according to their orientation and speed. The wind bars are divided in 18 sectors of $20^{\circ}$. Each wind bar is separated in 5 wind classes: $1-10 \mathrm{~km} / \mathrm{h} ; 10-20 \mathrm{~km} / \mathrm{h}$; 20-30 km/h; 30-40 km/h; $\geq 40 \mathrm{~km} / \mathrm{h}$. To illustrate, approximately $11 \%$ of northwesterly winds exceeded $40 \mathrm{~km} / \mathrm{h}$, with north-westerly winds defined by wind observations from the north-west quadrant of the wind rose.

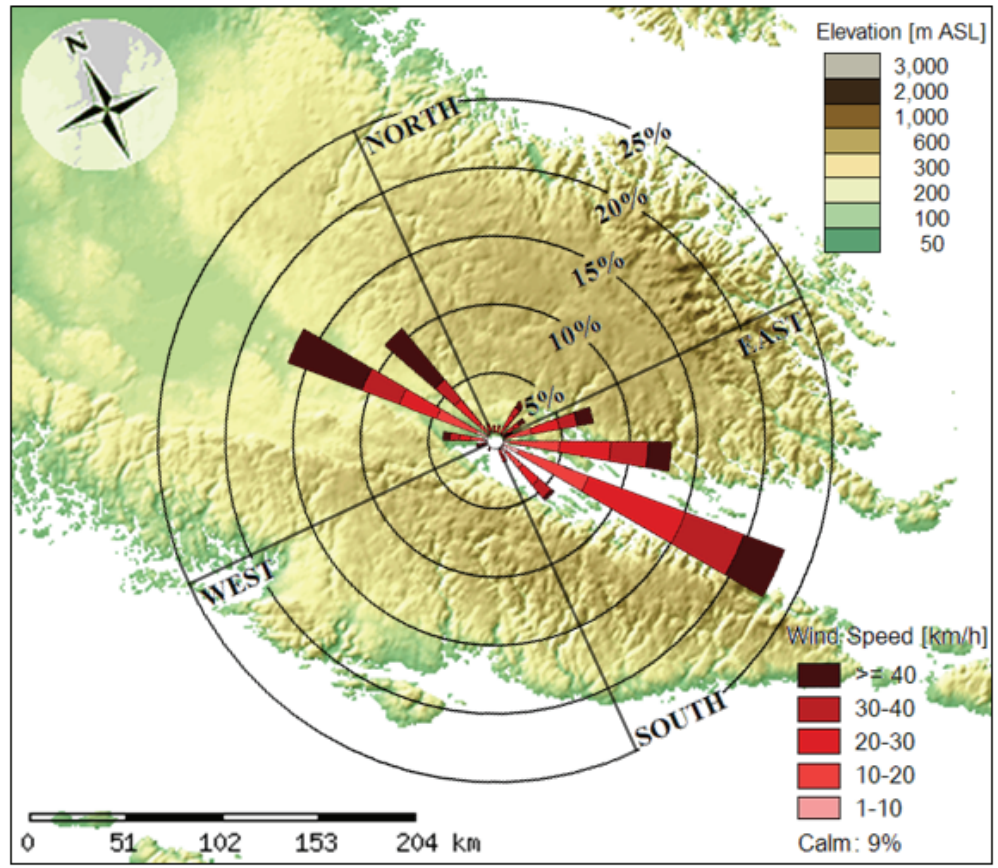

Figure 3-3: Percent-frequency of surface wind direction (in $20^{\circ}$ intervals) and speed $(\mathrm{km} / \mathrm{h})$ observed during the 194 major precipitation events at Iqaluit. A total of 4266 hourly observations are summarized (Background map adapted from the Atlas of Canada, 2008). 
Figure 3-4 shows the percent frequency of occurrence of wind direction for each 5 wind classes; percent frequency of occurrence regardless of wind speed is also shown and illustrates wind direction observations during the major precipitation events. As an example, 24\% of the wind speed observations were between 20 and $30 \mathrm{~km} / \mathrm{h}, 13 \%$ being southeasterly, $6 \%$ northwesterly, and $4 \%$ east-northeasterly.

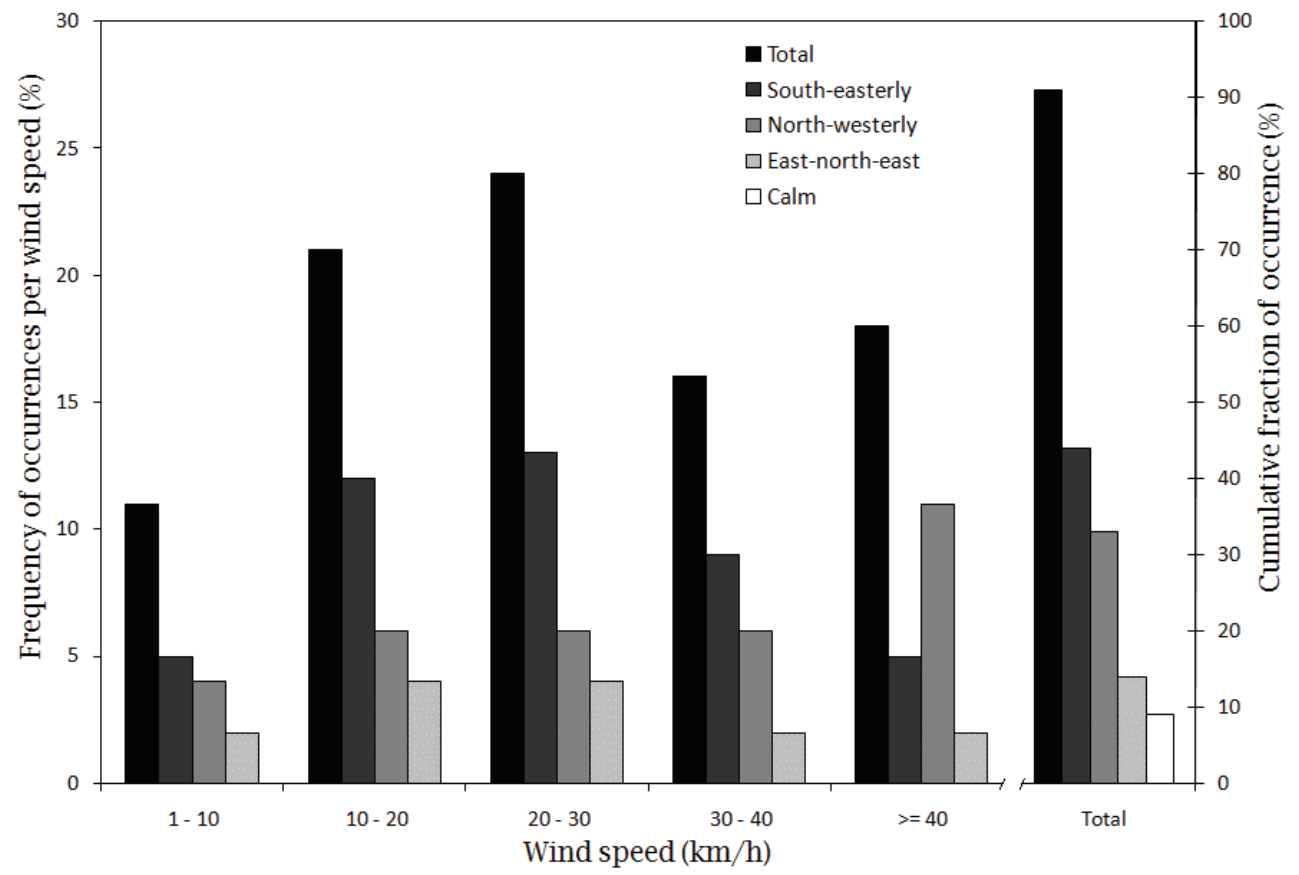

Figure 3-4: Frequency of occurrence (\%) of wind speed during the 194 major precipitation events at Iqaluit. The cumulative fraction of occurrence (\%) of wind observation during the 194 events from each direction is labelled on the secondary axis (right axis). No wind directions were associated with calm conditions.

The analysis of this information shows a dominance of wind direction in the north-west/south-east corridor (Figure 3-3); this occurs $77 \%$ of the time during the events (Figure 3-4). A bi-directional distribution of the wind direction in this corridor is observed as well. The wind was from the north-west in $33 \%$ of the wind observations; wind was from the south-east in $44 \%$ of the time 
(Figure 3-4). A total of $1 \%$ of wind observations events were south-westerly winds (Figure 3-3), whereas north-easterly and easterly winds accounted for $13 \%$ of the observations. Calm conditions were reported for $9 \%$ of the observations. During major precipitation events at Iqaluit, south-easterly winds dominate, followed by north-westerly and east-north-easterly winds.

The observed dominance of wind channelling during major precipitation events, independent of the wind speed, is in agreement with past studies focusing on winds at Iqaluit (e.g. Nawri and Stewart, 2006; Nadeau, 2007). These studies, however, never considered precipitation.

The average wind speed during major precipitation events is $25 \mathrm{~km} / \mathrm{h}$. Light wind (1-10 km/h) accounts for $11 \%$ of the wind observations, with $9 \%$ observed in the northwest-southeast corridor (Figure 3-4); this also represents $64 \%$ of $1-10 \mathrm{~km} / \mathrm{h}$ wind observations. Even at low speed, the surrounding topography influences on wind direction at Iqaluit.

A wind speed threshold of $40 \mathrm{~km} / \mathrm{h}$ has been chosen as severe wind threshold, according to the blizzard wind threshold from Environment Canada (2006). Wind observation satisfying this threshold during the 194 major precipitation events at Iqaluit is represented by the dark red regions in Figure 3-3; this represents $18 \%$ of wind observation (Figure 3-4).

In contrast with the total number of occurrences of wind observations, north-westerly winds are more frequently observed than south-easterly winds when wind speed exceeds $39 \mathrm{~km} / \mathrm{h}$ (Figure 3-3). Indeed, north-westerly winds $\geq 40 \mathrm{~km} / \mathrm{h}$ account for $11 \%$ of the wind observation, whereas south-easterly winds 
are observed during $5 \%$ of wind observation $\geq 40 \mathrm{~km} / \mathrm{h}$; east-north-easterly winds are observed during 2\% (Figure 3-4). In addition, $89 \%$ of the severe wind observations are characterized by north-west/south-east winds, thus channelling.

\subsubsection{Precipitation}

The cold-season defined in this study allows for the analysis of events during 7 months of the year, from October to April. Although the climatology of these months is characterized by cold temperature and the dominance of snowfall, other precipitation types may be observed resulting from the passage of a warm front or simply because of warmer than normal temperatures. The occurrence of the different precipitation types observed during the 1955-1996 major precipitation events at Iqaluit is described below.

The 194 events analysed over this period consisted of a total of 4477 hours of precipitation. Precipitation was either observed as liquid or solid phase. Liquid precipitation consisted of rain and freezing rain. Solid precipitation, on the other hand, included snow, ice crystals, ice pellets and snow grains. These precipitation types are defined in Table 3-2 and their monthly hours of occurrence are illustrated in Figure 3-5.

Precipitation was dominated by snow, observed during 3998 hours and representing $90 \%$ of the total hours of precipitation (Figure 3-5). The months of October, November and April have the highest occurrence of snowfall. The colder and drier months, December through March, experienced overall reduced hours of precipitation compared to the other months. 
Table 3-2: Definition of the different precipitation types observed during the major precipitation events at Iqaluit. Note that drizzle was classified under rain. Adapted from Environment Canada (2006).

\begin{tabular}{||l|l||}
\hline $\begin{array}{l}\text { SNOW } \\
\text { GRAINS }\end{array}$ & $\begin{array}{l}\text { Precipitation of very small white and opaque grains of ice, fairly flat or } \\
\text { elongated; their diameter is generally less than } 1 \mathrm{~mm} .\end{array}$ \\
\hline $\begin{array}{l}\text { ICE } \\
\text { PELLETS }\end{array}$ & $\begin{array}{l}\text { Precipitation of transparent or translucent pellets of ice that are } \\
\text { spherical or irregular, rarely conical, having a diameter } \leq 5 \mathrm{~mm} .\end{array}$ \\
\hline ICE & $\begin{array}{l}\text { A fall of non branched ice crystals, in the form of needles, columns or } \\
\text { plates, often so tiny that they seem to be suspended in the air. }\end{array}$ \\
\hline SNOW & $\begin{array}{l}\text { Precipitation of mainly hexagonal ice crystals, most of which are } \\
\text { branched (star-shaped). }\end{array}$ \\
\hline FREEZING & $\begin{array}{l}\text { Rain, the drops of which freeze on impact with the ground or with } \\
\text { other objects at or near the earth's surface. }\end{array}$ \\
\hline RAIN & $\begin{array}{l}\text { Precipitation of liquid water particles, either in the form of drops of } \\
\text { larger diameter than } 0.5 \text { mm, or of smaller widely scattered drops. }\end{array}$ \\
\hline
\end{tabular}

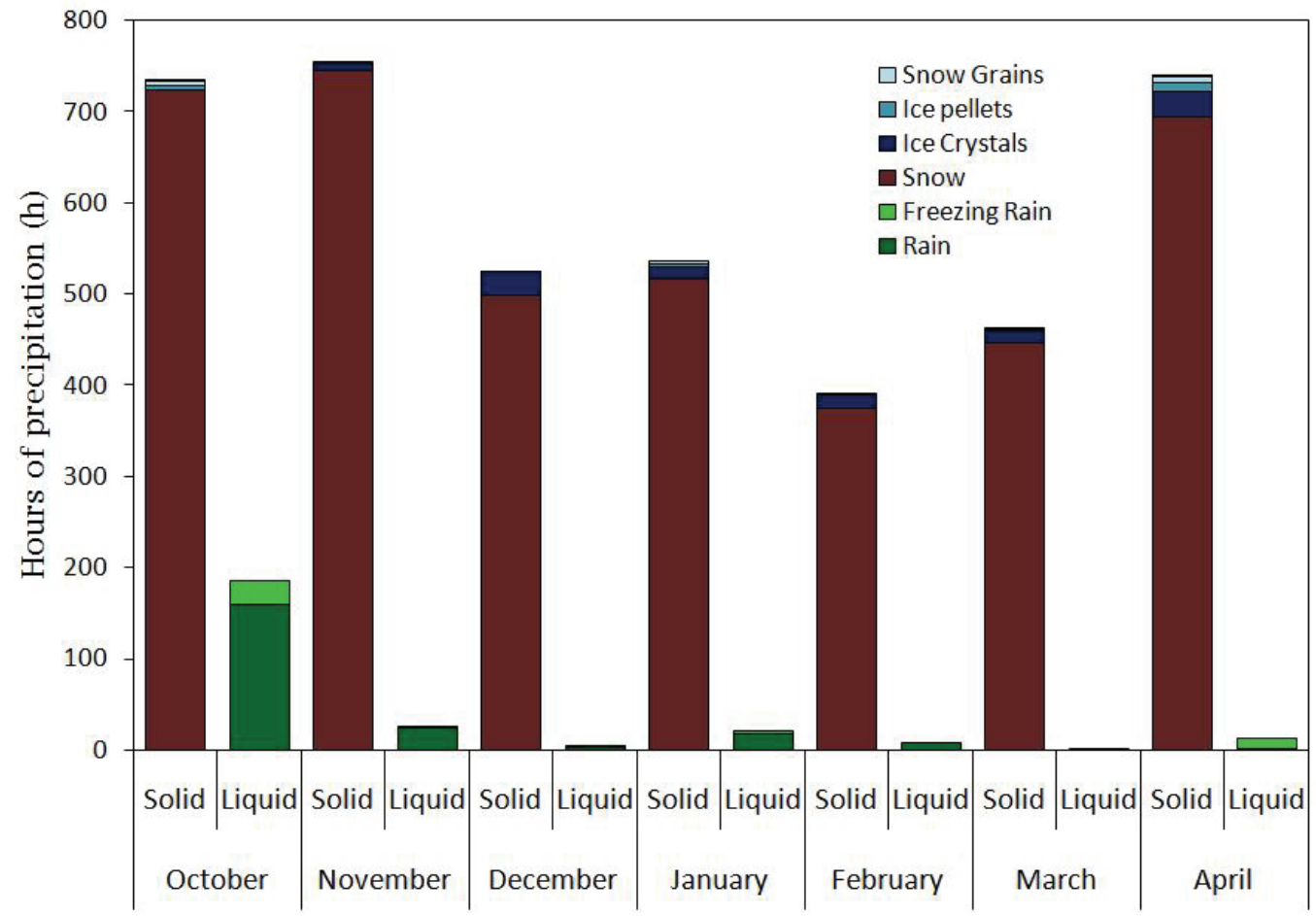

Figure 3-5: 1955-1996 monthly hours of precipitation of each precipitation type during the 194 major precipitation events. 
Liquid precipitation and freezing rain peaked during the month of October. October is the warmest and most humid month of the cold season (Environment Canada, 2008). It is thus subject to warmer surface conditions (closer to $0^{\circ} \mathrm{C}$ ) and the passage of a warm front aloft can result is optimal atmospheric conditions for freezing rain (Roberts et al., 2008). April, with an average of 2 days recording temperature above $0^{\circ} \mathrm{C}$ (Environment Canada, 2008), exhibits the largest solid precipitation variability. A warm front combined with cold surface temperature can lead to the creation of a transition zone between colder and warmer conditions at the surface, explaining the large variability of precipitation type during this month.

\subsubsection{Regions of origin and storm tracks}

The storm tracks of the 194 major events were manually retrieved using reanalysis data. The analysis of this information led to the identification of three dominant regions of origin of systems leading to major precipitation events at Iqaluit (Figure 3-6).

Storms were mainly from the South (tracks 1a-b), the West (tracks 2a-b) and the Atlantic (tracks 3a-b). Each main group was broken down into two subtracks for more homogeneous groups. A fourth group (Others), although not shown, was created for the events that followed no specific track or that were not associated with synoptic activity. Table 3-3 indicates the occurrence of origin group and their sub-storm tracks, as well as their average speed of motion. The speed of motion refers to the movement of the low-pressure centre. 


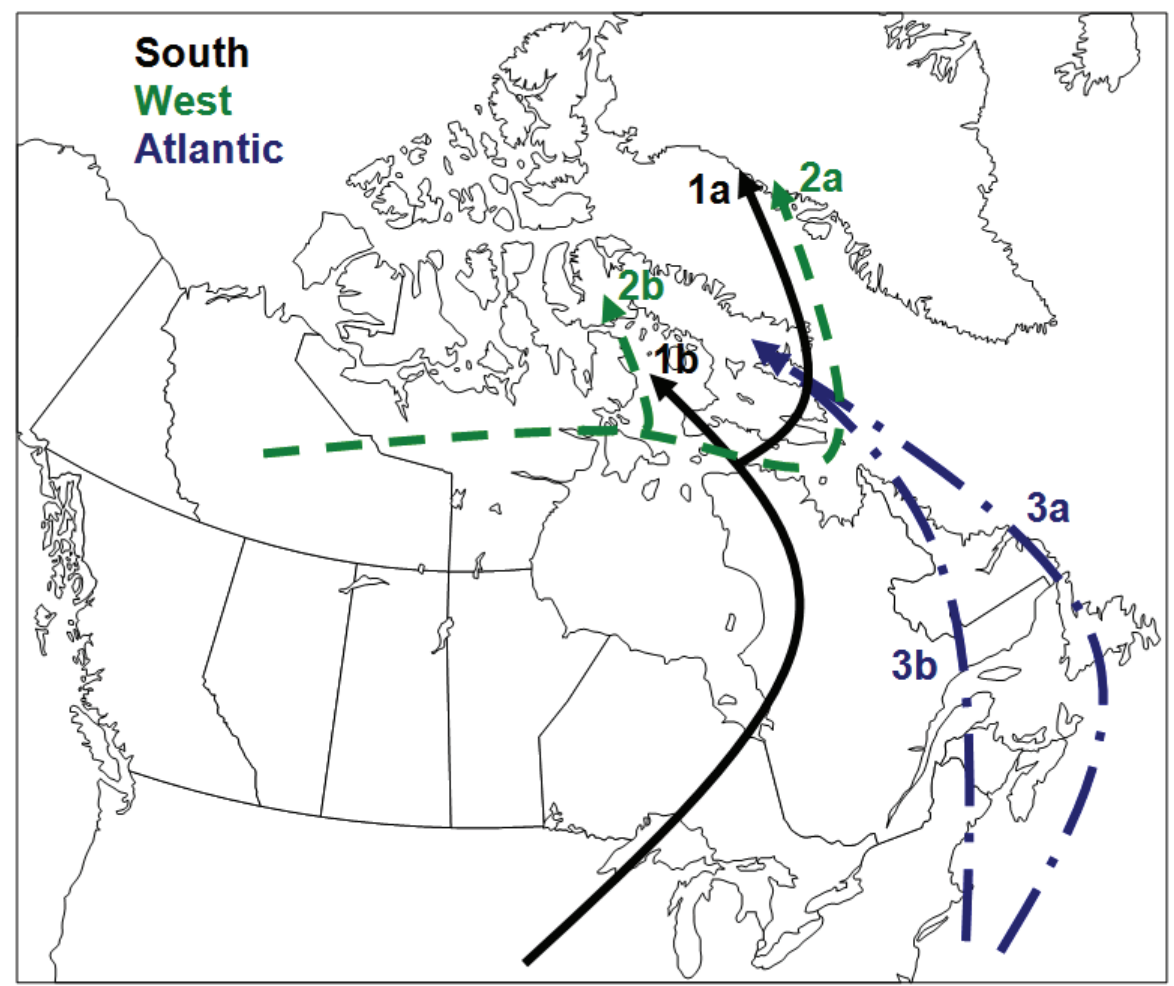

Figure 3-6: Cyclone tracks and sub-tracks associated with the major cold-season precipitation events at Iqaluit. Solid black lines are the South-originating storms (1a-1b); Green dashed lines are the West-originating storms (2a-2b); and Blue long-dashed lines are the Atlantic-originating storms (3a-3b).

Table 3-3: Occurrence and speed of motion of each origin group and their substorm tracks.

\begin{tabular}{|c|c|c|c|c|c|}
\hline $\begin{array}{l}\text { ORIGIN } \\
\text { GROUP }\end{array}$ & $\begin{array}{l}\text { SUB- } \\
\text { TRACK }\end{array}$ & \multicolumn{2}{|c|}{$\begin{array}{c}\text { NUMBER OF } \\
\text { EVENTS }\end{array}$} & \multicolumn{2}{|c|}{$\begin{array}{l}\text { SPEED OF MOTION } \\
(\mathrm{km} / \mathrm{h})\end{array}$} \\
\hline \multirow{2}{*}{ South } & $1 \mathrm{a}$ & 59 & \multirow{2}{*}{78} & 43 & \multirow{2}{*}{42} \\
\hline & $1 b$ & 19 & & 40 & \\
\hline \multirow{2}{*}{ West } & $2 a$ & 29 & \multirow{2}{*}{57} & 38 & \multirow{2}{*}{34} \\
\hline & $2 b$ & 28 & & 29 & \\
\hline \multirow{2}{*}{ Atlantic } & $3 a$ & 37 & \multirow{2}{*}{44} & 35 & \multirow{2}{*}{37} \\
\hline & $3 b$ & 7 & & 49 & \\
\hline Others & 4 & 15 & 15 & $\mathrm{~N} / \mathrm{A}$ & N/A \\
\hline
\end{tabular}


Storms originating from the South are more frequently observed, followed by the West- and Atlantic-originating ones; events classified as Others accounted for the lowest number of events, with only 15 out of 194 (Table 3-3).

On average, South-originating low-pressure systems move with an average speed of motion of $42 \mathrm{~km} / \mathrm{h}$, whereas West-originating storms are moving at an average speed of $34 \mathrm{~km} / \mathrm{h}$ (Table 3-3). Storms originating from the Atlantic Ocean and moving inland are faster, with an average speed of motion of $49 \mathrm{~km} / \mathrm{h}$. Storms part of the sub-group $2 \mathrm{~b}$, on the other hand, progress at a speed of 29 $\mathrm{km} / \mathrm{h}$, significantly slower than the other sub-groups (Table 3-3).

\subsubsection{Storm track characteristics}

The general characteristics of the tracks of each origin groups and subgroups presented in Figure 3-6 are further described. Detailed case studies of one event per origin group will be further discussed in Section 3.2.

The South-originating storms represented by the black tracks $1 \mathrm{a}$ and $1 \mathrm{~b}$ on Figure 3-6 are the most common systems resulting in major precipitation events at Iqaluit, accounting for 78 (40\%) of the 194 events (Table 3-3). Cyclones from each sub-group (1a and $1 \mathrm{~b}$ ) originate from the same region and follow the same route until they reached the southern edge of Baffin Island, in Hudson Strait. In general, South-originating cyclones are initiated in the central part of the UnitedStates or the Great Lakes region and are associated with a developing trough (Figure 3-6). This trough then slowly moves northward, steering the disturbance with it. Cyclones develop and intensify as they travel over the Great Lake region and move north towards James Bay and Hudson Bay. A weakening of the surface 
low-pressure system is commonly observed over northern Quebec due to the lost of energy available for the system as it passes over dry, open land. Surface lowpressure systems usually re-intensify over Hudson Strait, even though the upperlevel trough maintaining the system weakens as it moves northward. North of Hudson Strait, storm track variability is observed as cyclones enter their decaying stage (Figure 3-6). Indeed, cyclones seldom travel directly inland, towards the central part of Baffin Island. Fifty-nine of them (group 1a, 76\% of the South storms) veer to the east, travelling towards Greenland, while the other portion (group 1b, 24\% of the South storms) continues north-westward towards Foxe Basin.

Storms originating from the West are illustrated in green on Figure 3-6. They form the second greatest origin group and account for 57 major precipitation events observed at Iqaluit (29\%). Like the South storm-track group, cyclones from each sub-group ( $2 a$ and $2 b$, Figure 3-6) originate from the same region, the southern part of the Northwest Territories, east of the mountains. Cyclones initiate as a result of either lee-cyclogenesis east of the Rocky Mountains (14 events), or over the plains, due to orography (43 events). They then move east as weak developing cyclones. They reach their maximum intensity as they travel over the southern edge of Foxe Basin. At this point, two dominant sub-storm tracks regimes are observed. Approximately half of the West-originating storms veer northward (group 2b, Figure 3-6), traveling and decaying over Foxe Basin. The other half (group 2a, Figure 3-6) continues over Hudson Strait and moves north as it reaches the southern tip of Baffin Island, towards Greenland. 
The Atlantic-originating storms are illustrated in blue on Figure 3-6. They are the third most common systems, accounting for $23 \%$ of the major events. Here again, the group has been separated into two sub-track groups (3a and $3 b$, Figure 3-6). Like the South- and West-originating storm-track groups, cyclones from each sub-group originate from the same region. In contrast to the two other storm-track groups, Atlantic-originating storms decay over a single common region as well. The predominant region of formation was over the Atlantic Ocean, in the vicinity of the north-eastern coast of the United States. Group 3a is composed of cyclones that initiate over the Atlantic Ocean, travelling east of the Atlantic provinces of Canada (Figure 3-6). Thirty-seven events followed the 3atype track, representing $84 \%$ of the Atlantic storms and $19 \%$ of the total major events. Group $3 b$ is still characterized by cyclones originating over the Atlantic Ocean, but travelling inland over northern Quebec instead of following the Labrador coasts (Figure 3-6). Group $3 b$ is responsible for 11 events, representing $16 \%$ of the Atlantic storms and $4 \%$ of the major precipitation events. Storms from both sub-groups decay over Cumberland Sound or over the northern part of Baffin Island; 33 events exhibited a tilted trough pattern during their decaying phase (Table A-1). A detailed case study of a storm exhibiting a tilted trough pattern is further discussed in Section 3.2.3.

When an event does not originate from any of the aforementioned origin groups, or no large-scale synoptic activity is observed, the event is classified under the group Others. This category accounts for $8 \%$ (15 events) of the major precipitation events. Only one of them was the result of synoptic activity: a 
cyclone originating in the Arctic Ocean, moving south and along the southern portion of the Canadian Archipelago. The analysis of the $500 \mathrm{mb}$ thickness field showed that the 14 other events are associated with a short-wave trough present over southern Baffin Island. A short-wave trough is able to provide the upperlevel forcing for an upward air circulation without generating a surface lowpressure system. A detailed case study of a short-wave induced major precipitation event is further discussed in Section 3.2.4.

\subsubsection{Evolution and synoptic stage}

As previously discussed in Section 1.2.4, storms tend to decay over the Canadian Archipelago. The number of low-pressure systems leading to major precipitation at Iqaluit and decaying in the vicinity of the community, as well as the main regions of decay is further examined.

Close proximity of Iqaluit is defined according to the average surface diameter of the major precipitation events. This value has been obtained by averaging the diameter of the closed-isobar low-pressure systems at mean-sealevel during the mature stage of the major events; pressure contours varied depending on the depth of each system. The average diameter of these events is $600 \mathrm{~km}$. This value is used as the distance threshold for defining the area in close proximity of Iqaluit. As a result, storms decaying within a radius of $600 \mathrm{~km}$ from Iqaluit are said to be decaying in its vicinity (Figure 3-7). In comparison, Nielsen and Dole (1992) found that the median radius of extra-tropical cyclones forming over the Atlantic Ocean and moving over North America is $500 \mathrm{~km}$. 
The number of storms that decayed close to Iqaluit, near Greenland and in other regions is presented in Figure 3-7. Note that although one event part of the Others group was associated with cyclonic activity, it was not included in Figure 3-7; for reference, this event decayed in the vicinity of Iqaluit.

Regardless of their origin, many systems decayed in the vicinity of Iqaluit. A total of 84 low-pressure systems decayed within $600 \mathrm{~km}$ of Iqaluit, representing $43 \%$ of the total number of events (Figure 3-7). Half of the South-originating storms, $47 \%$ of the West-originating systems and $41 \%$ of the Atlantic-originating events decayed in the vicinity of Iqaluit.

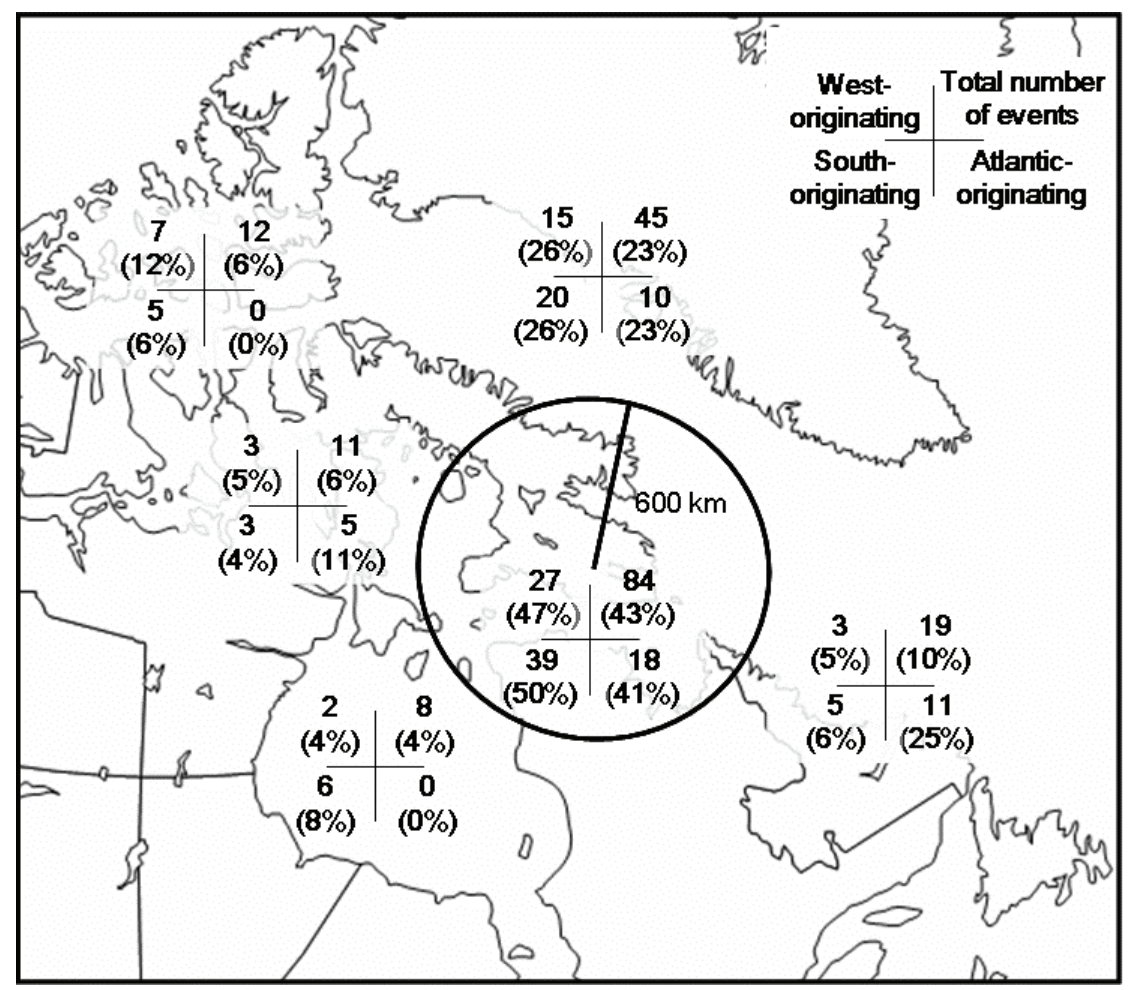

Figure 3-7: Main regions of decay of storms leading to major precipitation events at Iqaluit. The number occurrence of decay of 6 main regions is indicated for each storm-track group according to the upper-right legend. The number of occurrences is indicated by the number and the percentage is below it, in brackets. 
The north-western coast of Greenland is the second most common region of decay for low-pressure systems leading to major precipitation events at Iqaluit. Indeed, $23 \%$ of these events decayed over Greenland (Figure 3-7).

South- and West-originating storms also decayed over the Labrador Sea (5 and 3 events), over Hudson Bay (6 and 2 events), over the western shore of Foxe Basin ( 3 and 3 events) and over Northern Canadian Archipelago (5 and 7 events) (Figure 3-7). In contrast, Atlantic-originating storms show less variability in their regions of decay. Such events only decay over Labrador Sea (11 events) and the western shore of Foxe Basin (5 events) in addition to the two main aforementioned regions of decay.

\subsubsection{Monthly variability}

To determine the variability of each origin group during the cold-season, their cumulative monthly occurrence between 1955 and 1996 has been plotted (Figure 3-8).

Although a decrease in occurrence of storms originating from the South is observed between December and March, this pattern follows the general decrease in occurrence observed over the colder months (see Section 3.1.1). More than half of the storms originating from the West occur between October and November, whereas a significant decrease in their frequency is observed during January and February. In fact, only 4 out of the 57 West-originating events are observed during those months (Figure 3-8). On the other hand, storms coming from the Atlantic are more frequent during the colder months, with 10 storms in 
January and 8 in February. Events from the Others group are observed in all months, with the exception of the month of February.

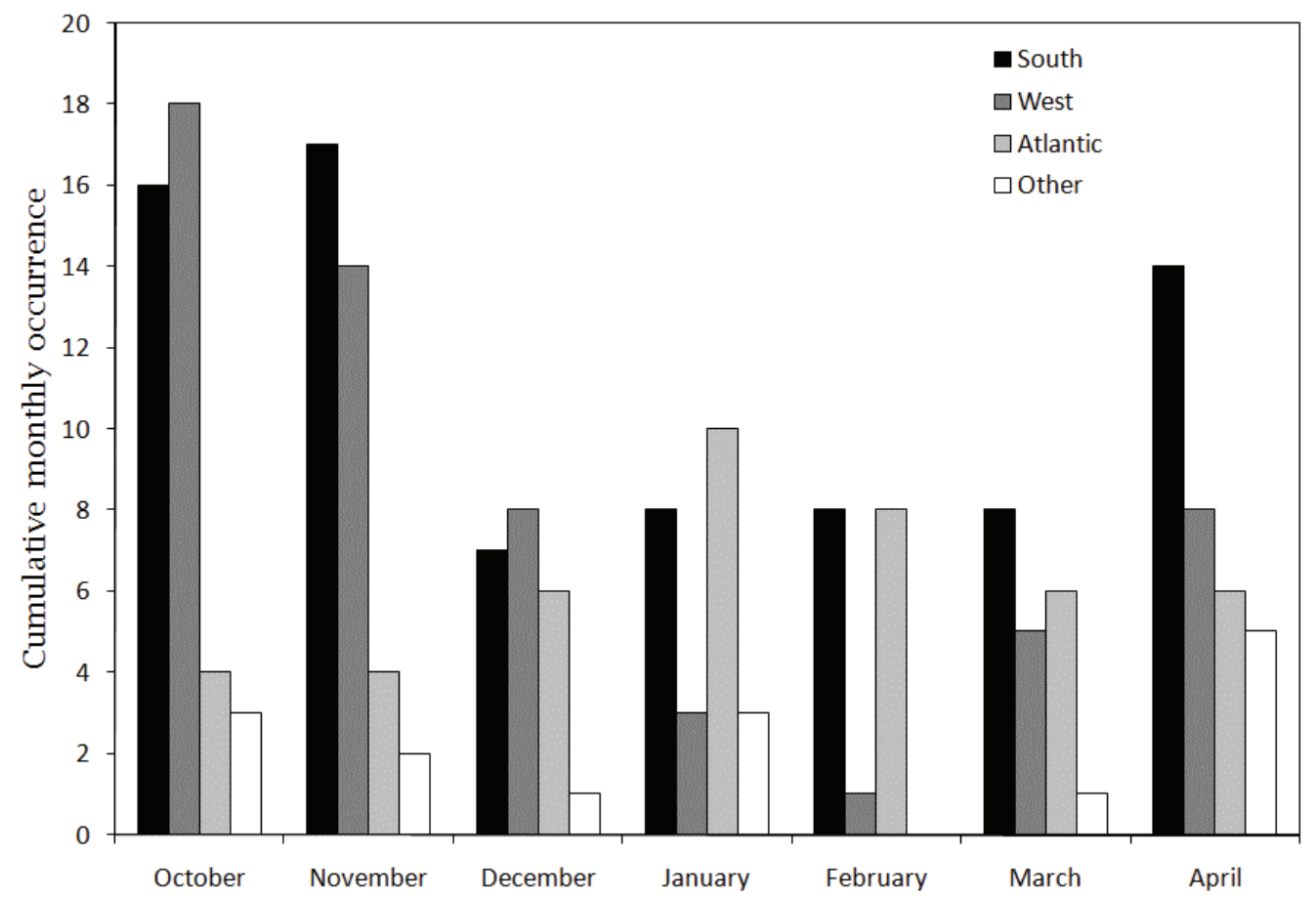

Figure 3-8: Cumulative monthly occurrence of each origin group over the 19551996 period.

\subsubsection{Trends of the extreme events}

With the Earth's climate currently changing, changes in the Arctic region's atmosphere are expected. As stated earlier, cyclonic activity and precipitation in the Arctic has increased or is expected to increase in the future (e.g. Groisman et al., 2003; Zhang et al., 2004). These hypotheses have been formulated for the entire Arctic region and none of the studies focused over one particular region. The evolution of the frequency of extreme events over Iqaluit since 1955, as well as its relation with the NAO index, is furthermore discussed. 
The cold-season occurrences of major precipitation events are illustrated on Figure 3-9.

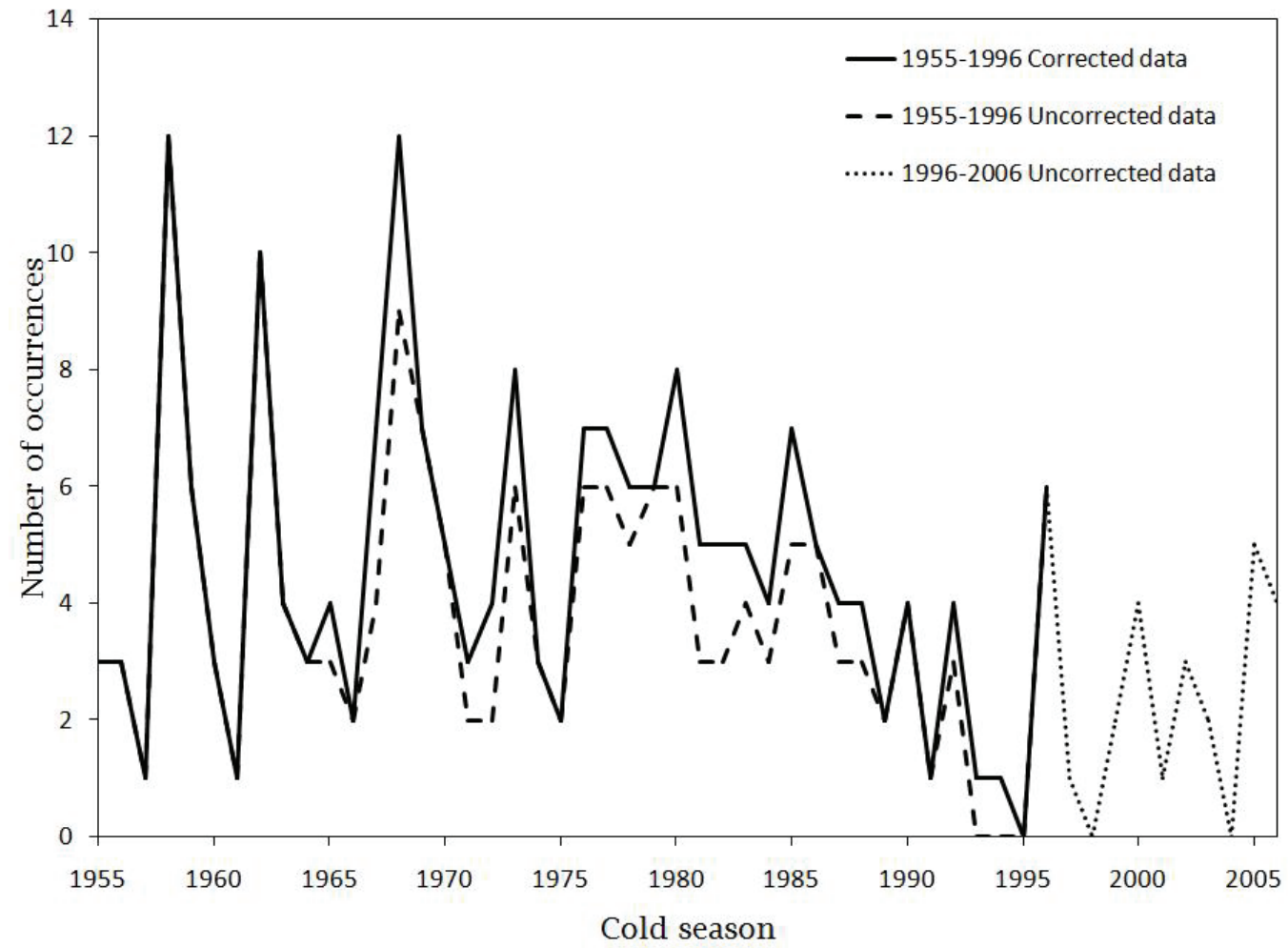

Figure 3-9: 1955-2006 Cold-season occurrences of major precipitation events. The thick solid line represents the 1955-1996 occurrence of extreme events using corrected precipitation data. The dashed-line is for the same interval, but using uncorrected precipitation data. The thin dotted-line represents the occurrence of major precipitation events between 1997 and 2006, a period when only uncorrected precipitation data is available. Note that the occurrence of major events is the same using both dataset for the 1955-1964 period.

The thick solid line represents the 1955-1996 frequency of extreme events using corrected precipitation data. To assess the significance of the distributions' tendency, the coefficient of determination $\left(R^{2}\right)$ of the linear regressions of the number of occurrences of major events has been calculated according to the equation 3.1 (Glantz and Slinker, 2000): 


$$
R^{2}=\left(\frac{\sum(x-\bar{x})(y-\bar{y})}{\sqrt{\sum(x-\bar{x})^{2} \sum(y-\bar{y})^{2}}}\right)^{2}
$$

where $x$ represent the number of years and $y$, the number of occurrences of major precipitation events; $\bar{x}$ and $\bar{y}$ are their respective averages.

Although corrected data is unavailable past 1996, the frequency distribution is extended until 2006 using uncorrected precipitation to investigate the significance of the observed downward tendency of major events (Figure 3-9). The dashed-line is for the same interval, but using uncorrected precipitation data. The thin dotted-line represents frequency of major precipitation events between 1997 and 2006, a period where only uncorrected precipitation data is available. The decision of including uncorrected precipitation data in the analysis has been made after comparing their major precipitation event distributions. The two datasets are correlated at the 0.05 confidence interval and their similarity is illustrated on Figure 3-9. They have matching frequencies of major events distribution until 1964 and their averages difference for $1955-1996$ is of $13 \%$.

After 1995, the occurrence of major events returns to its previous oscillatory behaviour, but with smaller amplitude and reduced frequency. The overall occurrence minimum is also observed within this last period. The year of 2003 was characterized by the lowest of all, with no extreme event observed. Note that the conclusions derived from the analysis of 1997-2006 dataset should not be used to diagnose definitive trends due to the unreliability associated with the uncorrected precipitation dataset; further analysis using corrected precipitation (when available) should confirm or discard the last hypothesis. 
Furthermore, major precipitation event anomalies have been computed for each cold-season. As stated in Section 3.1.1, the average number of cold-season major precipitation events for the $1955-1996$ period is 5 . The major precipitation event anomaly for each cold-season is then computed by subtracting the number of major events of each cold-season from the 1955-1996 cold-season average. The cold-season major precipitation events anomaly has been plotted against its associated Oct-April NAO index (Figure 3-10).

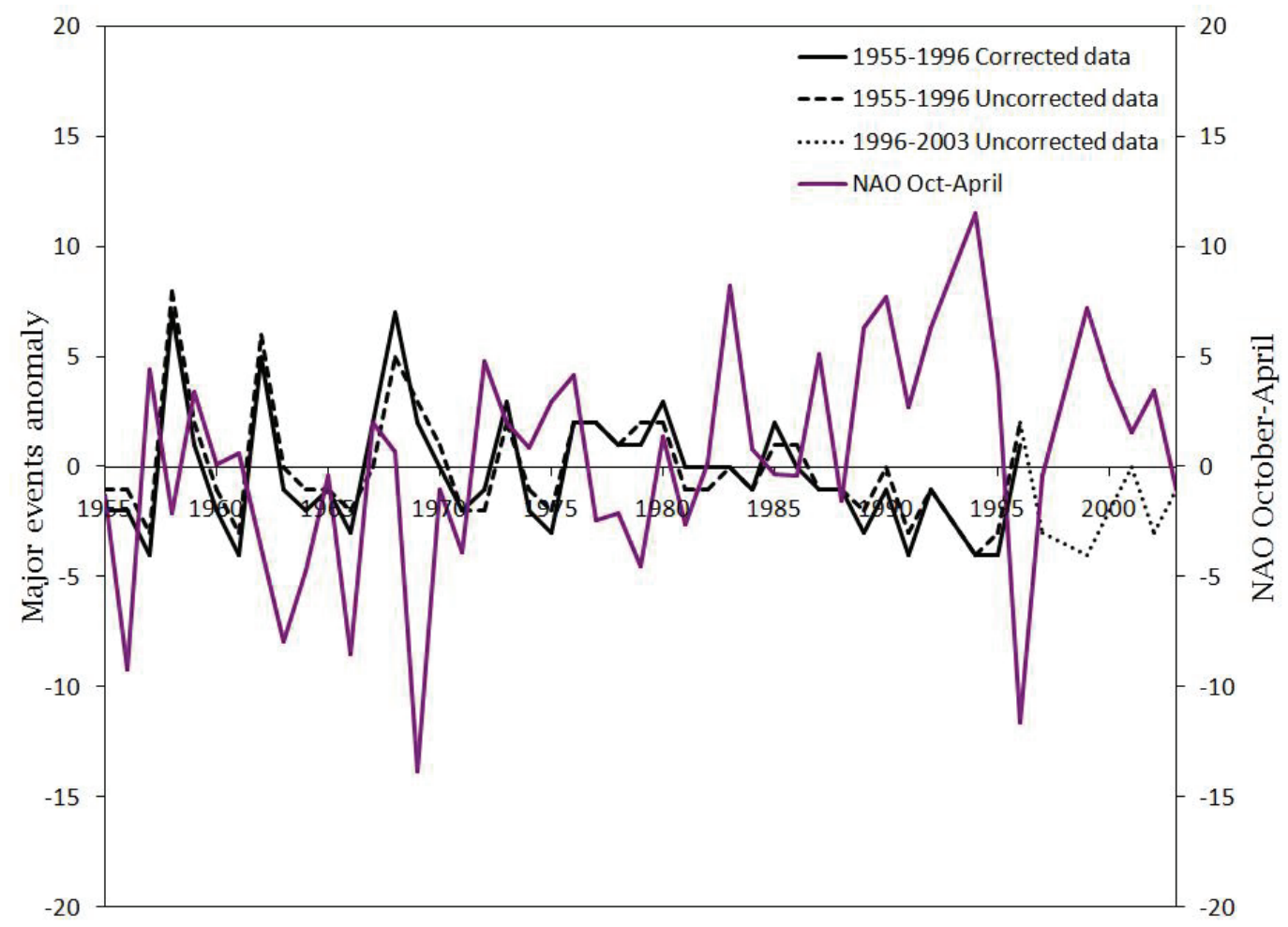

Figure 3-10: Variation of the major precipitation events anomaly and winter NAO index between 1955 and 2003. The thick black line represents the 1955-1996 major events anomalies using corrected precipitation data. The black dashed line is for the same interval, but using uncorrected precipitation data. The thin black dotted line represents the major precipitation events anomalies between 1997 and 2006, a period where only uncorrected precipitation data is available. The thick purple line represents the Oct-April NAO index. Note that the analysis does not extend beyond 2003 as monthly NAO data is not available after this year. 
A linear regression between the cold-season major precipitation events anomaly and the Oct-April NAO index has been performed to investigate a possible relationship between these two variables. Based on the corrected precipitation dataset, $R^{2}$ of the linear regression between the major events anomalies and the NAO index over the 1955-1996 cold-seasons is equal to 0.05. This value has been obtained based on equation (3.1), with $x$ representing the NAO index and $y$, the major events anomalies. Consequently, no significant relationship between the events' anomaly and the NAO index is identified.

According to Figure 3-10, however, there tends to be some inverse relation between the NAO index and the events anomaly. Indeed, there tends to have been more major events when the NAO is in a negative phase, as observed during the following years: 1953, 1958, 1963, the 1977-1979 period, and 1996 (Figure 3-10). In contrast, a positive NAO is often associated with fewer major precipitation events, as observed for 1957, 1972, 1983, 1987, and the 1989-1995 period (Figure 3-10).

As an example, a linear regression has been performed over the 1989-1996 period. Its $R^{2}$ increased from 0.048 for the $1955-1996$ period to 0.402 for the 1989-1996 period, indicating a stronger linear regression for the 1990-1996 period. The negative coefficient of the linear regression confirms the presence of an inverse relationship. However, its $R^{2}$ value is not large enough to be the only factor influencing on the occurrence of major precipitation events.

Major event anomalies are also plotted using uncorrected precipitation data until 2003. Event anomalies using corrected and uncorrected precipitation 
data are correlated at the 0.05 confidence interval until 1996, as seen by their similarities on Figure 3-10. Some inverse relation between the NAO index and the events anomaly between 1996 and 2003 is also observed. Indeed, a linear regression has been performed over this period. Its $R^{2}$ has a value of 0.715 . No final conclusions can be derived from the analysis using this dataset, but this result supports the hypothesis of an inverse relationship between the NAO and the major event's anomalies.

The NAO index tends to influence the occurrence of major precipitation events at Iqaluit. These results are in agreement with previous studies investigating the relationship between precipitation and the NAO index for the entire Arctic region (e.g. Hurrell, 1995; Bromwich et al., 1999). However, the confidence interval of their relationship is such the NAO cannot solely govern major precipitation events; other factors have to be taken into consideration.

\subsection{Case studies}

Major precipitation events at Iqaluit are produced by cyclones originating from three different regions (South, West, Atlantic), or by upper-level shortwaves troughs. The main characteristics of each group have been described in Section 3.1.4. In this Section, a detailed case study for each group is performed.

The events were chosen according their severity and data availability. Severity here was based on precipitation accumulation, with the event producing the largest amount of precipitation ranked first. As well, the most severe event studied in detail per origin group also had to occur after 1978 to benefit from the NARR and atmospheric soundings datasets. The synoptic evolution, surface 
variables, precipitation type and vertical profile of each event have been investigated and are described below.

\subsubsection{South-originating case}

The February 12, 1981 event was $3^{\text {rd }}$ most severe event originating from the south, and the $6^{\text {th }}$ overall (Table A-1). It has been chosen because it is the South-originating storm-track event with the most complete archived data, the $1^{\text {st }}$ and $2^{\text {nd }}$ South-originating cases happening prior to 1978 or missing archived data.

The cyclone responsible for the event followed the la sub-track (Figure 3-6). With an average speed of motion of $62 \mathrm{~km} / \mathrm{h}$, the system was the $3^{\text {rd }}$ faster moving South-originating event, and $5^{\text {th }}$ overall. A total of $38.3 \mathrm{~mm}$ of water-equivalent precipitation was recorded over $18 \mathrm{~h}$, representing an average precipitation rate of $2.1 \mathrm{~mm} / \mathrm{h}$; only snow was observed. The event accounted for $36 \%$ of the 106.4 mm February 1981 accumulation; precipitation during February 1981 was more than three times greater than the $33.5 \mathrm{~mm} 1955-1996$ average precipitation amount for the month of February (Table 3-4).

The low fraction of the monthly contribution of this major precipitation event is explained by the fact that it was not the only major event during February 1981 (Table A-1). In fact, the $13^{\text {th }}$ most severe precipitation event, producing $31.6 \mathrm{~mm}$ of precipitation, took place on February $25-26$ of the same year. Together, the two events accounted for $65 \%$ of February 1981 accumulation.

The synoptic and surface evolution of the February 12, 1981 event, followed by the characteristics of the main precipitation type and its associated atmospheric profiles are analyzed in the following Section. 
Table 3-4: Monthly precipitation accumulation statistics during the case studies.

\begin{tabular}{|c|c|c|c|c|}
\hline \multirow[t]{2}{*}{$\begin{array}{l}\text { ORIGIN } \\
\text { GROUP }\end{array}$} & \multicolumn{2}{|c|}{$\begin{array}{c}\text { CASE STUDY'S } \\
\text { MONTH } \\
\text { ACCUMULATION } \\
(\mathrm{mm})\end{array}$} & \multirow{2}{*}{$\begin{array}{c}\text { CASE STUDY } \\
\text { ACCUMULATION } \\
(\mathrm{mm})\end{array}$} & \multirow{2}{*}{$\begin{array}{c}\text { CONTRIBUTION } \\
\text { OF CASE STUDY } \\
\text { TO ITS YEAR'S } \\
\text { MONTHLY } \\
\text { ACCUMULATION } \\
(\%)\end{array}$} \\
\hline & $\begin{array}{c}1955-1996 \\
\text { average }\end{array}$ & $\begin{array}{c}\text { Case } \\
\text { study's year }\end{array}$ & & \\
\hline $\begin{array}{c}\text { South } \\
\text { February 12, } \\
1981 \\
\end{array}$ & 33.5 & 106.4 & 38.3 & 36 \\
\hline $\begin{array}{c}\text { West } \\
\text { October } \\
24-25,1985 \\
\end{array}$ & 52.6 & 102.5 & 53 & 52 \\
\hline $\begin{array}{c}\text { Atlantic } \\
\text { November } \\
25-27,1989 \\
\end{array}$ & 53.7 & 94.6 & 55.9 & 59 \\
\hline $\begin{array}{c}\text { Others } \\
\text { April 20, } \\
1981\end{array}$ & 37.2 & 54.6 & 20.2 & 37 \\
\hline
\end{tabular}

\subsubsection{Synoptic evolution}

Figure 3-11 illustrates the synoptic evolution of the cyclone, from its formation south of the Great Lakes to its decay near Greenland.

At 00 UTC on February 11, a surface low-pressure system is observed south of Lakes Erie and Ontario, associated with a deep upper-level trough (Figure 3-11a). The system slowly moves north, reaching the northern shore of the Great Lakes at 12 UTC on February 11 (Figure 3-11b) and central northern Quebec on February 12, 00 UTC (Figure 3-11c); the surface low-pressure system is observed over Ungava Bay 12 hours later (Figure 3-11d). 
(a)

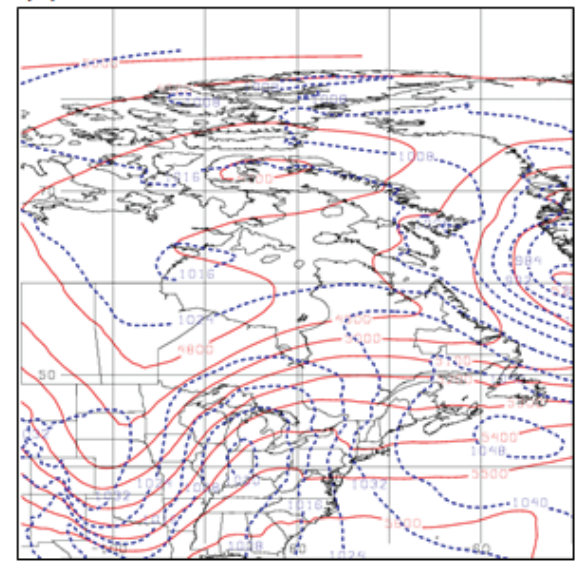

(c)

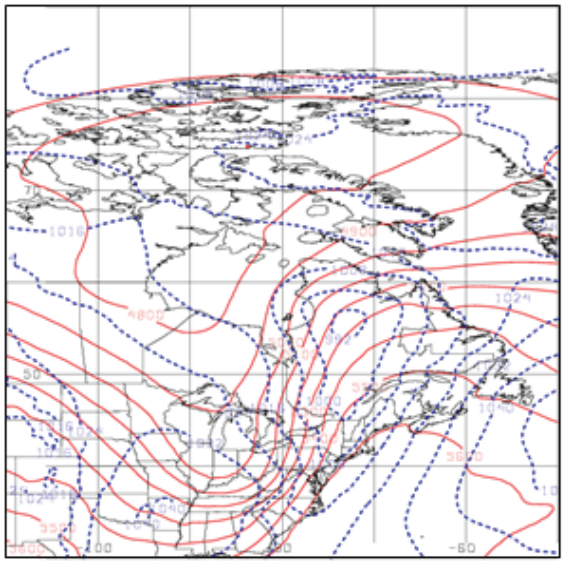

(e)

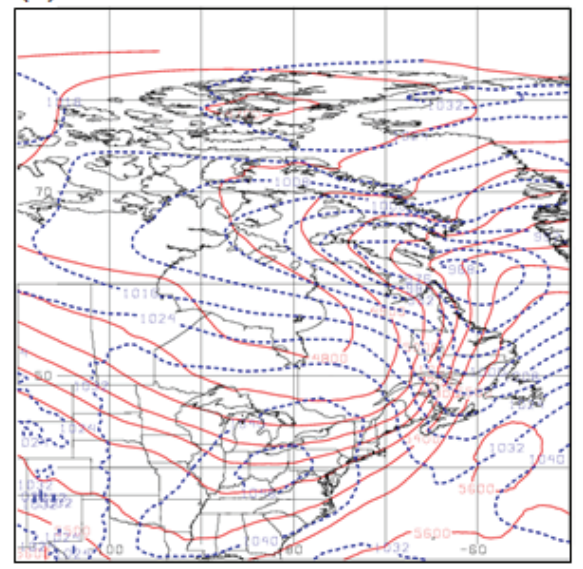

(b)

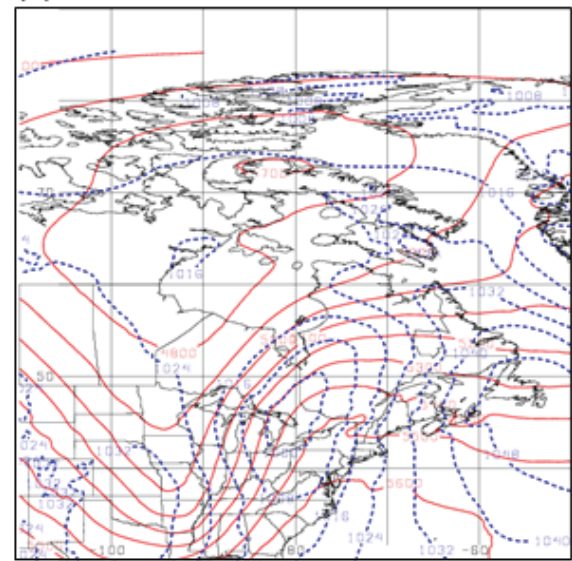

(d)

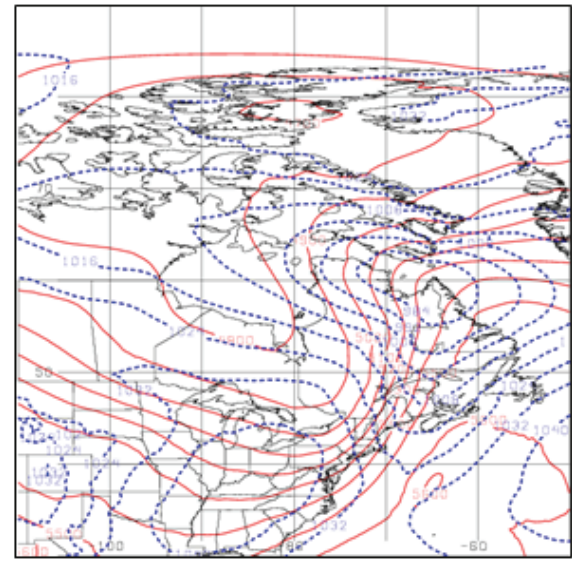

(f)

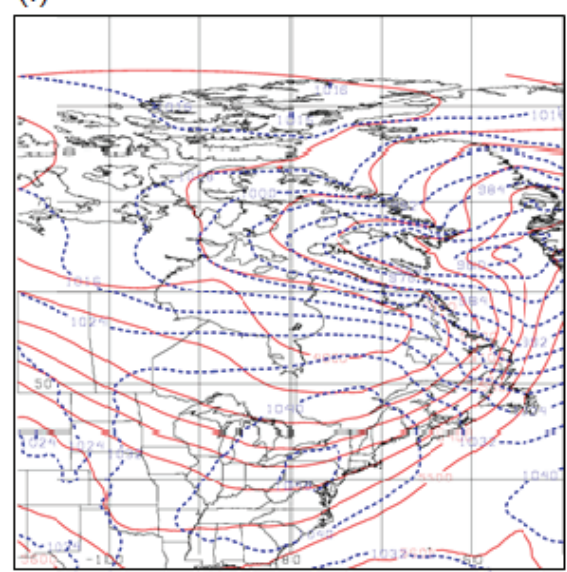

Figure 3-11: Synoptic conditions of the February 12, 1981 event at (a) 00 UTC Feb. 11, (b) 12 UTC Feb. 11, (c) 00 UTC Feb. 12, (d) 12 UTC Feb. 12, (e) 18 UTC Feb. 12 and (f) 00 UTC Feb. 13. Mean-sea-level pressure (mb) is represented by the blue-dotted lines and $1000-500 \mathrm{mb}$ thickness $(\mathrm{mb})$, by the redsolid lines. 
Throughout its northern path, the surface system was supported by the upward forcing from the upper-level trough. However, the upper-level trough started to tilt, positioning the surface system away from the main upper-level forcing region (Figure 3-11e).

This tilting did not prevent the system from deepening as it went from a $984 \mathrm{mb}$ center prior to the tilting (Figure 3-11d) to a $956 \mathrm{mb}$ center following the tilting (Figure 3-11f); this deepening of $24 \mathrm{mb}$ occurred in $18 \mathrm{~h}$. After reaching its deepest point, the system continued towards Greenland and, cut-off from its upper-level support, it decayed in less than 12 hours (not shown).

The February 12, 1981 event was selected according to its severity and because it had the most complete archived data, but the synoptic activity associated with this system was not the most typical to South-originating events. The synoptic evolution of this case study illustrates cases associated with a tilted upper-level trough; this characterizes 18 events originating from the South. In contrast, the other 60 South-originating events were characterized by weak upperlevel and surface pressure gradients, as well as non-tilted troughs (Table A-1). The surface system of this specific case was deeper than the average, with a minimum low-pressure of $956 \mathrm{mb}$ (mean-sea level) measured at 00 UTC February 13.

\subsubsection{Surface evolution}

Figure 3-12 shows the 6-hourly precipitation data, as well as the evolution of the surface pressure and temperature prior, during and after the event in Iqaluit. 
Although 6-hourly accumulation was first recorded at 06 UTC February 12, this accumulation contributed to February 11, 1981 daily-accumulation, which did not satisfied the severity threshold of this study (Section 2.3.2). To distinguish it from the February 12, 1981 case study precipitation accumulation, the 06 UTC February 12 accumulation is left unfilled on Figure 2-12.

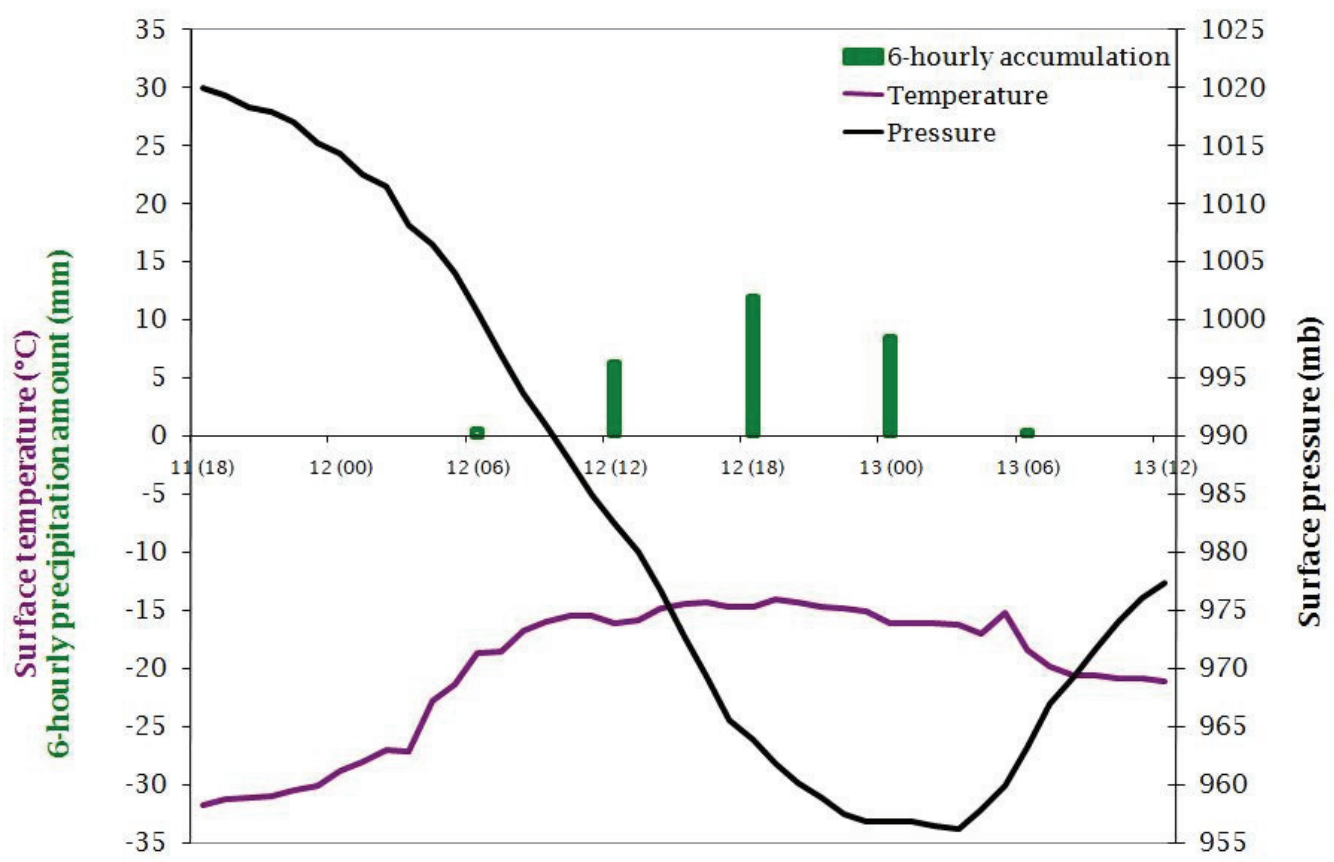

Figure 3-12: Evolution of the 6-hourly accumulation, surface temperature and surface pressure during the February 12, 1981 event. Precipitation accumulation is for the previous 6 hours. The days are labeled on the X-axis; the value in brackets is the time in UTC.

Precipitation contributing to the February 12, 1981 major event was initiated on February 12, 07 UTC and lasted until 06 UTC on February 13; precipitation was recorded during 18 of the $24 \mathrm{~h}$ based on Environment Canada hourly weather observations (Figure 3-12). 
The analysis of this graph indicates the presence of a warm front. In fact, surface temperature rose from $-31^{\circ} \mathrm{C}$ to $-18^{\circ} \mathrm{C}$ during the twelve hours prior to precipitation formation.

Moreover, precipitation was initiated when the surface pressure was still dropping and the lowest value was recorded at the end of the event. The cyclone's low-pressure center reached its lowest value of $956 \mathrm{mb}$ at 03 UTC on February 13, very low for an Arctic storm.

\subsubsection{Precipitation type and atmospheric profiles}

Table 3-5 shows the hours of precipitation for each precipitation type during the selected case studies. Precipitation during the February 12, 1981 South-originating event lasted $18 \mathrm{~h}$ and solely consisted of snow.

Table 3-5: Precipitation types during the selected case studies.

\begin{tabular}{||c||c|c|c|c|c||}
\hline \multicolumn{1}{||c||}{ ORIGIN GROUP } & \multicolumn{5}{c||}{ HOURS OF PRECIPITATION (H) } \\
\cline { 2 - 6 } $\begin{array}{c}\text { February 12, 1981 } \\
\text { Rain }\end{array}$ & 0 & 18 & 0 & 0 & 18 \\
\hline $\begin{array}{c}\text { West } \\
\text { October 24-25, 1985 }\end{array}$ & 24 & 12 & 9 & 2 & 47 \\
\hline $\begin{array}{c}\text { Atlantic } \\
\text { November 25-27, } \\
1989\end{array}$ & 0 & 59 & 0 & 0 & 59 \\
\hline $\begin{array}{c}\text { Others } \\
\text { April 20, 1981 }\end{array}$ & 0 & 18 & 0 & 0 & 18 \\
\hline
\end{tabular}

Atmospheric profiles are analyzed to retrieve the atmospheric conditions associated with the event. Figure 3-13a illustrates the atmospheric conditions 
preceding the event, whereas Figure 3-13b shows the atmospheric profile during the event.

The absence of other precipitation types outside of snow is explained by the below- $0^{\circ} \mathrm{C}$ atmospheric conditions at all levels (Figure 3-13).
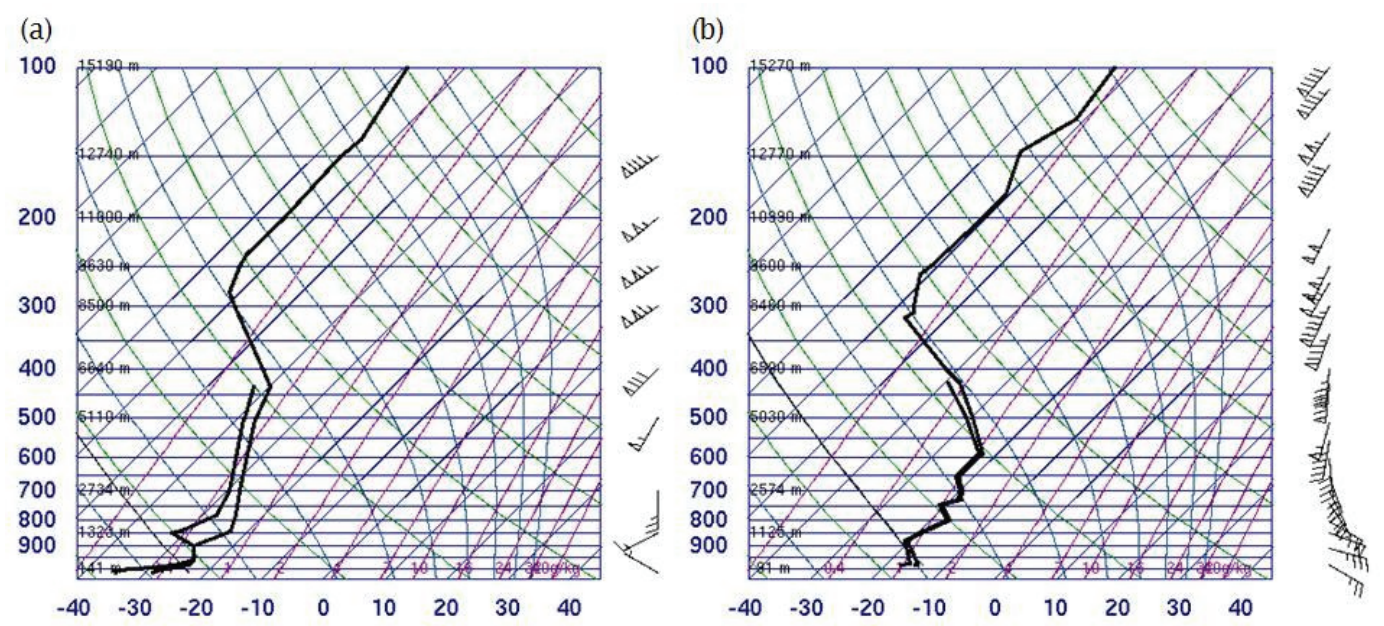

Figure 3-13: Skew T- $\log (\mathrm{p})$ plot of temperature $\left({ }^{\circ} \mathrm{C}\right)$ and dew point profiles $\left({ }^{\circ} \mathrm{C}\right)$ for Iqaluit at (a) 00 UTC and (b) 12 UTC on February 12 1981. Dry adiabats are indicated by the green lines, and moist adiabats are indicated by the blue lines. The horizontal wind profile is displayed along the right side of each diagram; pennant, full barb, and half barb denote 50,10, and 5 knots, respectively (adapted from the University of Wyoming, 2008).

Saturation or near saturation regions were retrieved from the atmospheric profiles using the dew point depression as an indicator for saturation. The dew point depression is defined as the difference between the temperature of the air and the dew point temperature at a given height (Ahrens, 2004). Saturation or near-saturation regions with respect to liquid were defined by a dew point depression of $0^{\circ} \mathrm{C}$, whereas saturation or near-saturation regions with respect to ice were defined by a dew point depression $\leq 5^{\circ} \mathrm{C}$.

Prior to the event, at 12 UTC on February 12 1981, the atmosphere was characterized by a saturated or near-saturated region with respect to liquid from 
$1000 \mathrm{mb}$ to $900 \mathrm{mb}$; a surface temperature inversion was observed as well (Figure 3-13a). A shallow drier layer was present just above that region, but a saturation or near-saturation region with respect to ice was observed from $800 \mathrm{mb}$ to $475 \mathrm{mb}$. No conclusions can be drawn above this level since no data for the dew point temperature was available above $475 \mathrm{mb}$.

The passage of the surface warm front was reflected by the increase in surface temperature from Figure 3-13a to Figure 3-13b. Following the front, midlevel inversion layers were observed between 900 and $800 \mathrm{mb}$, and between 750 and $725 \mathrm{mb}$ (Figure 3-13b). The warm front was also linked with a saturation or near-saturation region with respect to liquid from $950 \mathrm{mb}$ to $550 \mathrm{mb}$, and with a saturation or near-saturation region with respect to ice above $550 \mathrm{mb}$ (and until data is not available anymore) (Figure 3-13b). Such conditions enhance precipitation accumulation at the surface, rather than deplete precipitation due to sublimation of the ice crystals.

Moreover, a strong wind shear with a veering of the winds is also observed on Figure 3-13b. This vertical wind profile is typical to low-level warm air advection, enhancing cyclonic low-level forcing (Bluestein, 1992).

\subsubsection{West-originating case}

The October 24-25, 1985 event was the most severe West-originating storm and the overall second most severe event of the 1955-1996 cold-seasons at Iqaluit. The event was caused by a system following the $2 \mathrm{~b}$ sub-track group (Figure 3-6), producing $53 \mathrm{~mm}$ of precipitation in two days contributing to $60 \%$ of the October 1985 total precipitation (Table 3-4). The system moved at an 
average speed of $39 \mathrm{~km} / \mathrm{h}, 10 \mathrm{~km} / \mathrm{h}$ faster than an average $2 \mathrm{~b}$ system (Table $3-3$ ). The average precipitation rate was of $1.1 \mathrm{~mm} / \mathrm{h}$, observed for 47 consecutive hours (Table A-1).

Moreover, the $23.9 \mathrm{~mm}$ of precipitation recorded for October 24 holds the daily-precipitation record for the month of October according to Environment Canada (Environment Canada, 2008). October 1985 was wetter than normal, receiving more than twice the average amount of precipitation usually observed over this month (Table 3-4).

Rain, freezing rain and snow, as well as mixed precipitation were observed, allowing the investigation of the atmospheric conditions leading to different precipitation type within a single event. The synoptic evolution, as well as the surface variables and the conditions leading to a mixture of precipitation are further discussed.

\subsubsection{Synoptic evolution}

Although the event was the result of a single storm originating from the West, its early decay in the course of the event resulted in the formation of two low-pressure centers in the Iqaluit region. The 12-hourly synoptic evolution of the system between 00 UTC October 24 to 12 UTC October 261985 is illustrated in Figure 3-14 and will now be discussed.

Figures 3-15a-c illustrates the evolution of the first low-pressure center following the lee cyclogenesis. At 00 UTC on October 24 (Figure 3-14a), a wide low-pressure center is observed north-west of Hudson Bay, sustained by a weak

upper-level trough. Twelve hours later (Figure 3-14b), the system attained its 
deepest intensity (976 mb) when it reached the western shore of Foxe Basin. Shortly after, the surface low-pressure center started to evolve away from the upper-level trough, consequently losing its upper-level forcing. Indeed, the system becomes a closed low at 00 UTC on October 25, decaying over north-west of Baffin Island (Figure 3-14c).

(a)

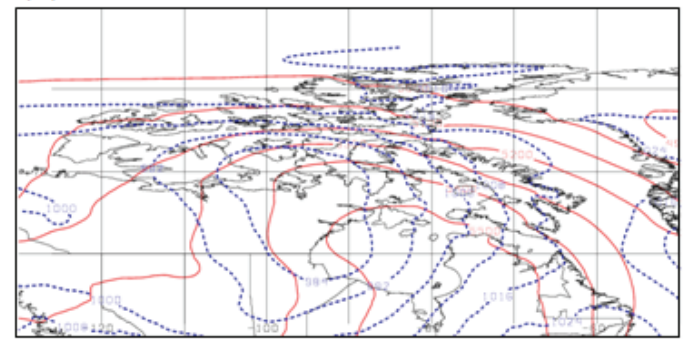

(c)

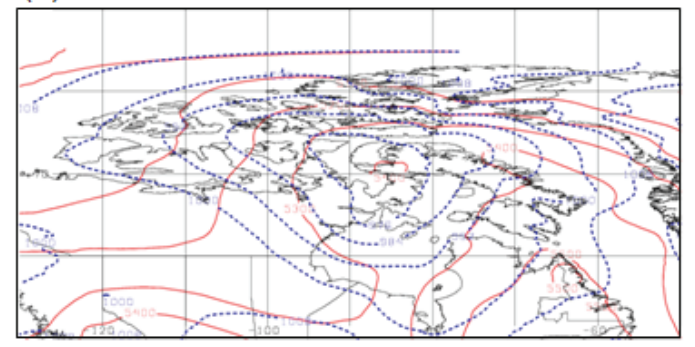

(e)

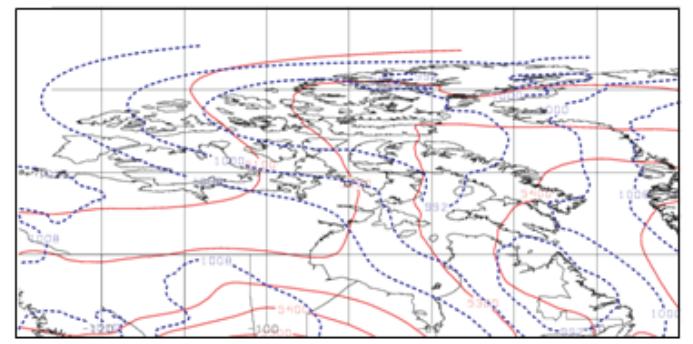

(b)

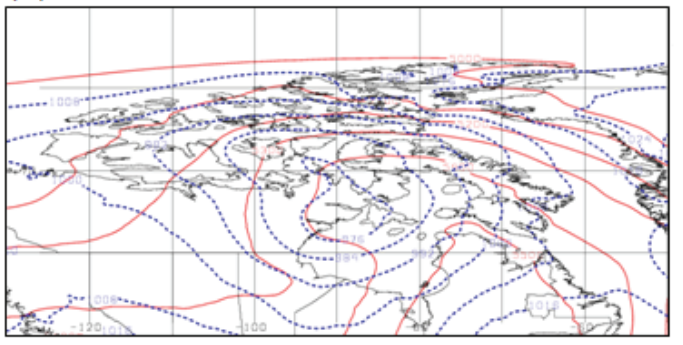

(d)

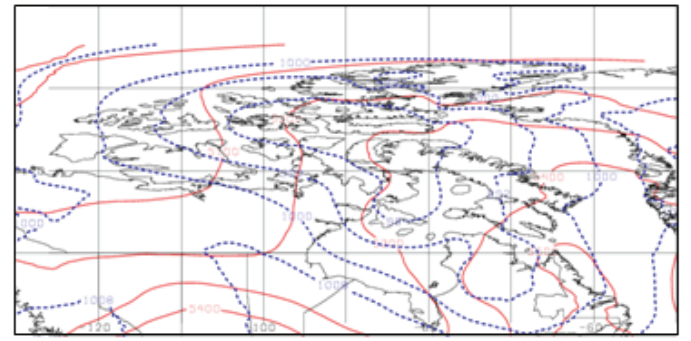

(f)

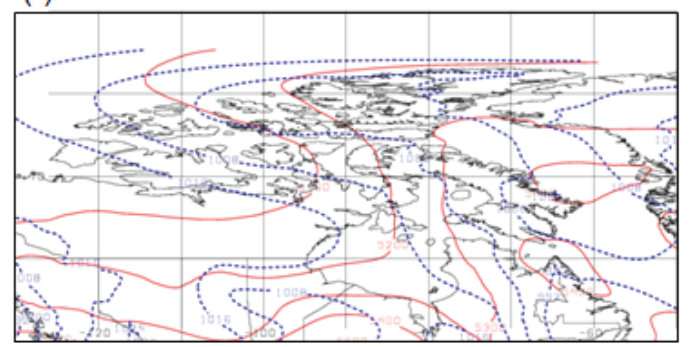

Figure 3-14: Synoptic conditions of the October 24-25, 1985 event at (a) 00 UTC Oct. 24, (b) 12 UTC Oct. 24, (c) 00 UTC Oct. 25, (d) 12 UTC Oct. 25, (e) 00 UTC Oct. 26 and (f) 12 UTC Oct. 26. Mean-sea-level pressure (mb) is represented by the blue-dotted lines and $1000-500 \mathrm{mb}$ thickness $(\mathrm{mb})$, by the redsolid lines.

At 12 UTC on October 25 (Figure 3-14d), the primary system has decayed over the northern Canadian Archipelago region; no major synoptic activity is 
present in the region. With no upper-level support remaining, the surface system became stationary over Foxe Basin. What remained of the system spread over northern Canadian Archipelago, as well as over northern Quebec.

The northern surface low decayed quickly with the lack of upper-level support, while the southern surface low strengthened over Labrador by interacting with an upper-level tough coming from the south. The rapid evolution and decay of the second surface system is shown on Figures 3-15e-f. It resulted in the formation of a wide surface system from southern Baffin Island to south-western Labrador (Figure 3-14e). The weak eastward-tilted upper-level trough associated with the second low-pressure system was not strong enough to provide sufficient upper-level forcing for the system to deepen. At 12 UTC October 26 (Figure 314f), the second system became closed and continued traveling south, towards Newfoundland, no longer affecting southern Baffin Island.

\subsubsection{Surface variables}

Surface pressure and temperature prior to and during the event are plotted on Figure 3-15, along with the 6-hourly precipitation data. Precipitation was initiated at 13 UTC on October 24, contributing to the 18 UTC October 24 precipitation accumulation. Precipitation stopped 47 hours later, on 12 UTC October 26.

Surface pressure and temperature prior to and during the event are plotted on Figure 3-15, along with the 6-hourly precipitation data. Precipitation was initiated at 13 UTC on October 24, contributing to the 18 UTC October 24 
precipitation accumulation. Precipitation stopped 47 hours later, on 12 UTC October 26.

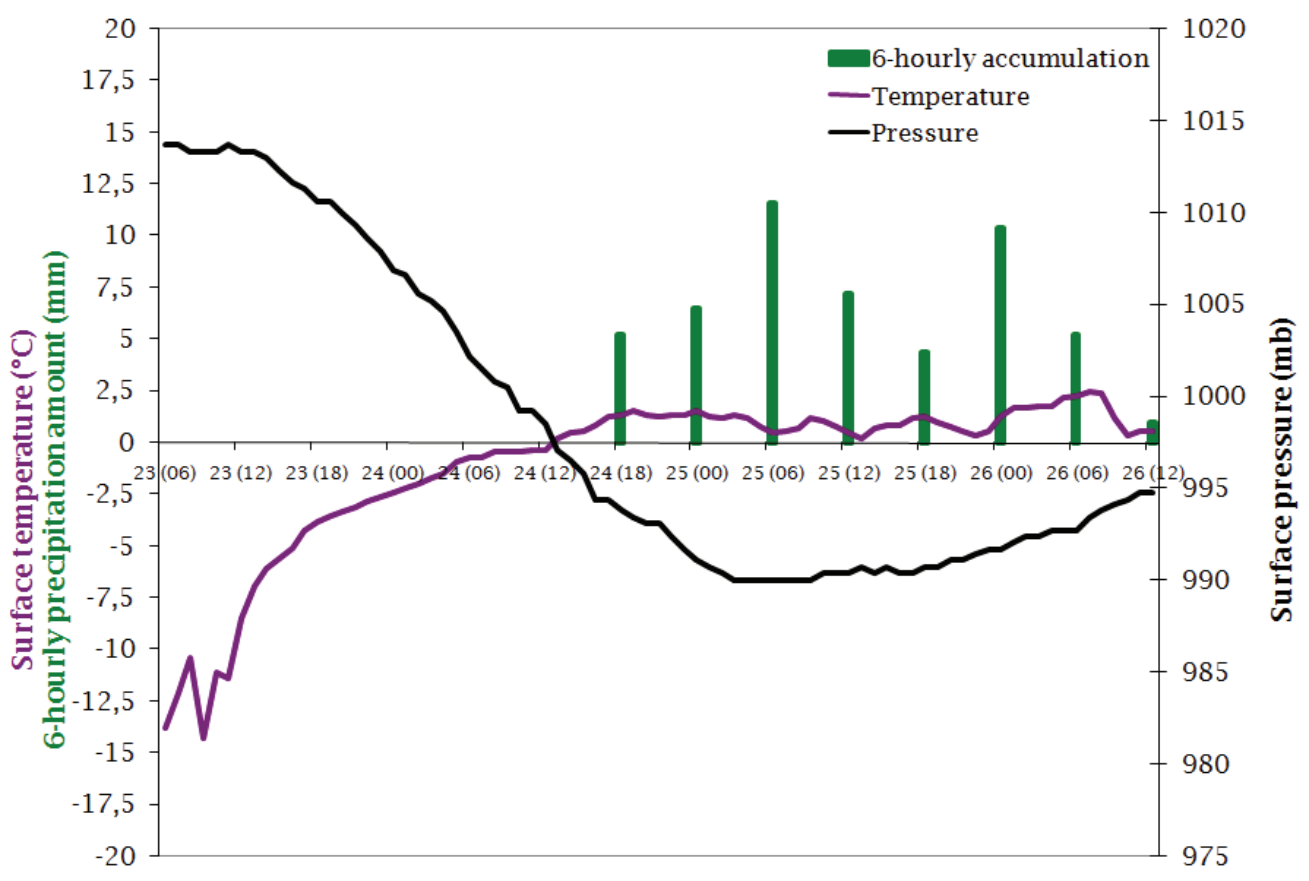

Figure 3-15: Evolution of the 6-hourly accumulation, surface temperature and surface pressure during the October 24-25, 1985 event. Precipitation accumulation is for the previous 6 hours. The days are labeled on the x-axis; the value in brackets is the time in UTC.

The effects of the passage of the two surface low-pressure center discussed in Section 3.2.2.1 are identified through the 6-hourly precipitation accumulation. The two accumulation peaks coincide with the time interval proper to each surface system. The highest 6-hourly accumulation (between 00 UTC and 06 UTC October 25) coincides with the decay of the first low-pressure system, remaining stationary over Foxe Basin. The second highest 6-hourly accumulation (between 18 UTC October 25 and 00 UTC October 26) is associated with the second low-pressure system. 
Moreover, the surface temperature prior to the first precipitation measurement and during the event suggests the presence of a warm front. Indeed, temperature rose of approximately $15^{\circ} \mathrm{C}$ during the 30 hours preceding precipitation and remained more or less stable above melting point throughout the event (Figure 3-15).

\subsubsection{Precipitation type and atmospheric profile}

Precipitation during the October 24-25, 1985 West-originating event was recorded during 47 consecutive hours. Precipitation type mainly consisted of rain and snow, but freezing rain and a combination of rain and snow (mixed) was also observed (Table 3-5).

Freezing rain was observed during the first 2 hours of the event, followed by rain. Then, rain, snow and mixed precipitation (snow-rain) occurred during the transition zone as the warm front advanced. Only snow was recorded at the end of the event.

The conditions leading to freezing rain and mixed precipitation are further described using atmospheric profiles. Figure 3-16a shows the vertical profile associated with the observation of freezing rain, while Figure 3-16b illustrates the atmospheric conditions leading to mixed precipitation.

Freezing rain was observed at the beginning of the event, between 13 UTC and 14 UTC on October 24, coinciding with the passage of the warm front. A region of saturation or near-saturation with respect to liquid was observed from $1000 \mathrm{mb}$ to $750 \mathrm{mb}$, and a region of saturation or near-saturation with respect to ice was observed between 500 and $250 \mathrm{mb}$. In between these two saturated 
regions, a dry region was observed between $750 \mathrm{mb}$ to $500 \mathrm{mb}$ (Figure 16-a) suggesting two cloud layers in the atmosphere. A shallow pool of cold air was present near the surface, underneath a stable inversion layer observed between 950 and $875 \mathrm{mb}$. The melting layer, with temperatures warmer than $0^{\circ} \mathrm{C}$, extended from $875 \mathrm{mb}$ to $825 \mathrm{mb}$. Such profile illustrates the preferential conditions for freezing rain (Ahrens, 2004). As well, the veering of the winds indicated warm air advection, providing aloft warm air necessary for the formation of freezing rain and low-level support to the cyclone.
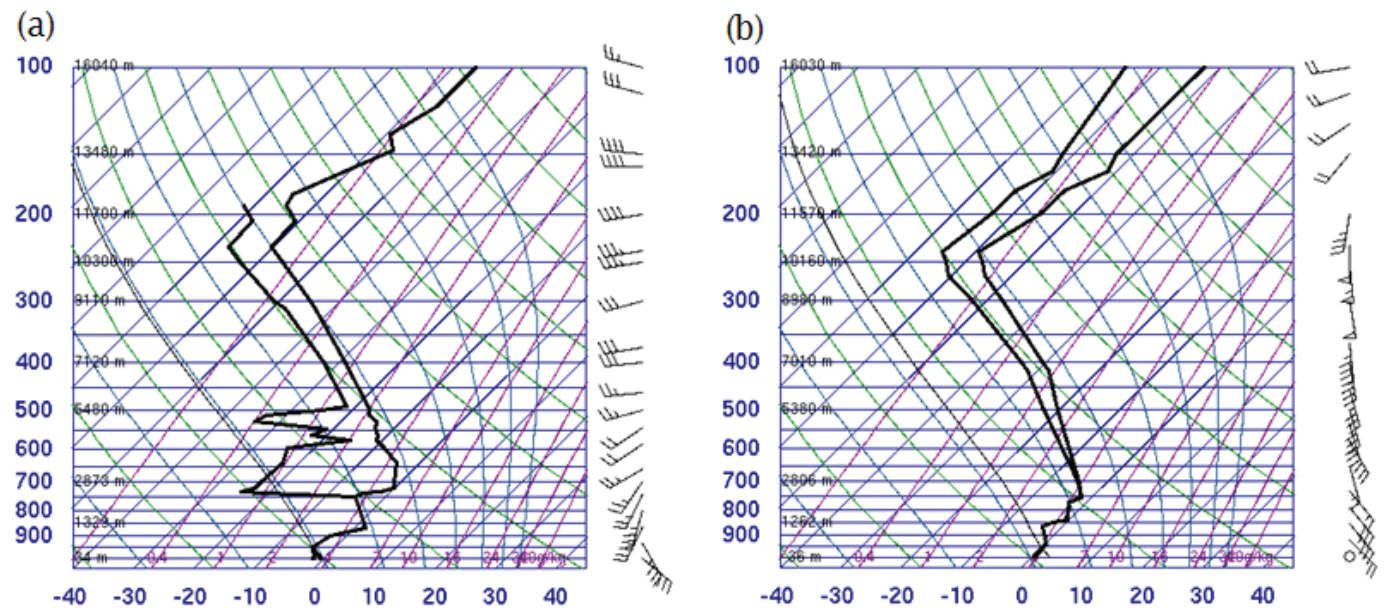

Figure 3-16: Skew T- $\log (\mathrm{p})$ plot of temperature $\left({ }^{\circ} \mathrm{C}\right)$ and dew point profiles $\left({ }^{\circ} \mathrm{C}\right)$ for Iqaluit at (a) 12 UTC October 241985 and (b) 00 UTC on October 261985. Dry adiabats are indicated by the green lines, and moist adiabats are indicated by the blue lines. The horizontal wind profile is displayed along the right side of each diagram; pennant, full barb, and half barb denote 50, 10, and 5 knots, respectively (adapted from the University of Wyoming, 2008).

A mixture of rain and snow was sporadically monitored between 20 UTC October 25 and 7 UTC October 26. In contrast to the October 2412 UTC atmospheric profile (Figure 3-16a), the atmosphere did not show any dry region aloft. The region extending from $1000 \mathrm{mb}$ to $650 \mathrm{mb}$ was saturated or nearsaturated with respect to liquid, and the region extending from 650 to $275 \mathrm{mb}$ 
(tropopause) was saturated or near-saturated with respect to ice (Figure 3-16b). It is possible that sublimation of ice crystals in the dry layer increased the water vapour content of the region, eventually saturating in with respect to water vapour. A thin isothermal layer of $0^{\circ} \mathrm{C}$ near the surface was also present between 950 and $1000 \mathrm{mb}$. Such layer is often characterized by mixed-phase precipitation (e.g. Kain et al., 2000). The melting-induced cooling associated with the melting layer observed at the beginning of the event is believed to have contributed to the formation of this layer (Findeisen, 1940) (Figure 3-16a).

Moreover, the weaker veering of the winds indicated weaker warm air advection at the surface warm. In fact, only snow was observed following 12 UTC October 26.

\subsubsection{Atlantic-originating case}

In addition to being the most severe of its group, the November 25-27, 1989 Atlantic-originating event was the most severe of the 1955-1996 major precipitation events at Iqaluit (Table A-1). It was also one of the longest duration events, consisting of three consecutive daily precipitation accumulations above the severity threshold; the only other event lasting three consecutive days took place on October 5-8, 1958 (Table A-1).

The November 25-27, 1989 Atlantic-originating event was caused by a cyclone following a 3a sub-track. The system was moving at an average speed of $53 \mathrm{~km} / \mathrm{h}$; it was the $5^{\text {th }}$ fastest Atlantic-originating system, and $13^{\text {th }}$ overall (Table A-1). A total of $55.9 \mathrm{~mm}$ precipitation was produced in three days, contributing to $59 \%$ of the November 1989 total precipitation (Table 3-4). Precipitation was 
recorded for a total of 59 hours during the three-day event, representing an average precipitation rate of $0.9 \mathrm{~mm} / \mathrm{h}$. Although November 1989 had more precipitation than normal with precipitation accumulation of 94.6 , the amount was still less than twice the historical average precipitation accumulation of $53.7 \mathrm{~mm}$ for this month (Table 3-4).

To better understand the mechanisms leading to the most severe precipitation event at Iqaluit, the synoptic evolution, as well as the surface variables, precipitation type and atmospheric profiles characteristics of this event are further discussed.

\subsubsection{Synoptic evolution}

The event was caused by a storm originating from the Atlantic Ocean, moving north following the coasts of Labrador. Although one main system affected Iqaluit, two surface features maintained by the same upper-level trough consecutively impacted the area. The evolution of the synoptic conditions observed during this event is illustrated in Figure 3-17.

Supported by a trough over the east coast of the United States, the cyclone initiated over the Atlantic Ocean at 00 UTC November 23 (Figure 3-17a). As a mature cyclone, the disturbance travelled north-east over the Atlantic Ocean, following the coast of the Atlantic Provinces (Figure 3-17b) until it reached Newfoundland (Figure 3-17c). Past this point, both the surface low-pressure center and the upper-level trough shifted trajectory. Instead of continuing eastward, the upper-level trough veered north and started to tilt; the surface 
system shifted its progression towards the north-west, following the upper-level forcing region (Figure 3-17d).

(a)

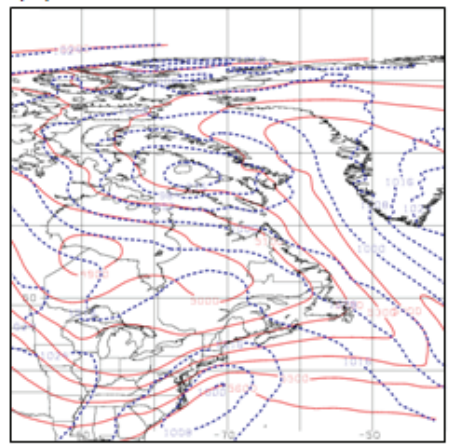

(d)

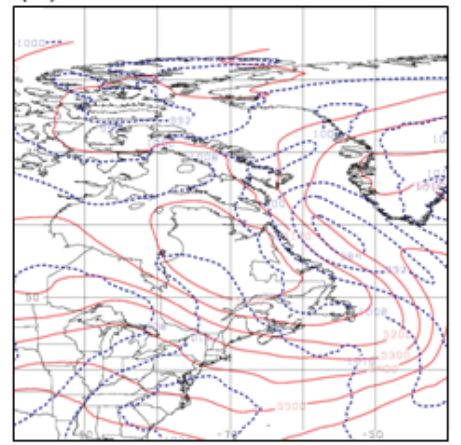

(g)

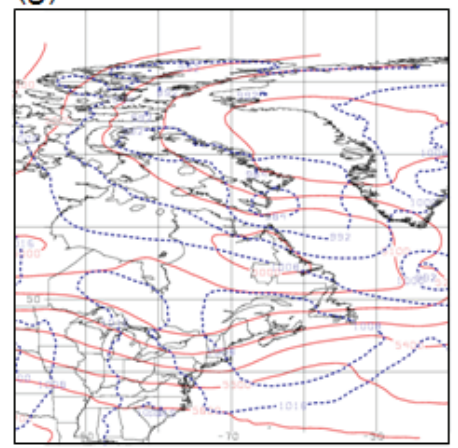

(b)

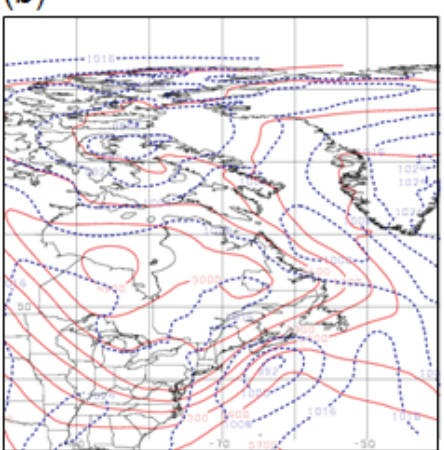

(e)

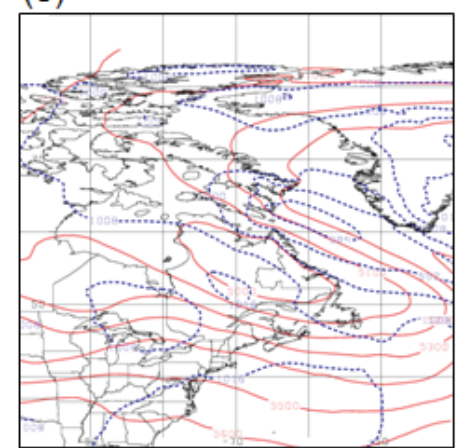

(h)

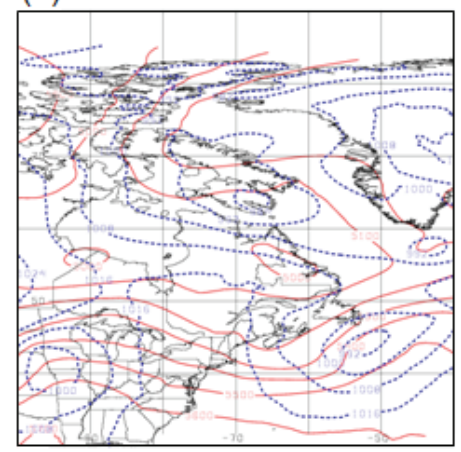

(c)

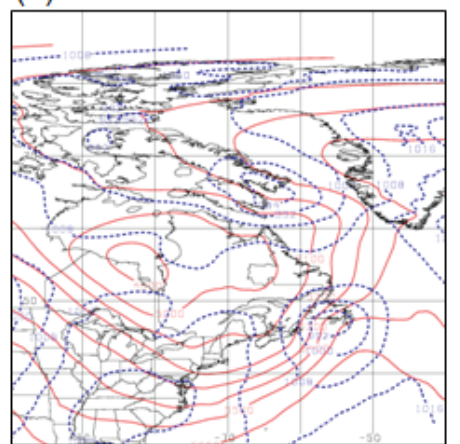

(f)

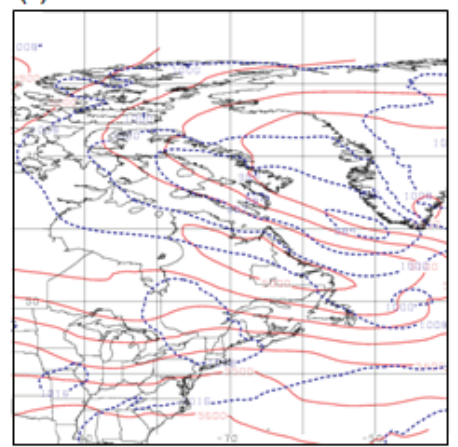

(i)

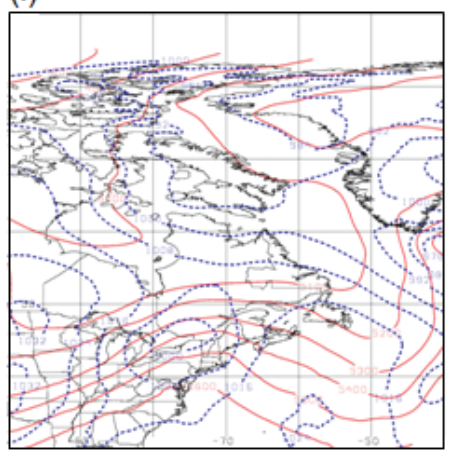

Figure 3-17: Synoptic conditions of the November 25-27, 1989 event at (a) 12 UTC Nov. 23, (b) 00 UTC Nov. 24, (c) 12 UTC Nov. 24, (d) 12 UTC Nov. 25, (e) 00 UTC Nov. 26, (f) 12 UTC Nov. 26, (g) 00 UTC Nov. 27, (h) 12 UTC Nov. 27, and (i) 12 UTC Nov. 28. Mean-sea-level pressure $(\mathrm{mb})$ is represented by the bluedotted lines and 1000-500 mb thickness (mb), by the red-solid lines.

At 00 UTC November 26 (Figure 3-17e) the upper-level trough was completely tilted and the surface low-pressure center was in the vicinity of Iqaluit. The tilt weakened the upper-level cyclonic forcing, causing the decay/retreat of 
the low-pressure system over Iqaluit 12 hours later, at 12 UTC November 26 (Figure 3-17f). At the same time, a second surface system formed west of Greenland. It moved towards the north-west, following the tilted trough. Its surface center passed directly over Iqaluit at 00 UTC November 27 (Figure 3$17 \mathrm{~g})$

At 12 UTC November 27, the upper-level trough completely decayed, with only the surface low-pressure system remaining over Iqaluit (Figure 3-17h). With the absence of an upper-level flow above it, the surface system became a cut-off low and decayed over Iqaluit (Figure 3-17i).

The synoptic evolution of this system is typical to Atlantic storm-track major events. In fact, 33 out of 44 Atlantic-originating storms exhibit a tilted trough pattern during the decaying phase of the cyclone (Table A-1).

\subsubsection{Surface evolution}

Figure 3-18 illustrates the evolution of the principal surface variables prior to and during the event. Precipitation accumulation was first observed at 00 UTC November 26, and lasted until 06 UTC November 28. Precipitation was observed during 59 hours over the 60-hour period of 6-hourly precipitation data.

Two maxima in precipitation accumulation were recorded, as shown by the 6-hourly accumulation data. The first maximum was recorded early in the event, during the 00-06 UTC period on November 26. The second peak in accumulation was produced half-way during the event, between 00 and 06 UTC November 27. This second peak is the highest 6-hourly precipitation accumulation of the event, with an accumulation of $15.2 \mathrm{~mm}$ water-equivalent 
precipitation measured during this period. Each of these maxima also coincided with a minimum in surface pressure, illustrating the presence of two distinct surface systems, as discussed in Section 3.2.3.1.

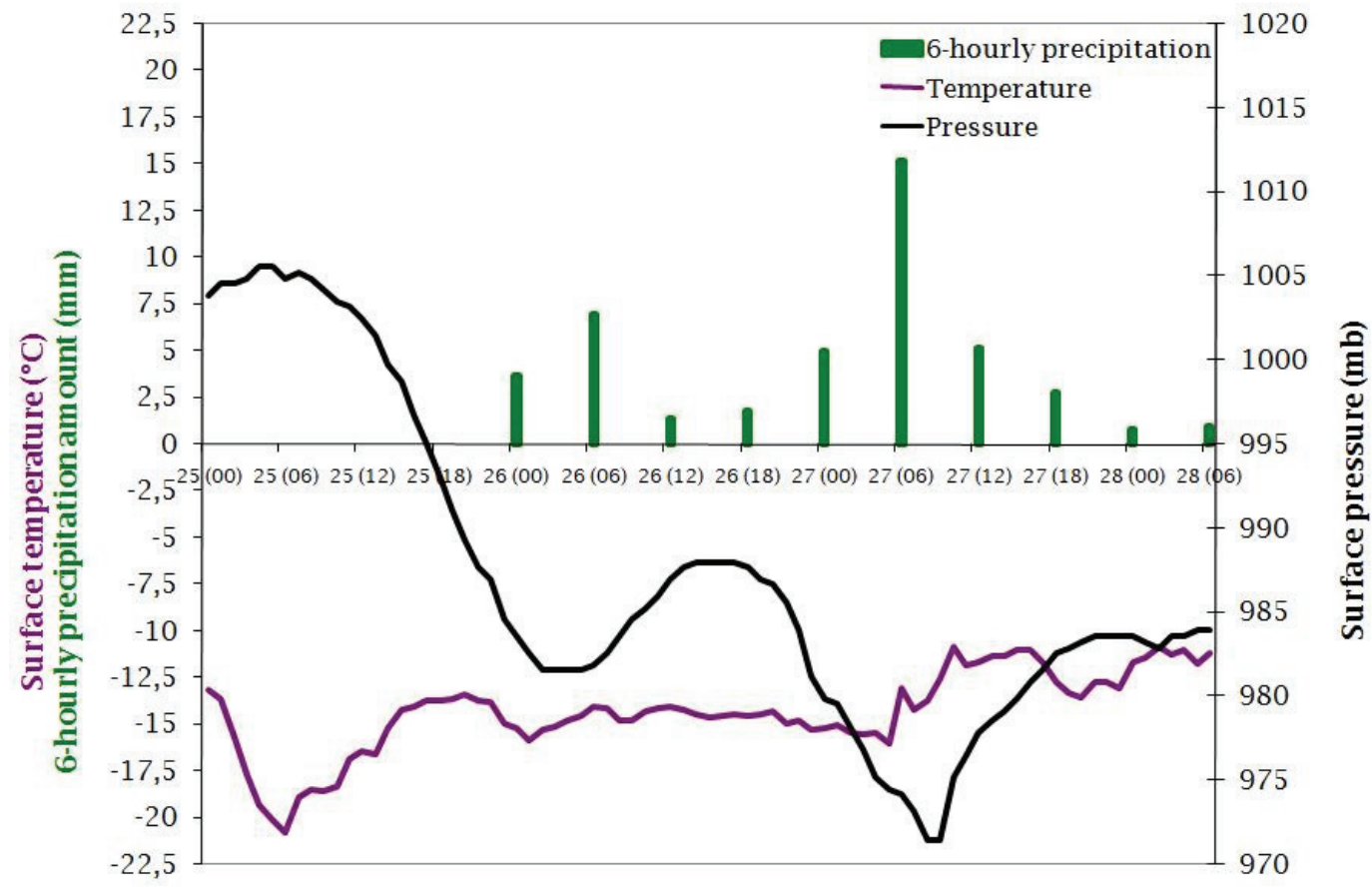

Figure 3-18: Evolution of the 6-hourly accumulation, surface temperature and surface pressure during the November 25-27, 1989 event. Precipitation accumulation is for the previous 6 hours. The days are labeled on the x-axis; the value in brackets is the time in UTC.

A rise in surface temperature was also observed prior to each of the peaks. Indeed, temperature rose of approximately $8^{\circ} \mathrm{C}$ between 06 and 18 UTC on November 25 , while an additional $5^{\circ} \mathrm{C}$ increase was observed between 00 and 12 UTC November 27 (Figure 3-18). These suggest that this event was the result of two warm-frontal periods. 


\subsubsection{Precipitation type and atmospheric profile}

Precipitation during the November 25-27, 1989 Atlantic-originating consisted of 59 hours of snow (Table 3-5), recorded between 00 UTC November 26 and 06 UTC November 28. Precipitation was intermittent between the two warm-frontal periods, and snow showers were mainly observed towards the end of the event. Figure 3-19 illustrates the vertical profiles of the atmosphere over Iqaluit following each 6-h peak accumulations.
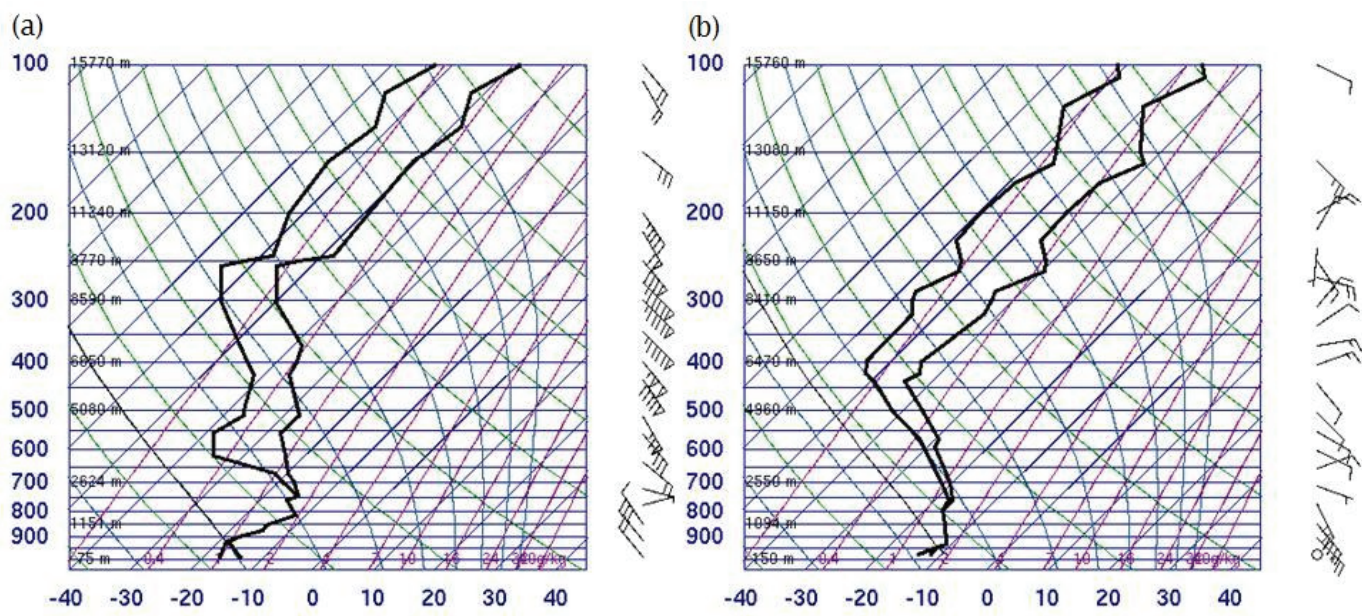

Figure 3-19: Skew T-log $(\mathrm{p})$ plot of temperature $\left({ }^{\circ} \mathrm{C}\right)$ and dew point profiles $\left({ }^{\circ} \mathrm{C}\right)$ for Iqaluit at (a) 12 UTC November 261989 and (b) 12 UTC on November 27 1989. Dry adiabats are indicated by the green lines, and moist adiabats are indicated by the blue lines. The horizontal wind profile is displayed along the right side of each diagram; pennant, full barb, and half barb denote 50, 10, and 5 knots, respectively (adapted from the University of Wyoming, 2008).

Just like the South-originating storm discussed earlier, below $0^{\circ} \mathrm{C}$ temperatures at all levels explain the formation of snow only. The low-level atmosphere was stable at 12 UTC on November 26, as reflected by the strong temperature inversion and a saturated or near-saturated region with respect to liquid was observed between 900 and $800 \mathrm{mb}$ (Figure 3-19a). The air was drier 
above $800 \mathrm{mb}$, but could still potentially be near-saturated with respect to ice even though the dew point depression was $>5^{\circ} \mathrm{C}$; to verify this hypothesis, saturation with respect to ice should be calculated using the environmental ice temperature. At the surface, colder and dry surface conditions were associated with cold air advection at the surface, as seen by backing of winds at and near the surface (Figure 3-19a). At 12 UTC on November 27, no low-level dry conditions were observed; the atmosphere was saturated or near-saturated with respect to liquid from the surface up to $750 \mathrm{mb}$, and saturated or near-saturated with respect to ice from $750 \mathrm{mb}$ to $450 \mathrm{mb}$, a level close to the tropopause level (Figure 3-19b).

The low-level regions of saturation or near-saturation with respect to liquid observed during the second accumulation peak (Figure 3-19b) enhanced precipitation formation. Moreover, surface saturation increased during the second warm-frontal period, as observed by the proximity of the temperature and dew point temperature curves on Figure 3-19b.

Finally, the analysis of the wind profiles provides information about the position of the low-pressure center during each warm-frontal period. Indeed, Figure 3-19a exhibits strong wind throughout the whole atmosphere, suggesting a strong pressure gradient at upper-level. On the other hand, the wind profile on Figure $3-19 \mathrm{~b}$ shows weak wind as low as $700 \mathrm{mb}$, suggesting a weak pressure gradient in the atmosphere and thus, few isobars at upper-levels in the vicinity of Iqaluit (recall Figure 3-17g). 


\subsubsection{Others}

The selected event took place on April 20, 1981 and was associated with a short-wave trough. It is the event that produced the second highest amount of accumulation for this group, and the highest amount of accumulation following 1978 for an Others event. It is ranked at the $43^{\text {rd }}$ position of the major precipitation events at Iqaluit (Table A-1).

The event produced a total of $20.2 \mathrm{~mm}$ of water-equivalent precipitation, contributing to $37 \%$ of the April 1981 total accumulation (Table 3-4). Precipitation consisted entirely of snow and was recorded for 18 hours, representing an average precipitation rate of $1.1 \mathrm{~mm} / \mathrm{h}$. Moreover, precipitation accumulation of $54.6 \mathrm{~mm}$ for April 1981 was 47\% above the 1955-1996 historical average for April (Table 3-4).

In the following Section, the synoptic evolution of the short-wave trough, the variations of the surface variables and the conditions leading to this observed snow are further discussed.

\subsubsection{Synoptic evolution}

The 6-hourly synoptic conditions of the short-wave trough between 00 UTC April 19 to 06 UTC April 21, 1981 are illustrated in Figure 3-20.

At 00 UTC April 20 (Figure 3-20a), a large synoptic trough-ridge pattern is present over the provinces of Ontario and Quebec, as well as over the southern part of Baffin Island, with the trough axis over south-eastern Hudson Bay and the ridge axis over Southern Baffin Island. 
Six hours later, perturbations of the $500 \mathrm{mb}$ thickness contours are observed along the upper-level trough axis (Figure 3-20b). The short-wave trough is present just north-east of Iqaluit, over Cumberland Sound between 12 and 18 UTC, April 20 (Figure 3-20c-d). During the later portion of the event, the shortwave trough is well-defined over north-east Baffin Island (Figure 3-20e-f).

(a)

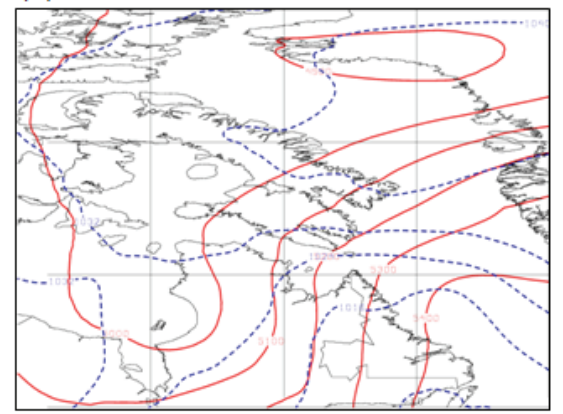

(c)

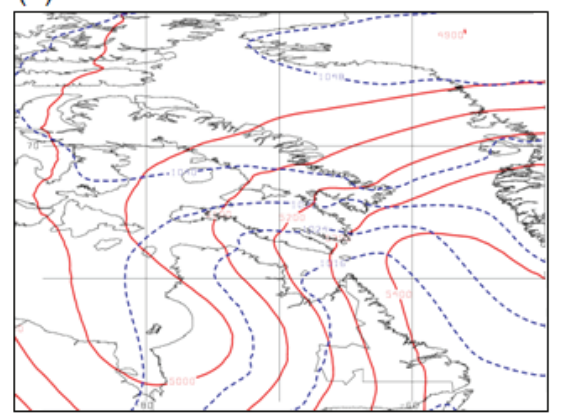

(e)

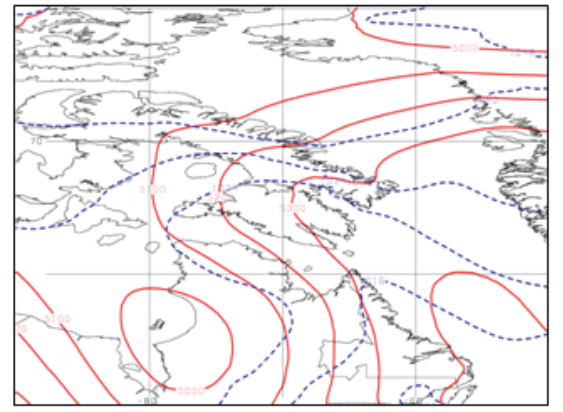

(b)

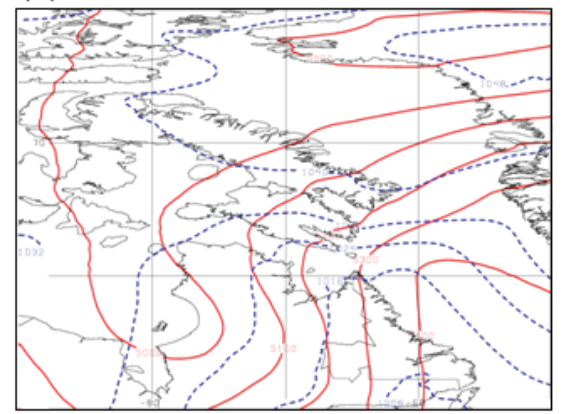

(d)

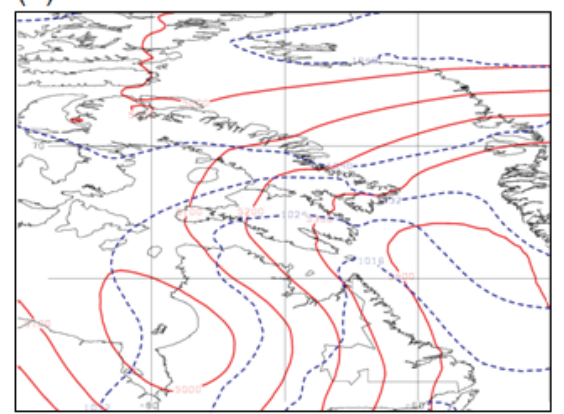

(f)

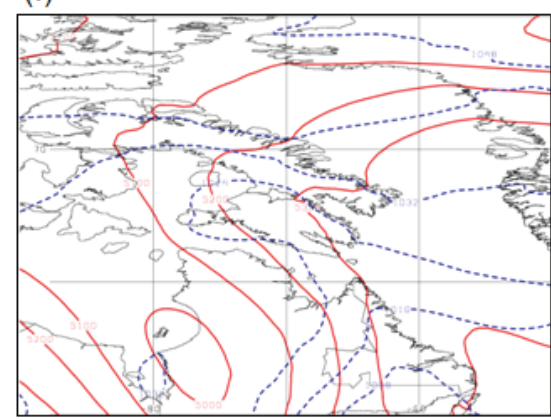

Figure 3-20: Synoptic conditions of the April 20, 1981 event at (a) 00 UTC April. 20, (b) 06 UTC April 20, (c) 12 UTC April 20, (d) 18 UTC April 20, (e) 00 UTC April 21 and (f) 06 UTC April 21. Mean-sea-level pressure (mb) is represented by the blue-dotted lines and 1000-500 mb thickness (mb), by the red-solid lines. 


\subsubsection{Surface evolution}

Figure 3-21 illustrates the evolution of the principal surface variables prior, during and following the event.

Although precipitation was first recorded at 00 UTC April 20, the 00 and 06 UTC April 20 accumulations contributed to April 19, 1981 dailyaccumulation, which did not meet the severity threshold of this study (Section 2.3.2). To distinguish them from the April 20, 1981 case study precipitation accumulation, the 00 and 06 UTC April 20 accumulations are left unfilled on Figure 2-21.

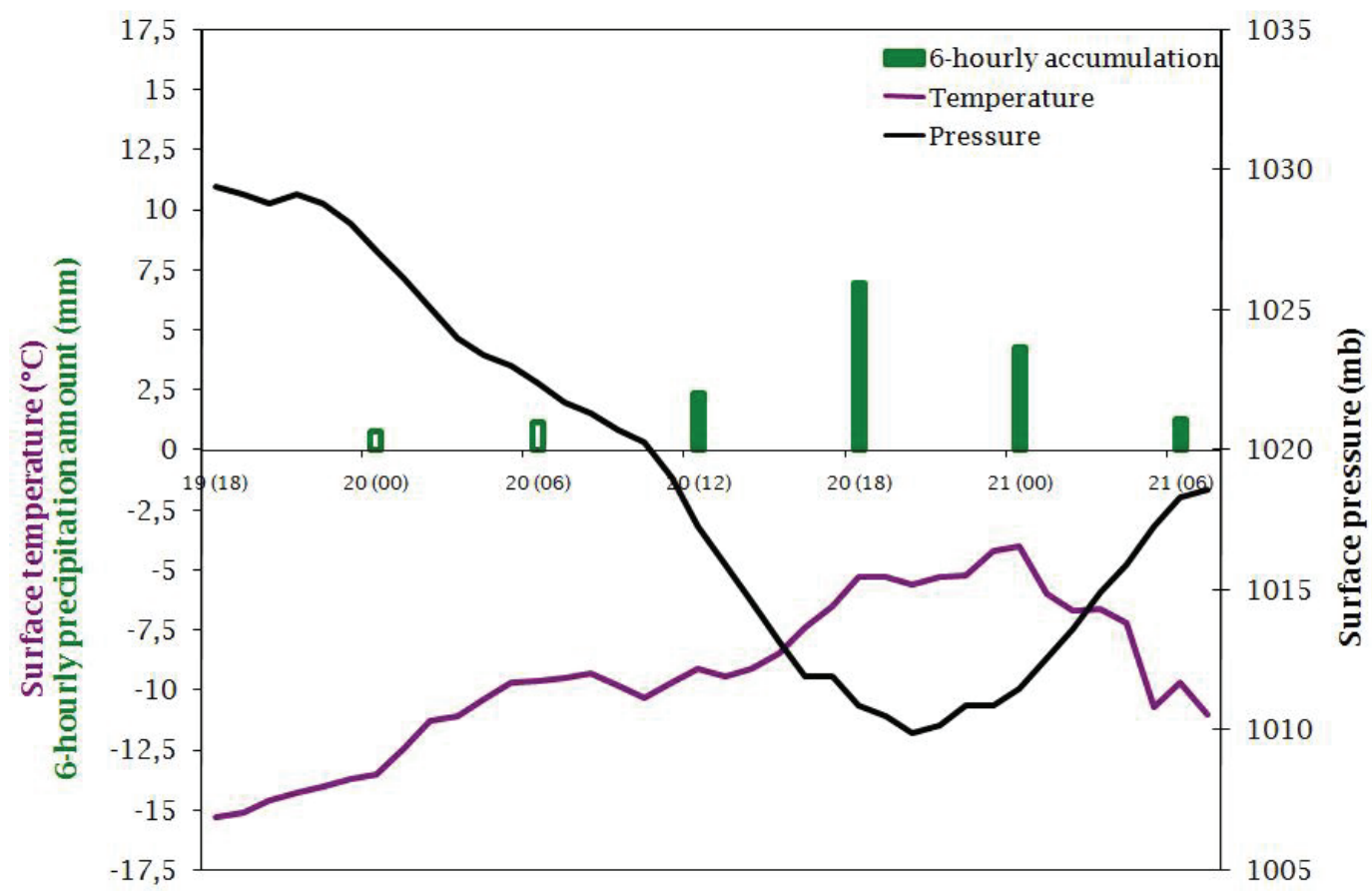

Figure 3-21: Evolution of the 6-hourly accumulation, surface temperature and surface pressure during the April 20, 1981 event. Precipitation accumulation is for the previous 6 hours. The days are labeled on the x-axis; the value in brackets is the time in UTC. 
Precipitation contributing to the April 20, 1981 major event started at 07 UTC, April 20 until 04 UTC, April 21. The 6-hourly precipitation accumulation peaked at 18 UTC April 20. Moderate snowfall was observed at the surface according to EC hourly surface weather observation (Environment Canada, 2006).

The analysis of the surface temperature evolution prior to the event indicates the presence of a warm front. In fact, surface temperature rose from $-15^{\circ} \mathrm{C}$ prior to the event, to $-5^{\circ} \mathrm{C}$ during the event. However, temperature started decreasing at 00 UTC April 21.

The influence of a short-wave trough rather than an organized lowpressure system supported the evolution of the surface pressure recorded during the event. Although surface pressure dropped during the event, this system was not as deep as the ones resulting from cyclonic activity and analyzed in Sections 3.2.1-3. Surface pressure never reached a value lower than $1010 \mathrm{mb}$ during the short-wave trough, whereas the three other case studies were associated with a surface pressure lower than $1000 \mathrm{mb}$.

\subsubsection{Precipitation type and atmospheric profile}

Snow was the only type of precipitation observed during the April 20, 1981 event (Table 3-5). Precipitation was recorded during 18 h, from 13 UTC April 20 to 06 UTC April 21 (Figure 3-21).

Figure 3-22 illustrates the vertical profiles of the atmosphere over Iqaluit preceding and following the 6-hourly accumulation peak. 
As stated earlier for the South- and Atlantic-originating cases, the absence of other types of precipitation with the exception of snow was associated with constant below $0^{\circ} \mathrm{C}$ temperatures.

A saturated or near-saturated region with respect to liquid atmospheric conditions was present between 950 and $550 \mathrm{mb}$ at 12 UTC on April 20 (Figure 3-22a), and between $1000 \mathrm{mb}$ and $550 \mathrm{mb} 12$ hours later (Figure 3-22b). A region of saturation or near-saturation with respect to ice, on the other hand, was present from $550 \mathrm{mb}$ to $475 \mathrm{mb}$ on both profiles. No data for the dew point temperature was available above $475 \mathrm{mb}$.
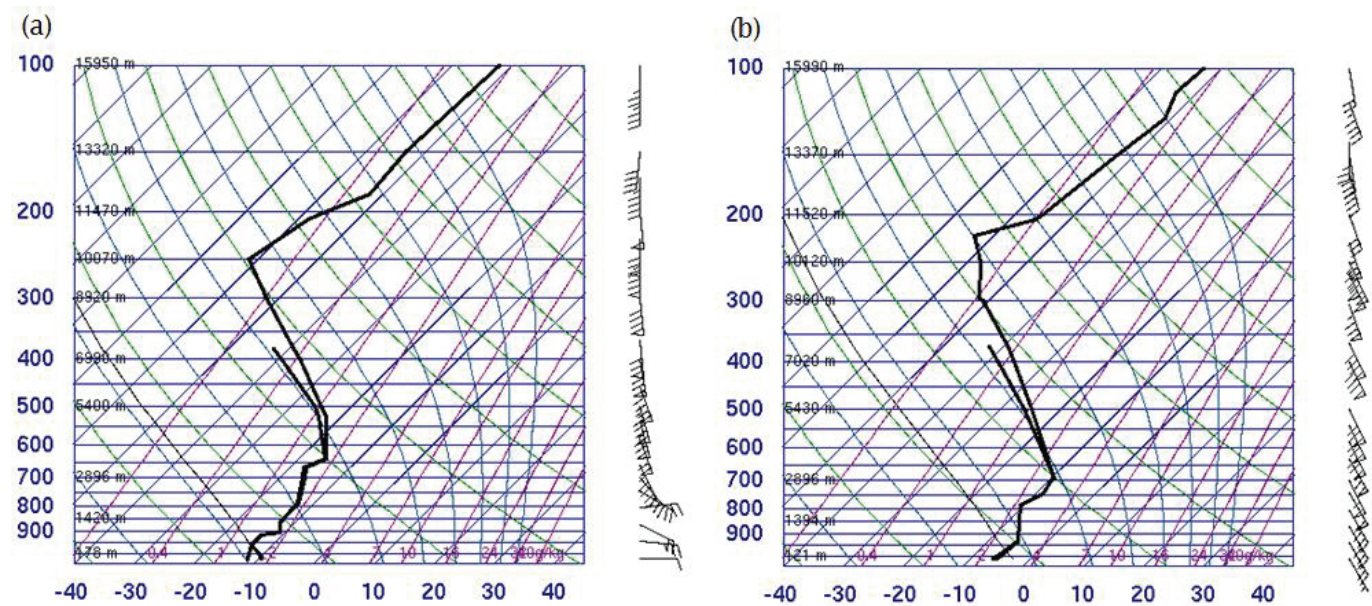

Figure 3-22: Skew T-log$(\mathrm{p})$ plot of temperature $\left({ }^{\circ} \mathrm{C}\right)$ and dew point profiles $\left({ }^{\circ} \mathrm{C}\right)$ for Iqaluit at (a) 12 UTC April 20, 1981 and (b) 00 UTC on April 21, 1981. Dry adiabats are indicated by the green lines, and moist adiabats are indicated by the blue lines. The horizontal wind profile is displayed along the right side of each diagram; pennant, full barb, and half barb denote 50, 10, and 5 knots, respectively (adapted from the University of Wyoming, 2008).

Veering of the wind was observed at the beginning of the event (Figure 3-22a). This type of wind profile is associated with warm air advection at the surface, explaining the presence of a warm front during the event. Indeed, surface temperature increased between 12 UTC, April 20 and 00 UTC, April 21 
(Figure 3-22). Surface saturation also increased between this time period, implying the advection of warm and moist air over Iqaluit by the low-level wind.

Finally, the decrease in surface temperature starting at 20 UTC on April 20 observed on Figure 3-21 is consistent with the vertical wind profile of Figure $3-22 b$. The absence of veering of the wind suggests the absence of the warm front and thus, inhibition of the warming at the surface. 


\section{CHAPTER 4 \\ Discussion}

A total of 194 cold-season major precipitation events at Iqaluit were analysed for the 1955-1996 period. The daily precipitation accumulation

exceeding the $97^{\text {th }}$ percentile of daily corrected precipitation accumulation was used as threshold to select the events. The climatological and variable internal features of these major precipitation events have been addressed in this study. Chapter 4 summarizes, interprets and discusses the results of these analyses. More precisely, the factors influencing precipitation accumulation, the severity variability, the origin groups and synoptic characteristics, the atmospheric conditions, the frontal structures, the surface characteristics and the 41-year tendency of occurrence of the major precipitation events at Iqaluit are discussed.

\subsection{Factors influencing precipitation accumulation}

The duration, precipitation rate and speed of motion are some of the variables that were used to characterize major precipitation events at Iqaluit in this study.

Major precipitation events at Iqaluit were normally of short duration. A total of 177 events (91\%) lasted $24 \mathrm{~h}$ or less, $15(9 \%)$ lasted between 32 and $48 \mathrm{~h}$ and two events lasted for three consecutive days (Table A-1). No event extended longer than three days. The shortest (longest) event lasted $5 \mathrm{~h}(62 \mathrm{~h})$ and produced $13.3 \mathrm{~mm}(46.2 \mathrm{~mm})$ of precipitation (Table A-1). On average, a major precipitation event at Iqaluit produced $16.7 \mathrm{~mm}$ of precipitation. 
The average precipitation rate ranged between $0.7 \mathrm{~mm} / \mathrm{h}$ for the Others events and $0.8 \mathrm{~mm} / \mathrm{h}$ for the South-, West-, and Atlantic-originating events. In comparison, the average precipitation rate during the 1996 Saguenay flood was of $8 \mathrm{~mm} / \mathrm{h}$ (Milbrandt and Yau, 2001), one order of magnitude higher than the precipitation rate during major precipitation events at Iqaluit.

In contrast to the precipitation rate, the average speed of motion varied between origin groups (Table 3-3). Figure 4-1 shows the number of events per speed of motion (in $9 \mathrm{~km} / \mathrm{h}$ intervals) for each origin group and sub-group during the 194 major precipitation events at Iqaluit.

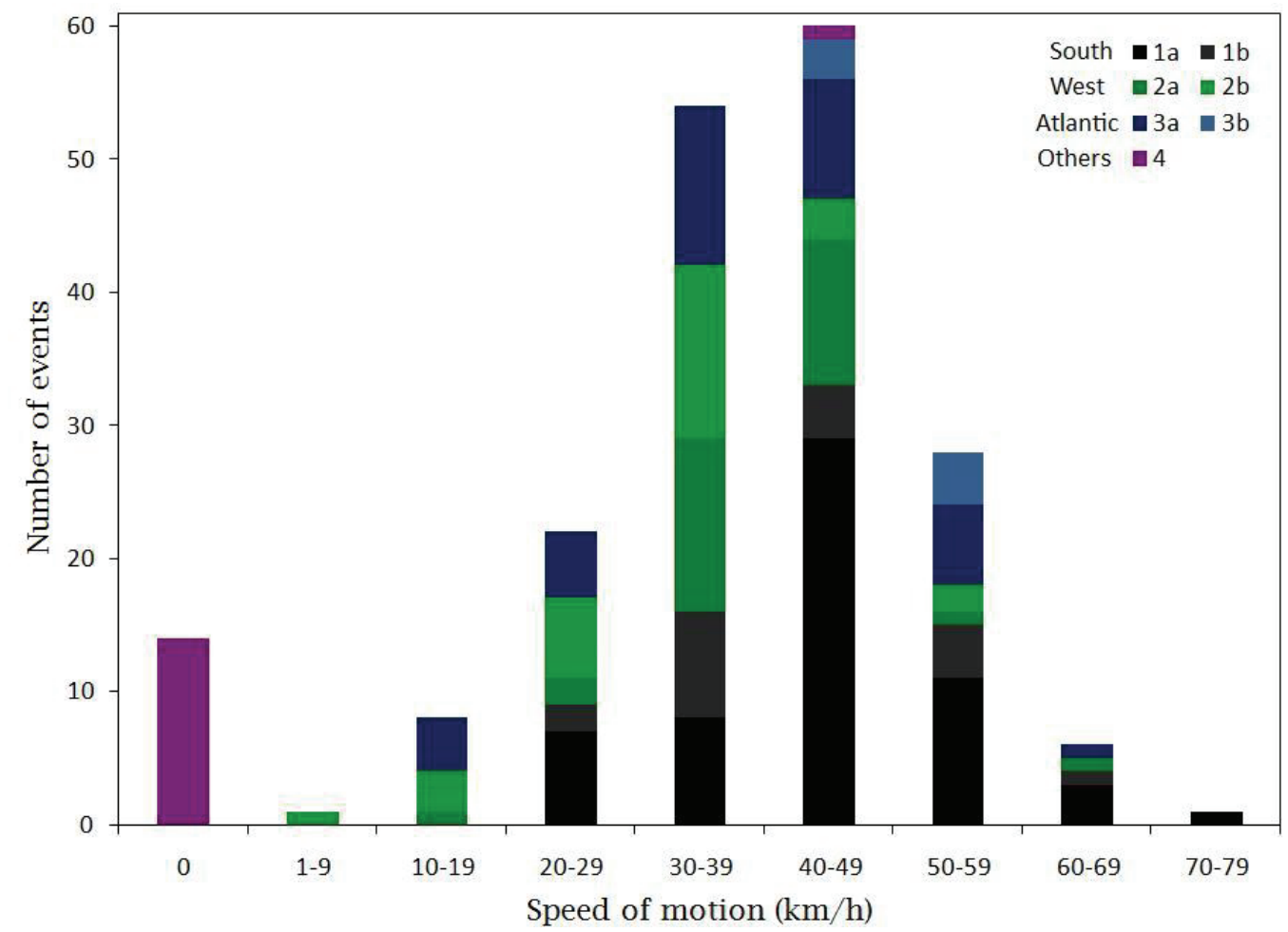

Figure 4-1: Number of events per speed of motion $(\mathrm{km} / \mathrm{h}$, in $10 \mathrm{~km} / \mathrm{h}$ intervals) for each origin group during the 194 major precipitation events at Iqaluit.

Regardless of a speed of motion of $0 \mathrm{~km} / \mathrm{h}$ associated with the 14 shortwave trough induced cases, the distribution of speed of motion during the 194 
major precipitation events follows a normal distribution (Figure 4-1). Indeed, the average speed of motion is $42 \mathrm{~km} / \mathrm{h}$, and the median of the distribution is of 41 $\mathrm{km} / \mathrm{h}$. The higher occurrences of West-originating systems at lower speed of motion is well shown by the green portion of the bars, whereas the higher occurrences of Atlantic-originating 3-b sub-track systems at speed of motion $\geq 40 \mathrm{~km} / \mathrm{h}$ is illustrated by the light blue portion of the bars. It is possible that West-originating systems tend to cut-off from the main westerly flow more rapidly, remaining stationary or advancing more slowly, whereas Atlanticoriginating systems tend to remain under the influence of the main westerly flow for a longer period of time.

The duration, precipitation rate and speed of motion of the events were analyzed to determine which of these variables were the key factors in influencing precipitation accumulation. Figure 4-2 shows the duration, precipitation rate and speed of motion as a function of precipitation accumulation.

Precipitation accumulations $<24 \mathrm{~mm}$ were associated with shorter events, all lasting $\leq 24 \mathrm{~h}$ for all origin groups (Figure 4-2a). Events producing between 24 and $40 \mathrm{~mm}$ were associated with both short and long duration events. For example, precipitation accumulations of approximately $30 \mathrm{~mm}$ were associated with an event lasting between 13 and $48 \mathrm{~h}$. Although some large accumulation cases were associated with shortest duration, especially for the South-originating group, the events producing precipitation accumulations $>40 \mathrm{~mm}$ were all associated with the longest events. 

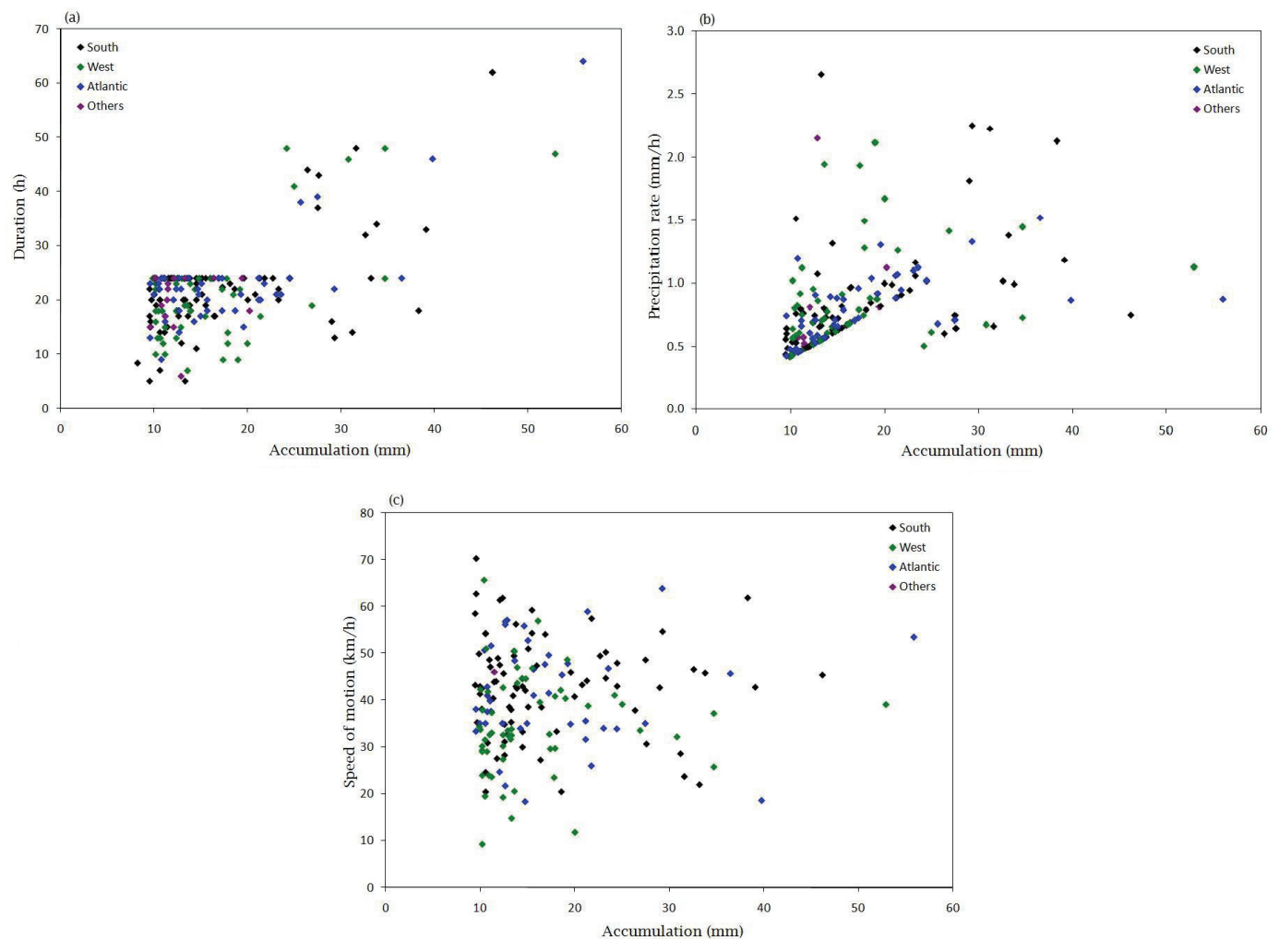

Figure 4-2: (a) Duration, (b) precipitation rate, and (c) speed of motion as a function of precipitation accumulation $(\mathrm{mm})$ for the 194 major precipitation events at Iqaluit per origin group.

Higher precipitation rates do not necessarily imply higher precipitation accumulation. The maximum precipitation rate during a major precipitation event was of $2.7 \mathrm{~mm} / \mathrm{h}$, recorded during a South-originating event producing $13.3 \mathrm{~mm}$ of precipitation; the event was ranked $106^{\text {th }}$ out of 194 . In contrast, some of the highest precipitation accumulation events were associated with the lower precipitation rate (Figure 4-2b). Indeed, the most severe precipitation event for the South, West- and Atlantic originating group were associated with precipitation rate ranging from $0.7 \mathrm{~mm} / \mathrm{h}$ for the South-originating system, to $1.1 \mathrm{~mm} / \mathrm{h}$ for the West-originating system. 
The speed of motion of the events does not tend to be a critical issue for large accumulation, regardless of the origin group. As illustrated on Figure 4-2c, a given speed of motion can be associated with low and high precipitation accumulation. For example, a system moving at a speed of approximately 55 $\mathrm{km} / \mathrm{h}$ can lead to both the highest and some of the lowest precipitation accumulation, just like a system moving at a speed of approximately $20 \mathrm{~km} / \mathrm{h}$ can either lead to precipitation accumulation of $10.5 \mathrm{~mm}$ or $40 \mathrm{~mm}$.

The factors influencing precipitation accumulation were the same for all origin groups. Longer (shorter) events tend to produce higher (lower) amount of precipitation and low precipitation rate are associated with higher precipitation accumulation. In contrast, speed of motion does not tend to influence precipitation amount as much.

\subsection{Severity variability}

One issue to address is whether one (or more) origin group leads to the formation of the most severe events at Iqaluit. To address this, the cumulative fraction of occurrences of events from each origin group (South, West, Atlantic, Others) has been plotted as a function of the rank of the events; the event producing the largest amount of precipitation was ranked first and the one producing the smallest amount of precipitation was ranked $194^{\text {th }}$. The cumulative fraction of occurrence for each origin group is illustrated in Figure 4-3.

Both South- and Atlantic-originating storms show a greater frequency of occurrence within the top-ranked precipitation events. For example, 29\% of the South-originating and $32 \%$ of the Atlantic-originating events are ranked in the top 
50 , in contrast to only $18 \%$ and $20 \%$ of the West-originating and Others cases (Figure 4-3). Similarly, 56\% of the South-originating and 59\% of the Atlanticoriginating events are ranked in the top 100 compared to $46 \%$ for the Westoriginating events; the gap is even greater for the events classified under the group Others, with only $27 \%$ of them making the top 100 .

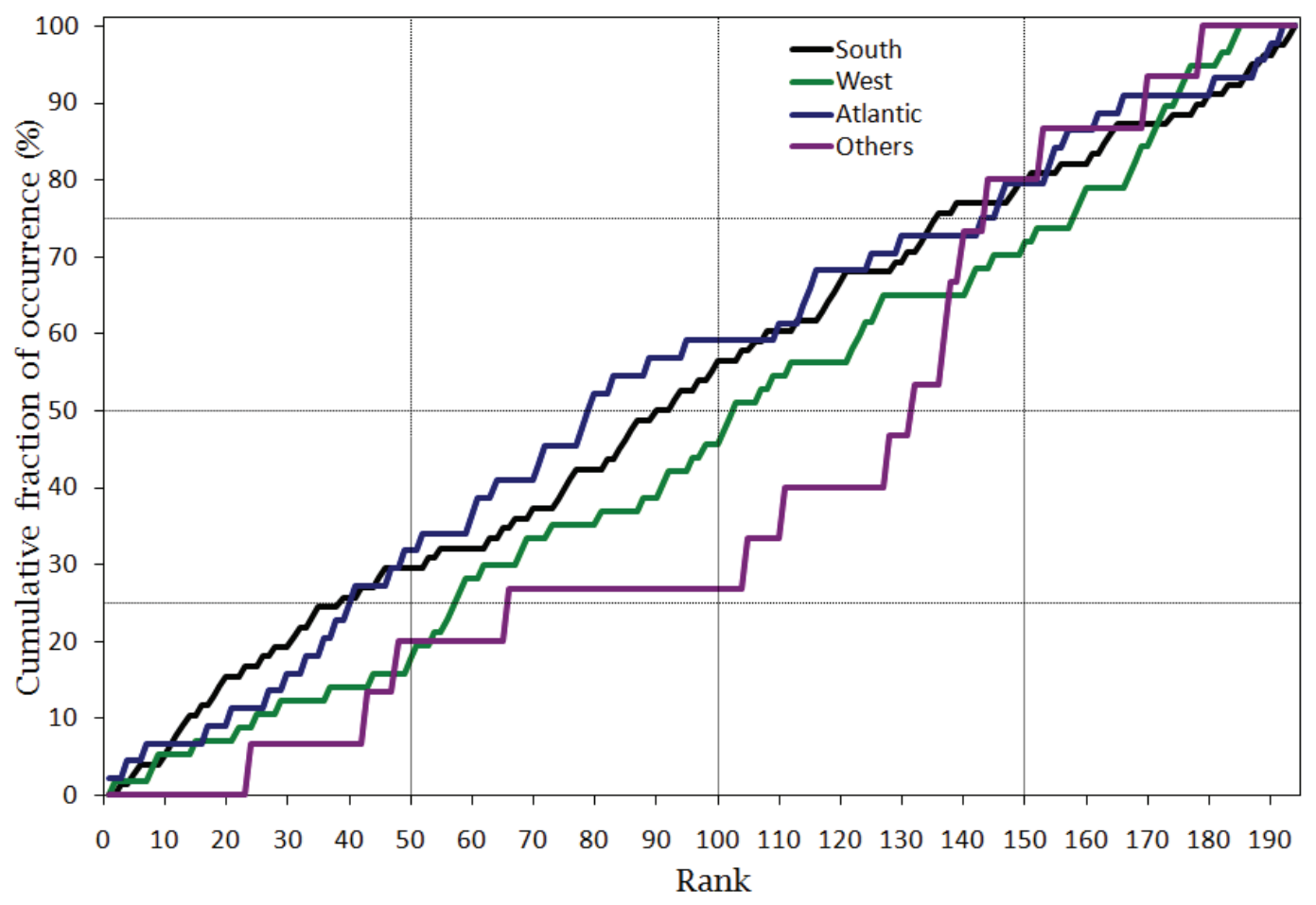

Figure 4-3: Cumulative fraction of occurrence (\%) of major events for each origin group as a function of the rank.

Considering the cumulative fraction of occurrence, half of the Southoriginating storms were observed in the top 90 events and half of the Atlanticoriginating storms were ranked in the top 80 . Half of the West-originating and Others storms, on the other hand, were respectively ranked $100^{\text {th }}$ and $130^{\text {th }}$ or more severe (Figure 4-3). 
The highest occurrences of Others events is observed between the $104^{\text {th }}$ and $154^{\text {th }}$ rank; $60 \%$ of the events part of this group are situated in this interval (Figure 4-3). Such distribution suggests a tendency for storms being generating with the absence of synoptic forcing to lead to the formation of less severe events.

The South and Atlantic-originating systems tend to be associated with the most severe events, whereas Others events tend to produce lower-accumulation major events more frequently. In contrast, West-originating storms produced a diversity of accumulation amounts.

\subsection{Origin groups and synoptic characteristics}

Major precipitation events were mainly associated with synoptic activity, with a total of 180 events (93\%) associated with cyclonic activity. The remaining 14 events showed no sign of synoptic activity and were believed to be associated with short-wave trough. A large variability in the synoptic activity during the major events was observed.

Systems leading to major precipitation events at Iqaluit can come from several directions (Table 3-3). A total of 78 events were associated with Southoriginating systems and initiated in the central part of the United States or the Great Lakes region, whereas 57 systems were initiated on the lee-ward side of the Rockies over the Northwest Territories and were defined as West-originating; these systems moved with a significant westerly component. Atlantic-originating systems, forming over the Ocean near the east coast of the United States accounted for 44 events; these systems moved southerly and then easterly as they progress from the Labrador Sea towards Baffin Island. One event advanced with 
a strong northerly component, originating from the Arctic Ocean. Hudson et al. (2001) and Intihar and Stewart (2005) observed a large variability in the region of origin of systems leading to hazardous weather during the cold-season.

Moreover, many systems decayed in the vicinity of Iqaluit, but a large variability in their secondary regions of decay was observed (Figure 3-7). In fact, $43 \%$ of the systems decayed within $600 \mathrm{~km}$ of Iqaluit, but systems also decayed over the coast of Greenland, off the coast of Labrador, over Hudson Bay, over Foxe Basin and over Northern Canadian Archipelago. Roberts et al. (2008) and Intihar and Stewart (2005) also noted the occurrence of storms decaying over the Canadian Archipelago.

In addition to the large variability in region of origin and decay of systems leading to major precipitation events at Iqaluit, storms seldom moved directly over Iqaluit; they mainly moved east or west of the community, towards Davis Strait or Foxe Basin respectively (Figure 3-6). Table 4-1 shows the number of occurrences of the position of the systems with respect to Iqaluit during the 194 major precipitation events at Iqaluit for each origin group.

Table 4-1: Position of the low-pressure systems with respect to Iqaluit during the 194 major precipitation events at Iqaluit. Other here represents the position of the systems that did not moved east or west of Iqaluit; i.e. the short-wave trough events and storms that stopped off the coast of Labrador or over Hudson Bay.

\begin{tabular}{||c||c||c||c||c||}
\hline ORIGIN GROUP & EAST & WEST & OTHER & TOTAL \\
\hline \hline South & 54 & 13 & 11 & 78 \\
\hline West & 26 & 26 & 5 & 57 \\
\hline Atlantic & 28 & 5 & 11 & 44 \\
\hline Others & 0 & 0 & 15 & 15 \\
\hline Total & 108 & 44 & 42 & 194 \\
\hline \hline
\end{tabular}


The different positions of the systems with respect to Iqaluit add to the large variability of the storm tracks leading to major precipitation events at Iqaluit. A total of 152 events, representing $78 \%$ of the major events moved either east (108 events) or west (44 events) of Iqaluit (Table 4-1). Some cyclonic systems decayed before reaching Iqaluit. These systems stopped off the coast of Labrador or over Hudson Bay and just like the events associated with a shortwave trough, neither moved east nor west of the community.

In contrast to Iqaluit, storms leading to major precipitation events in other regions of the Arctic and at mid-latitudes exhibit less storm track variability. Beaufort Sea storms mainly enter the region with a significant westerly component, either arriving from the Pacific of the north-western Arctic Oceans (Hudak and Young, 2002). The same is also true for the Russian side of the Arctic, with all primary and secondary cyclones exhibiting a significant westerly component. On rare occasions over eastern Russia, cyclones originate from the south and have a northward track, but a westerly component is always present (Whittaker and Horn, 1984). Similar conclusions are derived for extratropical cyclones over Montreal, situated at a latitude of $45^{\circ} 28^{\prime} \mathrm{N}$ (Environment Canada, 2008). Indeed, cyclones primarily originate from the Canadian Prairies or central United States and move towards Montreal with a prevailing westerly component. 


\subsection{Atmospheric conditions}

Cold-season in the Arctic is characterised by dry atmospheric conditions (Stewart et al., 1995). The moisture content of the atmosphere during major precipitation events was examined to determine how significant precipitation accumulation can be generated in a climatologically dry environment.

Regions of saturation or near-saturation with respect to liquid and ice during major precipitation events were examined using the vertical profiles from the University of Wyoming available following 1978. Out of the 194 major coldseason precipitation events examined at Iqaluit between 1955 and 1996, 75 were observed following 1978. However, two had missing vertical profile data; 73 events (28 South-originating, 22 West-originating, 16 Atlantic-originating and 7 Others) were thus examined.

As explained in section 3.2, the regions of saturation or near-saturation were identified based on a dew point depression of $0^{\circ} \mathrm{C}$ for liquid and $\leq 5^{\circ} \mathrm{C}$ for ice. Regions anywhere in the profile associated with a dew point depression $>5^{\circ} \mathrm{C}$ were defined as dry. The sounding exhibiting the deepest layer of high moisture content during each event was used to assess the depth of saturation or nearsaturation depth with respect to both liquid and ice. The lower and upperboundaries of these regions retrieved from the 73 events were averaged to determine the average depth of regions of saturation or near-saturation for each origin group. Table 4-2 summarizes the atmospheric characteristics during the 73 major events. 
Table 4-2: Atmospheric characteristics during the 73 major events following 1978.

\begin{tabular}{|c|c|c|c|c|}
\hline \multirow[t]{2}{*}{$\begin{array}{l}\text { ORIGIN } \\
\text { GROUP }\end{array}$} & \multicolumn{2}{|c|}{$\begin{array}{c}\text { SATURATION OR } \\
\text { NEAR-SATURATION } \\
\text { AVERAGE DEPTH } \\
(\mathrm{mb})\end{array}$} & \multirow{2}{*}{$\begin{array}{c}\text { OCCURRENCE OF } \\
\text { NEAR-SATURATION } \\
\text { REACHING THE } \\
\text { TROPOPAUSE }\end{array}$} & \multirow[t]{2}{*}{$\begin{array}{l}\text { OCCURRENCE } \\
\text { OF DRY REGION }\end{array}$} \\
\hline & Liquid & Ice & & \\
\hline South & $950-700$ & $700-375$ & 23 & 4 \\
\hline West & $950-700$ & $750-350$ & 19 & 5 \\
\hline Atlantic & $950-700$ & $750-375$ & 13 & 2 \\
\hline Others & $725-600$ & $625-375$ & 7 & 0 \\
\hline
\end{tabular}

Saturation or near-saturation regions with respect to either liquid or ice were typically deep during major precipitation events. A total of 62 events were linked with regions of deep saturation or near-saturation conditions with either liquid or ice, continuously extending from the surface to a level close to the tropopause (Table 4-2). In contrast, the vertical profiles of 11 events showed the presence of a dry region, typically between 900 and $700 \mathrm{mb}$ (Table 4-2 and A-1).

Regions of saturation or near-saturation with respect to liquid were typically observed from the surface $(950 \mathrm{mb})$ to $700 \mathrm{mb}$ for all origin groups with the exception of the Others (Table 4-2). This latter was characterized by shallower near-saturation conditions at a higher level, on average between 725 and $600 \mathrm{mb}$. No events were linked with near-saturation with respect to liquid above $500 \mathrm{mb}$ (Table A-1). The high occurrence of liquid saturation or near-saturation during major events suggests that liquid water was present in the atmosphere. Indeed, 
Shupe et al. (2006) observed mixed-phased clouds (both supercooled droplets and ice crystals) in all seasons in the Arctic. Moreover, several glories were observed during research flights in the vicinity of Iqaluit during the fall 2007 Storm Studies in the Arctic (STAR) field campaign (Hanesiak et al., 2008); such an optical phenomenon is associated with liquid clouds.

Regions of saturation or near-saturation with respect to ice, on the other hand, were observed from approximately the upper-boundary of near-saturation with respect to liquid and up to the tropopause level for all origin group (Table 4-2).

High moisture content is required to produce significant precipitation accumulation at Iqaluit. Deep regions of saturation or near-saturation with respect to liquid, combined to a region of saturation or near-saturation with respect to ice reaching the tropopause level, suggest that deep saturation conditions are required to overcome the usually dry atmospheric conditions in the Arctic in order to generate precipitation with significant accumulation. As well, high moisture content was observed during the case studies. Their atmospheric characteristics are presented in Table 4-3.

Just like the 73 major precipitation events, all atmospheric profiles during the case studies showed deep saturated or near-saturated atmospheric conditions (Table 4-3). Atmospheric saturation or near-saturation with respect to liquid was observed from 950 to $550 \mathrm{mb}$ during the South-originating and Others cases. The layer of saturation or near-saturation with respect to liquid was shallower for the West- and Atlantic- originating events, extending from 950 to $750 \mathrm{mb}$. With the 
exception of the West-originating case, atmospheric saturation or near-saturation with respect to ice was continuously observed up to the tropopause level (Table 4-3); a dry layer was observed during the West-originated case.

Table 4-3: Atmospheric characteristics during the four case studies. The reference figures of the vertical profiles used to determine these characteristics are identified below the origin group of each case study.

\begin{tabular}{||c||c|c|c||c||}
\hline \hline \multirow{2}{*}{$\begin{array}{c}\text { ORIGIN } \\
\text { GROUP }\end{array}$} & \multicolumn{3}{c||}{$\begin{array}{c}\text { SATURATION OR NEAR } \\
\text { SATURATION DEPTH (mb) }\end{array}$} & $\begin{array}{c}\text { DRY } \\
\text { REGION } \\
(\mathrm{mb})\end{array}$ \\
\cline { 2 - 5 } & LIQUID & ICE & $\begin{array}{c}\text { REACHING } \\
\text { TROPOPAUSE }\end{array}$ & \\
\hline \hline $\begin{array}{c}\text { South 1a } \\
\text { Figure 3-13b }\end{array}$ & $950-550$ & $550-450$ & $\mathrm{x}$ & - \\
\hline $\begin{array}{c}\text { West 2b } \\
\text { Figure 3-16a }\end{array}$ & $950-750$ & $500-250$ & $\mathrm{x}$ & $750-500$ \\
\hline $\begin{array}{c}\text { Atlantic 3a } \\
\text { Figure 3-19b }\end{array}$ & $950-750$ & $750-450$ & $\mathrm{x}$ & - \\
\hline $\begin{array}{c}\text { Others } \\
\text { Figure 3-22b }\end{array}$ & $950-550$ & $550-475$ & $\mathrm{x}$ & - \\
\hline \hline
\end{tabular}

\subsection{Frontal structures}

We have already shown that major precipitation events were mainly associated with cyclonic activity (Section 4.2). It is well known that extratropical cyclones are associated with a warm and a cold front (e.g. Bkerknes, 1919; Schultz et al., 1998; Ahrens, 2004). The contribution of frontal structures to the generation of major events has been investigated.

An event was said to be linked with a surface front when an arbitrary temperature variation of at least $\pm 10^{\circ} \mathrm{C}$ was observed prior to or during the event. 
Table 4-4 shows the number of occurrence of surface warm and cold fronts during major precipitation events, as well as the surface front observed during the four selected case studies.

Table 4-4: Frontal structures observed during the 194 major cold-season precipitation events, as well as during the 4 case studies.

\begin{tabular}{||c||c|c|c||c||}
\hline \multicolumn{1}{||c||}{ ORIGIN GROUP } & \multicolumn{4}{c||}{ SURFACE FRONT } \\
\cline { 2 - 5 } & Warm & Cold & None & Case study \\
\hline \hline South & 43 & 6 & 29 & warm \\
\hline West & 32 & 5 & 20 & warm \\
\hline Atlantic & 27 & 5 & 12 & warm \\
\hline Others & 7 & 1 & 7 & warm \\
\hline \hline
\end{tabular}

Surface frontal structures were observed in the majority of the cases. Warm and cold fronts were observed during 109 and 17 events, respectively. A total of 68 cases were not associated with frontal passage, representing $35 \%$ of the events. Roberts et al. (2008) also noticed the presence of frontal passages during hazardous weather conditions at Iqaluit.

As well, surface warm-frontal passages were observed during the four case studies, with well-defined surface temperature changes visible on the surface temperature evolution. Moreover, the veering of the winds between the surface and $650 \mathrm{mb}$ during all cases on the atmospheric profiles is one indication of warm air advection (Section 3.2). Frontal passages aloft were also detected on the 
atmospheric profiles by the mid- to low-levels temperature inversions; no lowlevel inversion was observed during the short-wave trough case (Section 3.2).

The high occurrence of surface fronts, especially warm fronts, illustrates the critical role of cyclonic activity in systems leading to major precipitation events at Iqaluit.

\subsection{Surface characteristics}

Major precipitation events produced accumulation ranging between 9.5 and $55.9 \mathrm{~mm}$ (Table 3-1). Each major event was unique, but they all exhibited similar surface characteristics.

The number of occurrences of major events per precipitation type and combination of precipitation types is shown in Table 4-5. We showed that $91 \%$ of the precipitation accumulation during the 194 major precipitation events was linked with snow (Figure 3-5). This result is supported by the number of events producing only snow. Indeed, a total of 142 events producing this single type of precipitation.

Although snow was the dominant precipitation type, a total of 52 events (27\%) produced at least one other type of precipitation besides snow. Rain events accounted for 4 events (5\%) and were associated with either South or Westoriginating systems. Mixed precipitation consisting of snow and liquid precipitation was observed from each group during a total of 22 events. A mixture of solid precipitation types was also observed during 22 cases, whereas 6 events produced a combination of a variety of solid and liquid precipitation types. 
Table 4-5: Number of occurrences of major events per precipitation type. Liquid type consists of rain and freezing rain, whereas solid type consists of snow grains, ice pellets and ice crystals.

\begin{tabular}{|c|c|c|c|c|c|c|}
\hline $\begin{array}{l}\text { ORIGIN } \\
\text { GROUP }\end{array}$ & $\begin{array}{l}\text { ONLY } \\
\text { SNOW }\end{array}$ & $\begin{array}{l}\text { ONLY } \\
\text { RAIN }\end{array}$ & $\begin{array}{c}\text { SNOW } \\
\text { AND } \\
\text { LIQUID } \\
\text { TYPE }\end{array}$ & $\begin{array}{l}\text { SNOW } \\
\text { AND } \\
\text { SOLID } \\
\text { TYPE }\end{array}$ & $\begin{array}{c}\text { SNOW, } \\
\text { LIQUID } \\
\text { AND SOLID } \\
\text { TYPES }\end{array}$ & TOTAL \\
\hline South & 60 & 2 & 4 & 10 & 2 & 78 \\
\hline West & 40 & 2 & 8 & 5 & $2^{*}$ & 57 \\
\hline Atlantic & 33 & 0 & 4 & 5 & 2 & 44 \\
\hline Others & 9 & 0 & 4 & 2 & 0 & 15 \\
\hline Total & 142 & 4 & 22 & 22 & 6 & 194 \\
\hline
\end{tabular}

*No snow was observed

The topographic features surrounding Iqaluit played a crucial role in influencing the wind speed during major precipitation events. Wind exhibited a strong bi-directional distribution in the north-west/south-east corridor resulting from the channelling effects of the surrounding topography. Indeed, such wind pattern was observed $77 \%$ of the instance; $44 \%$ of the time, wind observations were from the south-east and 33\%, from the north-west. South-originating events exhibited a bi-directional wind direction distribution than the overall 194 major events, whereas Atlantic-originating and Others storms also exhibited this bidirectional distribution, but with north-westerly and south-easterly winds respectively dominating (Figure A-1). In contrast, west-originating systems were mainly associated with south-easterly winds (Figure A-1).

North-easterly and easterly winds were observed in all origin groups and accounted for $13 \%$ of the observations. Only $1 \%$ of the wind observations were 
from the south-west, exclusively during Atlantic-originating events. Calm conditions were reported for $9 \%$ of the observations.

Comparing this result to other studies revealed a distinct wind characteristic for cold-season major precipitation events. Nawri and Stewart (2006) showed that north-westerly winds were dominant during the cold-season, south-easterly winds only occurring during the month of October. Moreover, Nadeau (2007) found that $89 \%$ of the winds recorded during high-wind events were north-westerly. In contrast, south-easterly winds at Iqaluit were observed during $44 \%$ of the major precipitation events. However, Nawri and Stewart (2006) and Nadeau (2007) never considered precipitation. Thus, the high occurrence of south-easterly winds during major precipitation events suggests that south-easterly winds are more likely to be linked with major precipitation events than no-weather or high winds events.

When combined with strong wind, heavy precipitation (especially snow) can lead to hazardous conditions characterized by low-visibility and blizzard conditions. We have already showed that $18 \%$ of wind observation exceeded speeds the blizzard wind threshold from Environment Canada (2006) of $40 \mathrm{~km} / \mathrm{h}$ (Figure 3-4). However, the number of events associated with these conditions is much greater. The number of events for each origin group associated with winds $\geq 40 \mathrm{~km} / \mathrm{h}$ and their duration statistics are presented in Table 4-6.

A total of 116 events were associated with severe winds; this represents $60 \%$ of the 1955-1996 major precipitation events. Most of the time, these severe winds were associated with significant wind channelling from the surrounding 
topography (Figure 3-3). On average, severe winds were observed between 7 and $9 \mathrm{~h}$ duration, but observations ranged from between $1 \mathrm{~h}$ during one event, to almost the entire event. For example, the October 5, 1958 South-originating event was associated with severe wind for a total of 52 consecutive hours; the event was $62 \mathrm{~h}$ long (Table A-1). Severe wind is thus a typical surface characteristic of major precipitation events, occurring during 116 events.

Table 4-6: Number of occurrences of events associated with winds $\geq 40 \mathrm{~km} / \mathrm{h}$ and their duration statistics.

\begin{tabular}{||c||c||c||c||c||}
\hline $\begin{array}{c}\text { ORIGIN } \\
\text { GROUP }\end{array}$ & $\begin{array}{c}\text { NUMBER } \\
\text { OF EVENTS }\end{array}$ & $\begin{array}{c}\text { AVERAGE } \\
\text { DURATION PER } \\
\text { EVENT* }(\mathrm{h})\end{array}$ & $\begin{array}{c}\text { MAXIMUM } \\
\text { DURATION }(\mathrm{h})\end{array}$ & $\begin{array}{c}\text { MINIMUM } \\
\text { DURATION } \\
(\mathrm{h})\end{array}$ \\
\hline \hline South & 51 & 9 & 52 & 1 \\
\hline West & 29 & 8 & 18 & 1 \\
\hline Atlantic & 27 & 9 & 33 & 1 \\
\hline Others & 9 & 7 & 20 & 1 \\
\hline
\end{tabular}

Total number of events associated with severe winds : 116

* Events associated with severe winds only

Four events, one per origin group, were selected for a more detailed analysis (Section 3.2). Their surface characteristics are compared to their origingroup typical characteristics; Table 4-7 summarizes the characteristics of the four case studies.

In comparison with major precipitation events in general (Table 3-3; Section 4.1), the selected case studies were associated with fast moving systems delivering precipitation at a higher rate than average (Table 4-7). However, their surface conditions were typical to major precipitation events' surface conditions. 
South-, Atlantic-originating and Others events produced only snow, like 142 of the major precipitation events (Table 4-5). In contrast, freezing rain, rain, a mixture of rain and snow, and snow were produced during the West-originating case. This event was one of the 6 producing such mixed precipitation (Table 4-2).

Table 4-7: Summary of the surface characteristics of the four case studies. ZR indicates freezing rain. Severe wind is defined as wind speed $\geq 40 \mathrm{~km} / \mathrm{h}$.

\begin{tabular}{|c|c|c|c|c|c|c|c|c|}
\hline \multirow{2}{*}{$\begin{array}{l}\text { ORIGIN } \\
\text { GROUP }\end{array}$} & \multirow{2}{*}{$\begin{array}{c}\text { ACCUM. } \\
(\mathrm{mm})\end{array}$} & \multirow{2}{*}{$\begin{array}{c}\text { DUR. } \\
\text { (h) }\end{array}$} & \multirow{2}{*}{$\begin{array}{c}\text { PRECIP. } \\
\text { RATE } \\
(\mathrm{mm} / \mathrm{h})\end{array}$} & \multirow{2}{*}{$\begin{array}{c}\text { SPEED } \\
\text { OF } \\
\text { MOTION } \\
(\mathrm{km} / \mathrm{h})\end{array}$} & \multirow{2}{*}{$\begin{array}{c}\text { PRECIP. } \\
\text { TYPE }\end{array}$} & \multicolumn{2}{|c|}{$\begin{array}{c}\text { AVERAGE } \\
\text { WIND }\end{array}$} & \multirow{2}{*}{$\begin{array}{c}\text { SEVERE } \\
\text { WIND } \\
\text { (h) }\end{array}$} \\
\hline & & & & & & dir. & $\begin{array}{l}\text { speed } \\
(\mathrm{km} / \mathrm{h})\end{array}$ & \\
\hline $\begin{array}{c}\text { South } \\
\text { 1a }\end{array}$ & 38.3 & 18 & 2.1 & 62 & snow & $\begin{array}{l}\text { SE- } \\
\text { NW }\end{array}$ & 30 & no \\
\hline $\begin{array}{c}\text { West } \\
2 b\end{array}$ & 53 & 47 & 1.1 & 39 & $\begin{array}{l}\text { rain, } \\
\mathrm{ZR} \text {, } \\
\text { snow }\end{array}$ & SE & 17 & $\begin{array}{l}\text { yes } \\
(1 \mathrm{~h})\end{array}$ \\
\hline $\begin{array}{c}\text { Atlantic } \\
3 \mathrm{a}\end{array}$ & 55.9 & 59 & 0.9 & 53 & snow & $\begin{array}{l}\text { SE- } \\
\text { NW }\end{array}$ & 36 & $\begin{array}{c}\text { yes } \\
(33 \mathrm{~h})\end{array}$ \\
\hline Others & 20.2 & 18 & 1.1 & 0 & snow & $\mathrm{NE}$ & 14 & $\begin{array}{l}\text { yes } \\
(1 \mathrm{~h})\end{array}$ \\
\hline
\end{tabular}

Wind direction of the case studies was in the majority typical to the ensemble of major precipitation events. South, West and Atlantic-originating case study exhibited strong wind channelling by the surrounding topography, blowing in the north-west/south-east corridor. Unlike the majority of the Others events (Figure A-1d), winds during this Others event were not along the northwest/south-east corridor, but from the north-east; the geostrophic flow rather than topography had a greater influence on wind direction. All cases except the South- 
originating one were characterized by severe winds, but only the Atlanticoriginating severe winds were sustained, recorded during 33 consecutive hours.

\subsection{1-year tendency of occurrence}

A total of 194 major precipitation events were observed at Iqaluit for the 1955-1996 period, with an average of 5 events per cold-season. Some cold seasons had a greater occurrence of major events (1958, 1968 with 12), whereas others experienced few events (1957, 1961, 1991, 1993 and 1994 with 1) (Figure 3-2b).

October experienced 41 major events during a 41-year period (Figure 3-2a). This represents, on average, one major precipitation events per year during October. In contrast, February experienced 17 events over the 41year period, representing less than one major event every two years during the month of February.

Fewer major events during between December and March illustrate the dry Arctic atmospheric conditions and suggest poorer storm efficiency in converting water vapour into precipitation compared to the other cold-season months. A drier atmosphere will enhance ice crystals evaporation before reaching the ground, limiting the amount of precipitation accumulation. Moreover, the minimum monthly occurrence of major events (Figure 3-2a) is consistent with the minimum cyclonic activity in the Arctic observed during the month of February by Zhang et al. (2004). This illustrates the importance of synoptic forcing in triggering systems leading to major precipitation events at Iqaluit. 
No significant trend in the occurrence of major precipitation events has been observed (Figure 3-9), although Zhang et al. (2004) reported an increase in cyclonic activity over the past 50 years and a northward shift of storms tracks towards the Arctic region is observed (McCabe et al., 2001; Wang et al., 2004; Yin, 2005).

The NAO index appears to influence the occurrence of some major precipitation events. Indeed, an inverse relationship linking the NAO index to the major precipitation event anomalies is observed in some instances during the 1955-1996 period. Fewer (more) major events were observed when the NAO index is positive (negative). However, the $R^{2}$ value of the linear regression between these two variables (maximum value of 0.4 for the 1989-1996 period, Figure 3-10) is not strong enough for the NAO index to solely explain the occurrence of major precipitation events. Other factors such as sea-ice extend (e.g. Zhao et al., 2004) or sea surface temperature anomaly may need to be taken in consideration to better explain the occurrence of major precipitation events at Iqaluit. For example, reduced sea-ice cover and/or warmer temperatures could lead to an increase of moisture in the atmosphere, which could increase storm efficiency.

In addition, the occurrence of major precipitation events based on a daily threshold was compared to the NAO index based on monthly values. NAO events are believed to be of short duration, with the occurrence of a strong positive/negative NAO event reflecting on the monthly NAO value (Jia et al., 2007). Strong NAO events and major precipitation events at Iqaluit do not always 
happen simultaneously, possibly misleading our analysis the relationship between these two variables.

Moreover, we have investigated the relation between the NAO index and the occurrence of major precipitation events regardless of their origin. However, the NAO might not have the same effect on all origin regions. The precipitation pattern associated with the NAO is governed by the shifts of the storm tracks associated with the variation of the pressure gradient between the Icelandic Low and the Azores High (Marshall et al., 2001). It is well known that Greenland and Southeastern Baffin Island receive higher (lower) precipitation accumulation during negative (positive) NAO phases in response to the variation of the storm track originating from the Atlantic Ocean and moving towards the Canadian Arctic (e.g. Appenzeller et al., 1998; Marshall et al., 2001). On the synoptic scale, this storm track is observed more frequently during negative NAO phases, impacting either Greenland or Baffin Island (Visbeck et al., 2001).

As a result, one would expect that the Atlantic-originating major events should be more influenced by the NAO index than the other origin groups analyzed in this study. Figure 4-4 illustrates the Atlantic-originating major precipitation events anomaly against the Oct-April NAO index. In some occasions, more Atlantic-originating major events were observed when the NAO was in a negative phase (Figure 4-4), similar to the relationship observed on Figure 3-10 for the 194 major events. However, positive Atlantic-originating events anomalies mainly tend to be observed when the NAO is in a positive phase, as observed between 1960 and 1974 (Figure 4-4). Such tendency suggests 
a direct linear relationship between these two variables, thus a higher occurrence of Atlantic-originating events when the NAO is in a positive phase.

This result contrasts the work of Visbeck et al. (2001) which suggested an inverse relationship between these two variables. It should be noted that Visbeck et al. (2001) focused on the global scale and considered Greenland and the southern Canadian Arctic as a single region, whereas this present study considered major precipitation events as never done before for the Canadian Arctic. It should also be noted that a total of 44 Atlantic-originating events over a 41-year period represents too few events to formulate definite conclusions on the presence of a relationship between the NAO and the Atlantic-originating systems.

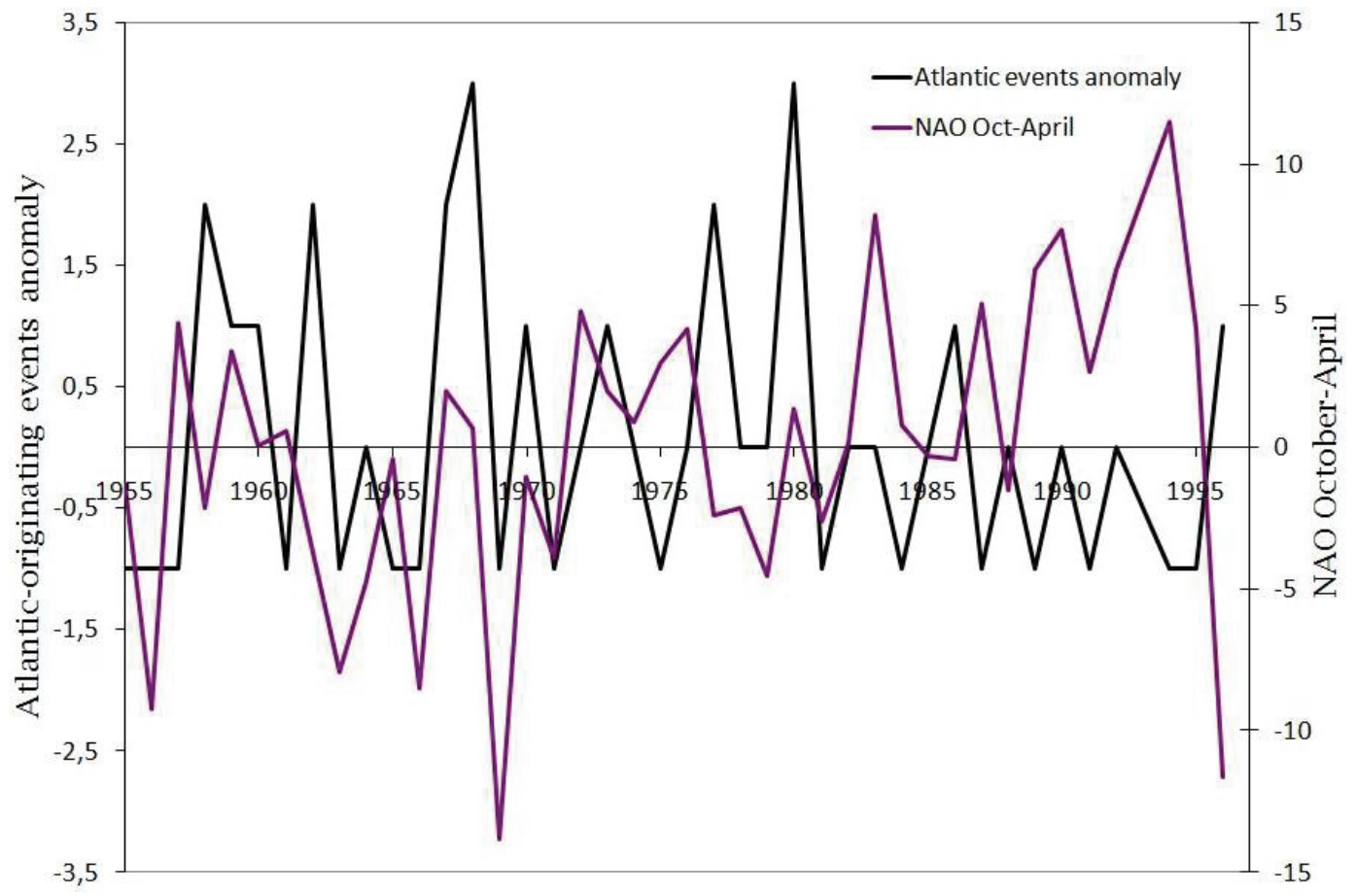

Figure 4-4: Variation of the Atlantic-originating major precipitation events anomaly and winter NAO index between 1955 and 1996. The black line represents the 1955-1996 major events anomalies and the purple line represents the Oct-April NAO index. 


\section{CHAPTER 5}

\section{Conclusion}

Although precipitation and storms over the western Canadian Arctic have been examined (e.g. Hanesiak et al., 1997; Hudak and Young, 2002), few published studies focused on the Canadian Archipelago (Intihar and Stewart, 2005; Roberts et al., 2008). This study has documented the main characteristics of the 1955-1996 major precipitation events at Iqaluit. Moreover, the analysis of the events producing the highest precipitation accumulation after 1978 for each origin group has been carried out to better understand the internal features of major precipitation events.

A daily precipitation accumulation that exceeded the $97^{\text {th }}$ percentile of daily corrected precipitation accumulation was used to select major events. Allowing multi-day events as long as the daily accumulation threshold was satisfied and considering all types of precipitation, a total of 194 cold-season significant precipitation events at Iqaluit satisfied the threshold. This definition is based after Beniston et al. (2007), Frich at al. (2002), and Jones (2000), which led to a station-specific threshold.

The duration of the event and the precipitation rate were the most important factors influencing on the amount of precipitation. On average, a major precipitation event at Iqaluit produced $16.7 \mathrm{~mm}$ of precipitation, mainly under the form of snow, with and average precipitation rate of $0.8 \mathrm{~mm} / \mathrm{h}$. Larger precipitation accumulation events tend to be associated with longer events and low precipitation rate. In contrast, the speed of motion of a system was not a critical factor influencing on the precipitation amount. For example, fast-moving 
systems were associated with both low and high precipitation accumulation events.

A large variability in the origin region and storm tracks of systems leading to major events was observed in contrast to other regions of the Arctic. Systems affecting Iqaluit were from the South, the West, the Atlantic, the Arctic Ocean or were triggered by short-wave troughs. In addition, systems either passed east or west of Iqaluit. In contrast, storms affecting the Beaufort Sea or northern Russia were mainly from the South or the West (e.g. Whittaker and Horn, 1984; Hudak and Young, 2002).

The most severe events tend to be associated with South and Atlanticoriginating systems. In contrast, storms with no obvious origin, Others, tend to be associated with the lower-accumulation major events, and West-originating events produced a diversity of accumulation amounts (Figure 4-3)

The deep regions of saturation or near-saturation with respect to liquid/ice were the common tropospheric structures during major precipitation events at Iqaluit (Table 4-5). Such high moisture content in the atmosphere suggests that deep saturation or near-saturation regions are required to overcome the usually dry atmospheric conditions in the Arctic and major precipitation events.

The presence of a surface front was observed during 126 cases, illustrating the critical role of cyclonic activity in generating of major precipitation events. Warm fronts were typical of these events, observed during 109 events (56\%), whereas cold fronts accounted for 17 events. In contrast, 68 events were not associated with surface fronts. 
As expected for cold-season precipitation events, 142 events produced only snow. However, more than a quarter of the events produced at least one other type of precipitation besides snow, possibly linked with the high occurrence of warm surface fronts.

The surrounding topographic features influenced the surface wind direction during major precipitation events. In $77 \%$ of the cases, wind direction during was in the north-west/south-east corridor. North-easterly winds accounted for $13 \%$ of the observations whereas $1 \%$ of the winds were from the Southwesterly. Moreover, it was not uncommon for major precipitation events to be associated with strong winds; $60 \%$ of the major events recorded winds $\geq 40 \mathrm{~km} / \mathrm{h}$.

Despite the increase in cyclonic activity in the Arctic reported by McCabe et al. (2001) and Zhang et al. (2004), no trend in the occurrence of major precipitation events has been observed over the last 41 years. The NAO index tends to influence their occurrence, but it is not a determinant factor.

Future work on precipitation events at Iqaluit needs to consider several issues. For example, storm tracks and atmospheric conditions leading to major precipitation events could be compared with the ones leading to average and weak events to determine if major precipitation events are the result of different atmospheric dynamics. The analysis of cases in great detail needs to be carried out following the fall 2007 STAR field campaign based at Iqaluit (Hanesiak et al., 2008). In terms of the global water cycle (Dai and Trenberth, 2002), source regions of water vapour and storm efficiency could also be addressed. An increase in temperature and decrease in sea-ice cover are predicted by climate change 
studies (e.g. Johannessen et al., 1999; Zhang et al., 2000). Such changes may affect the mechanisms leading to major precipitation events and could lead to increased storm intensity in the Arctic. Finally, the analysis of major precipitation events at Iqaluit should be performed until the present day when corrected precipitation is made available and the extension of this study to additional sites over the Canadian Archipelago and the entire Canadian Arctic is considered.

In summary, the thesis has examined the characteristics and internal features of 194 major precipitation events observed at Iqaluit over a 41-year period. The occurrence of such events was mainly linked with synoptic-scale activity, but smaller scale embedded features such as surface fronts, short-wave troughs, deep regions of high moisture content, and topographic alteration were contributing factors. 

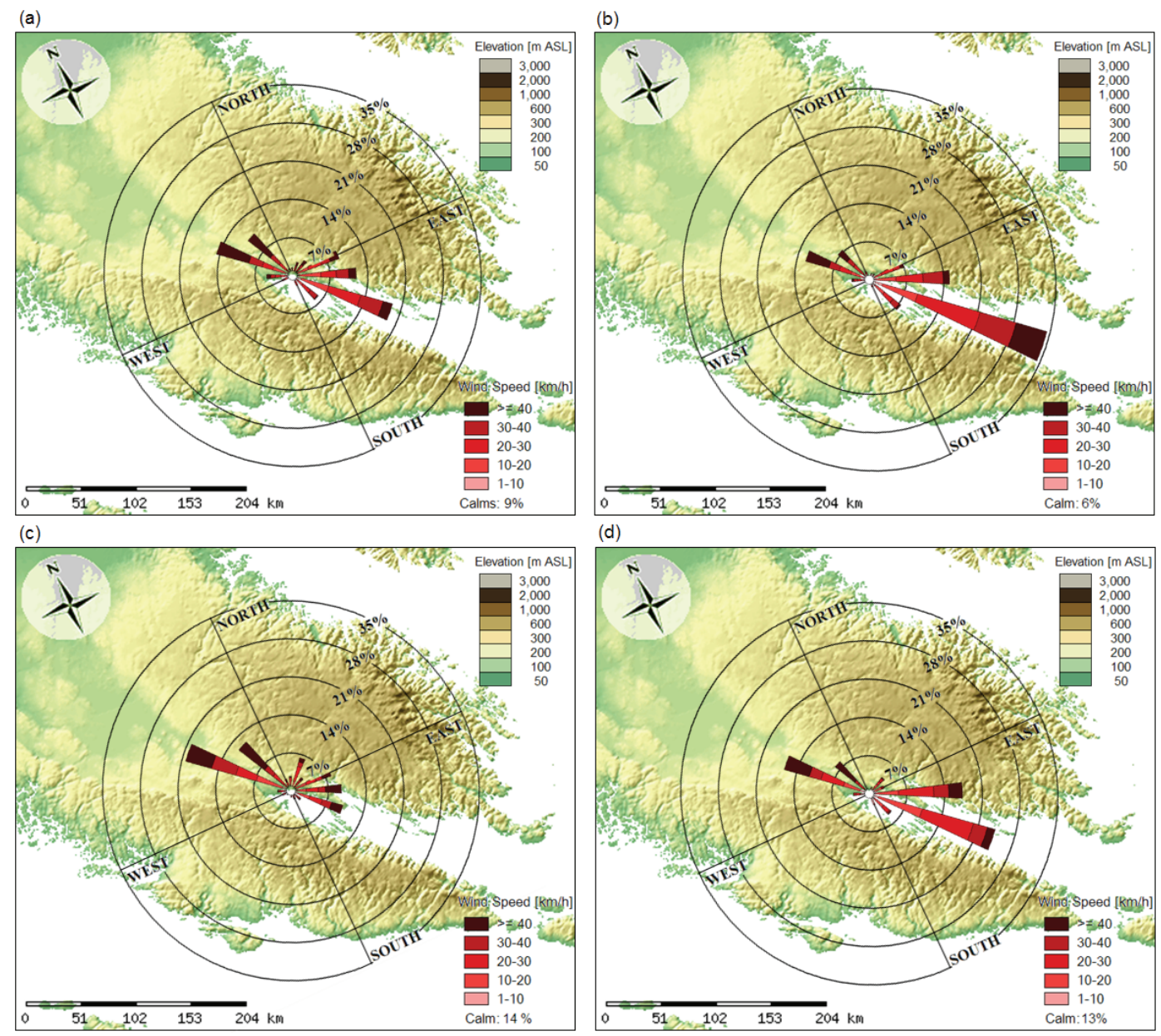

Figure A-1: Percent-frequency of surface wind direction (in $20^{\circ}$-intervals) and speed $(\mathrm{km} / \mathrm{h})$ observed during the (a) the 78 South-originating events, (b) the 57 West-originating events, (c) the 44 Atlantic-originating events, and (d) the 15 Others events (Background map adapted from the Atlas of Canada, 2008). 


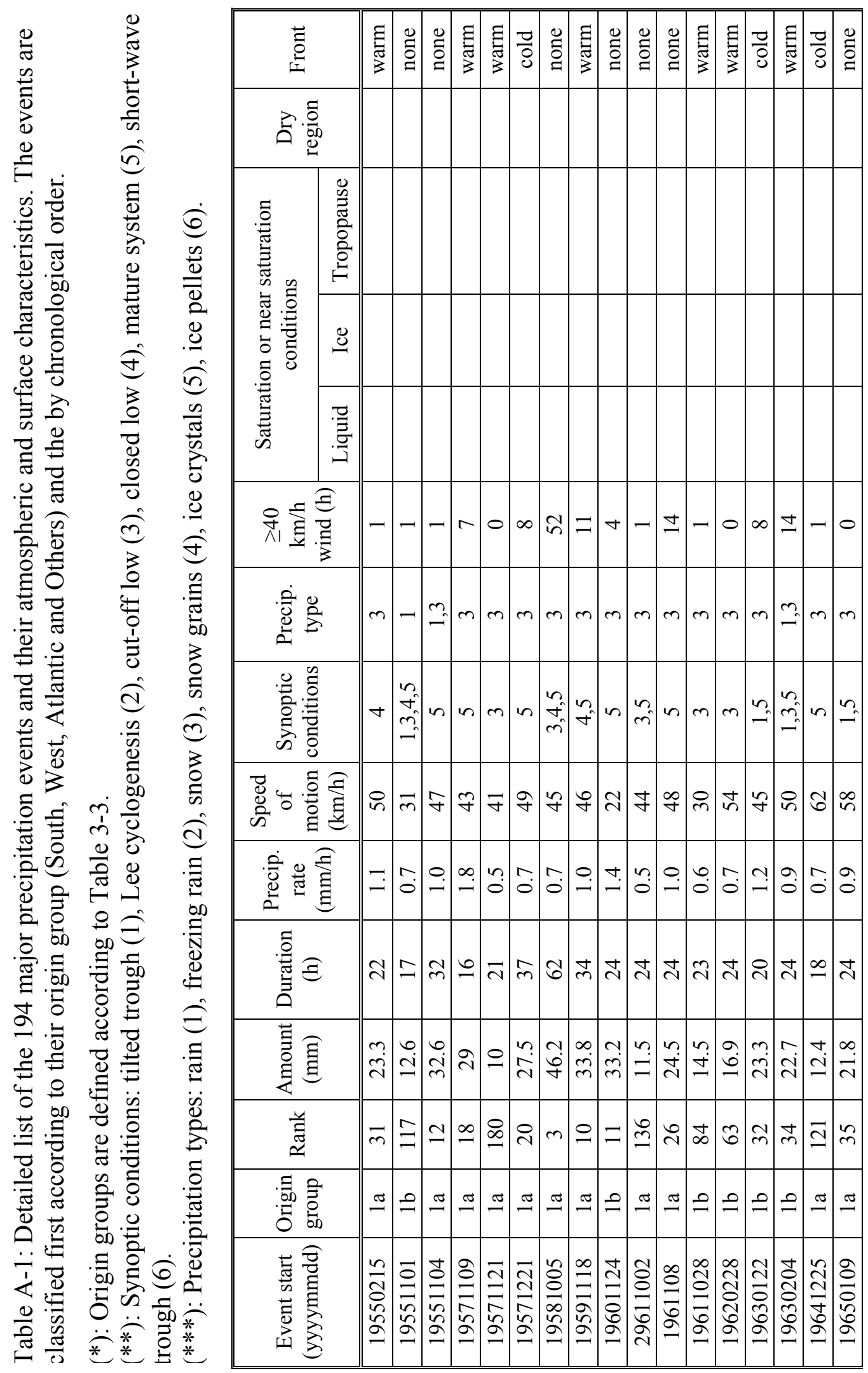




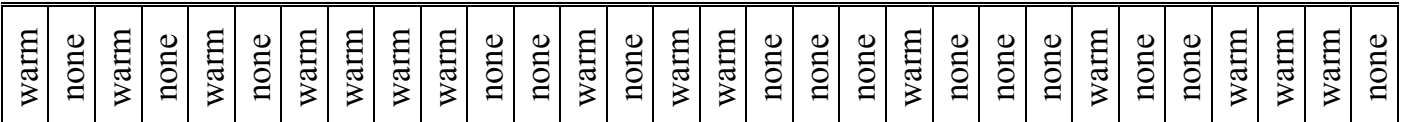

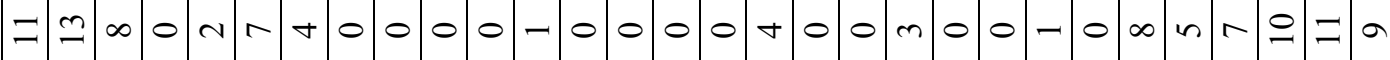

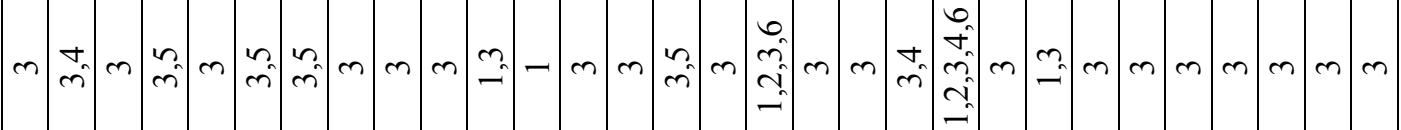

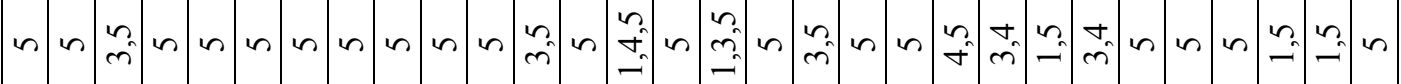

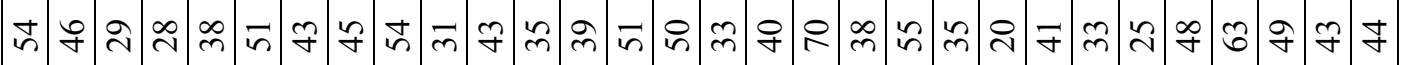

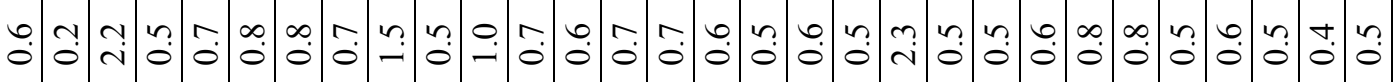

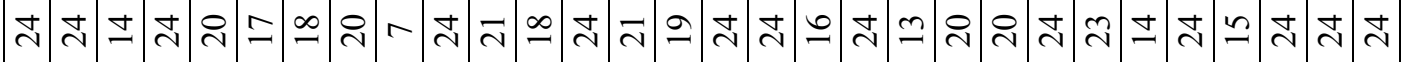

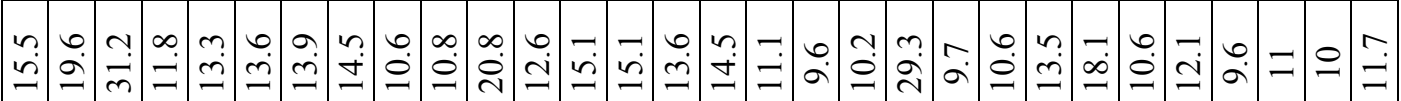

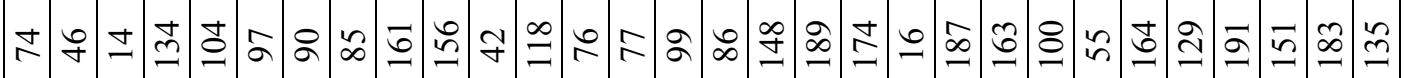

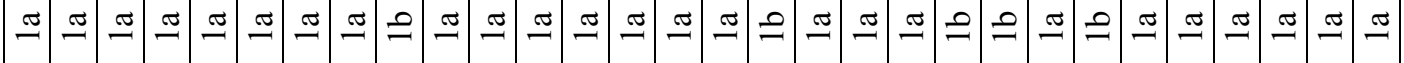

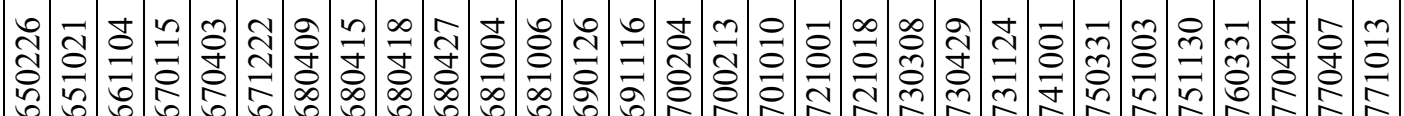
ఏ丶万人 


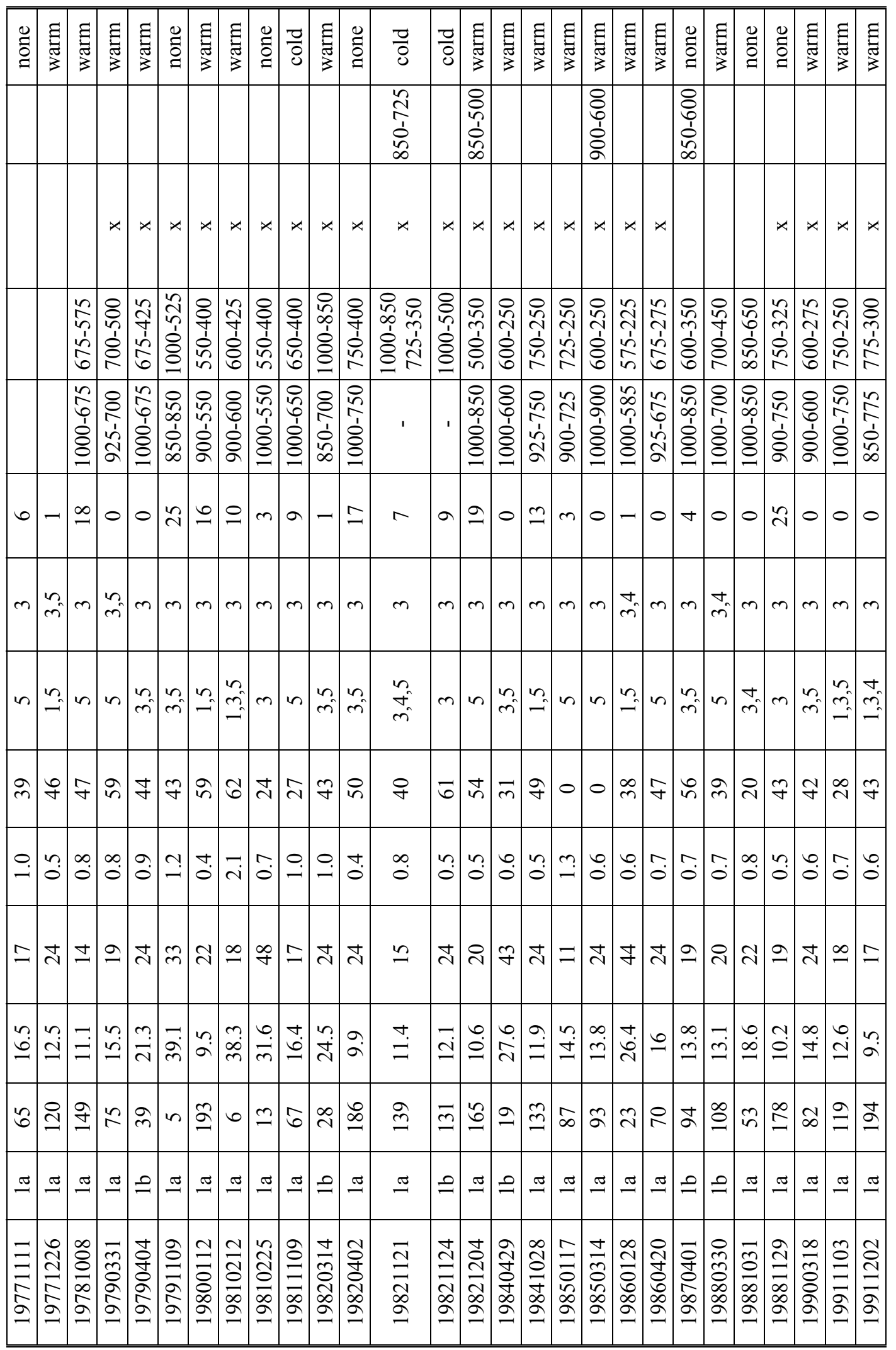




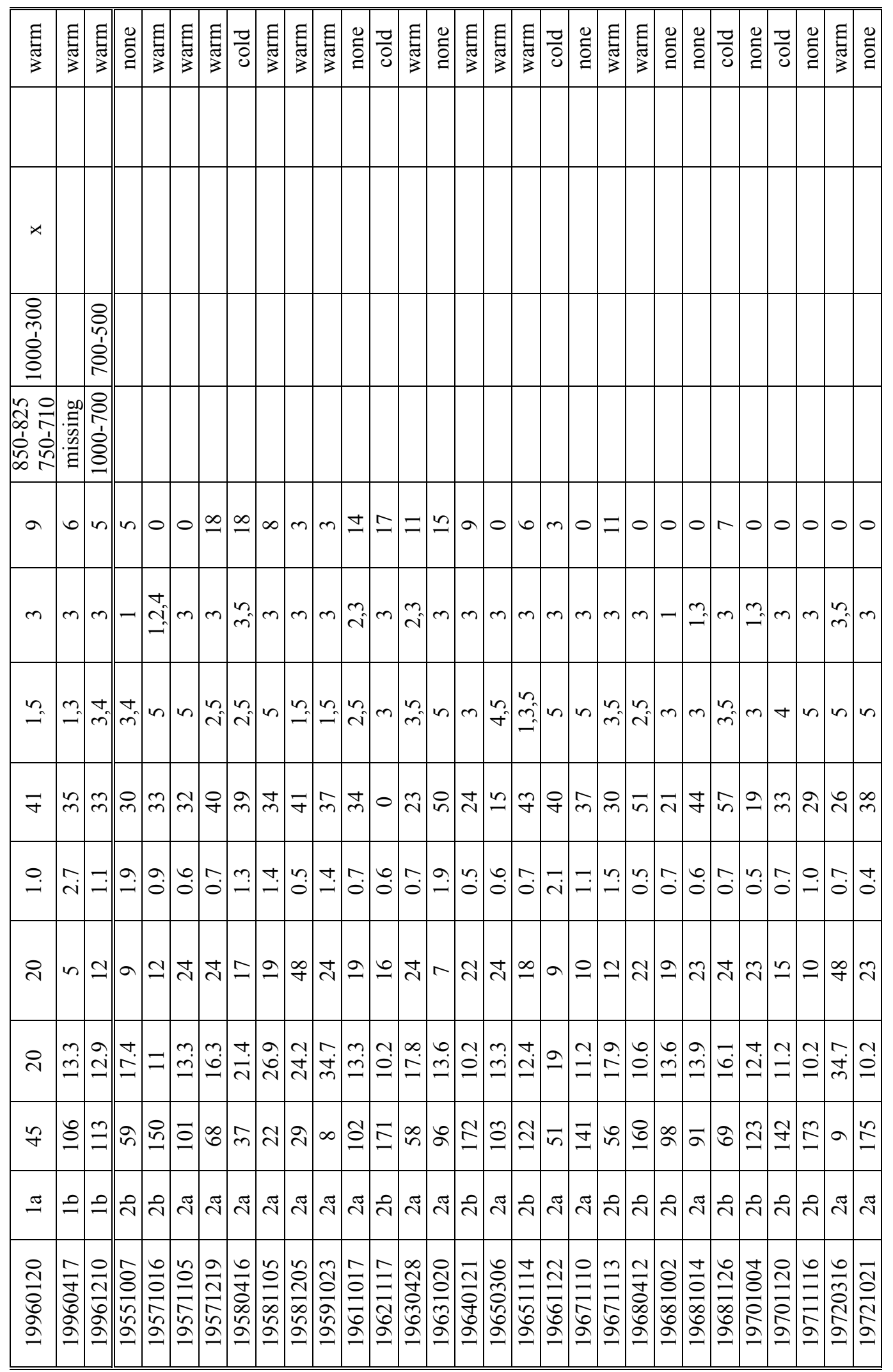




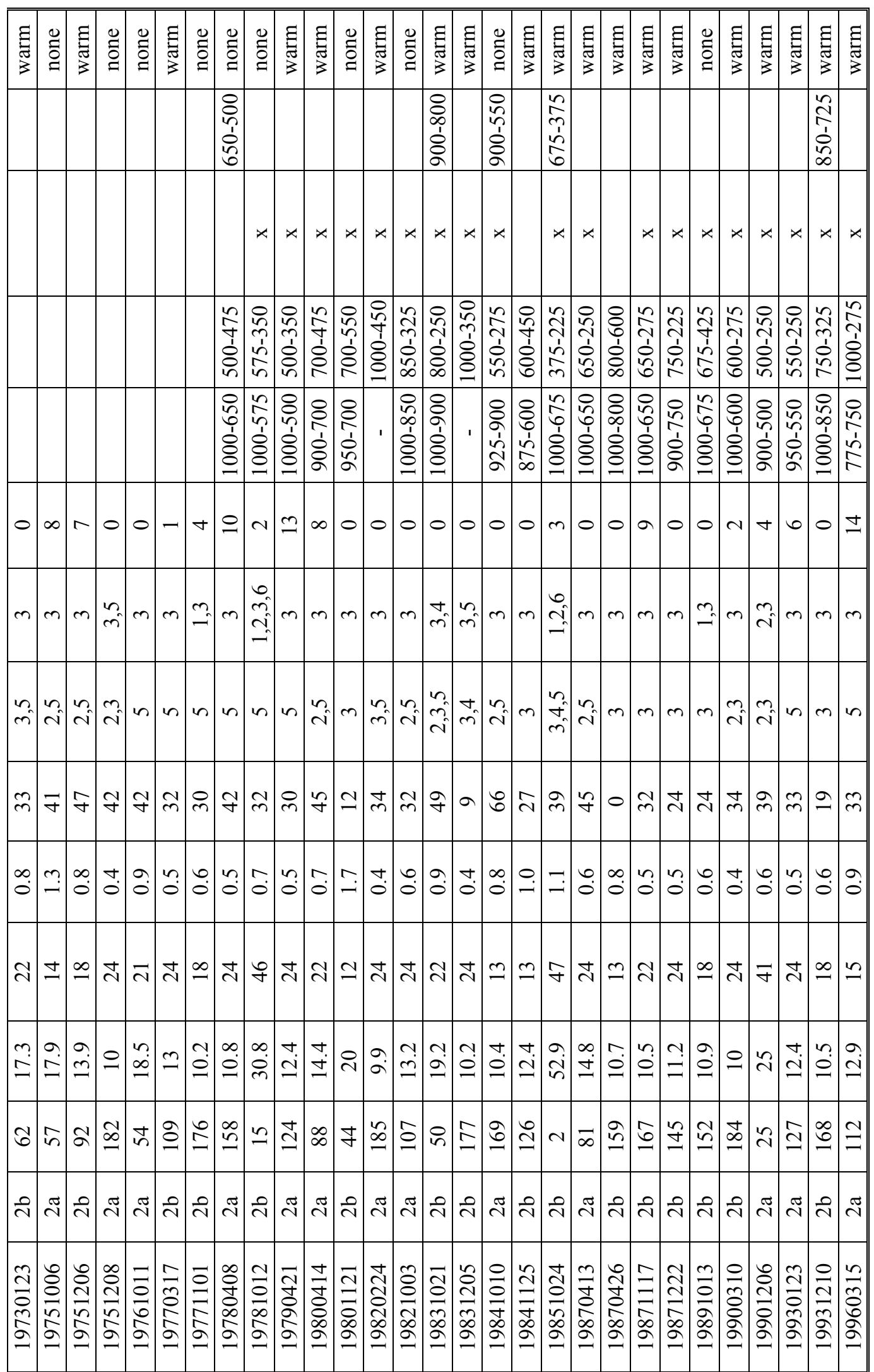




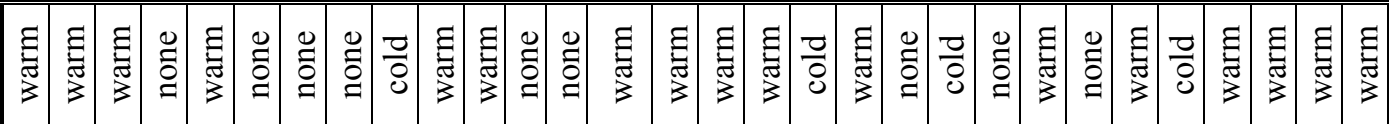

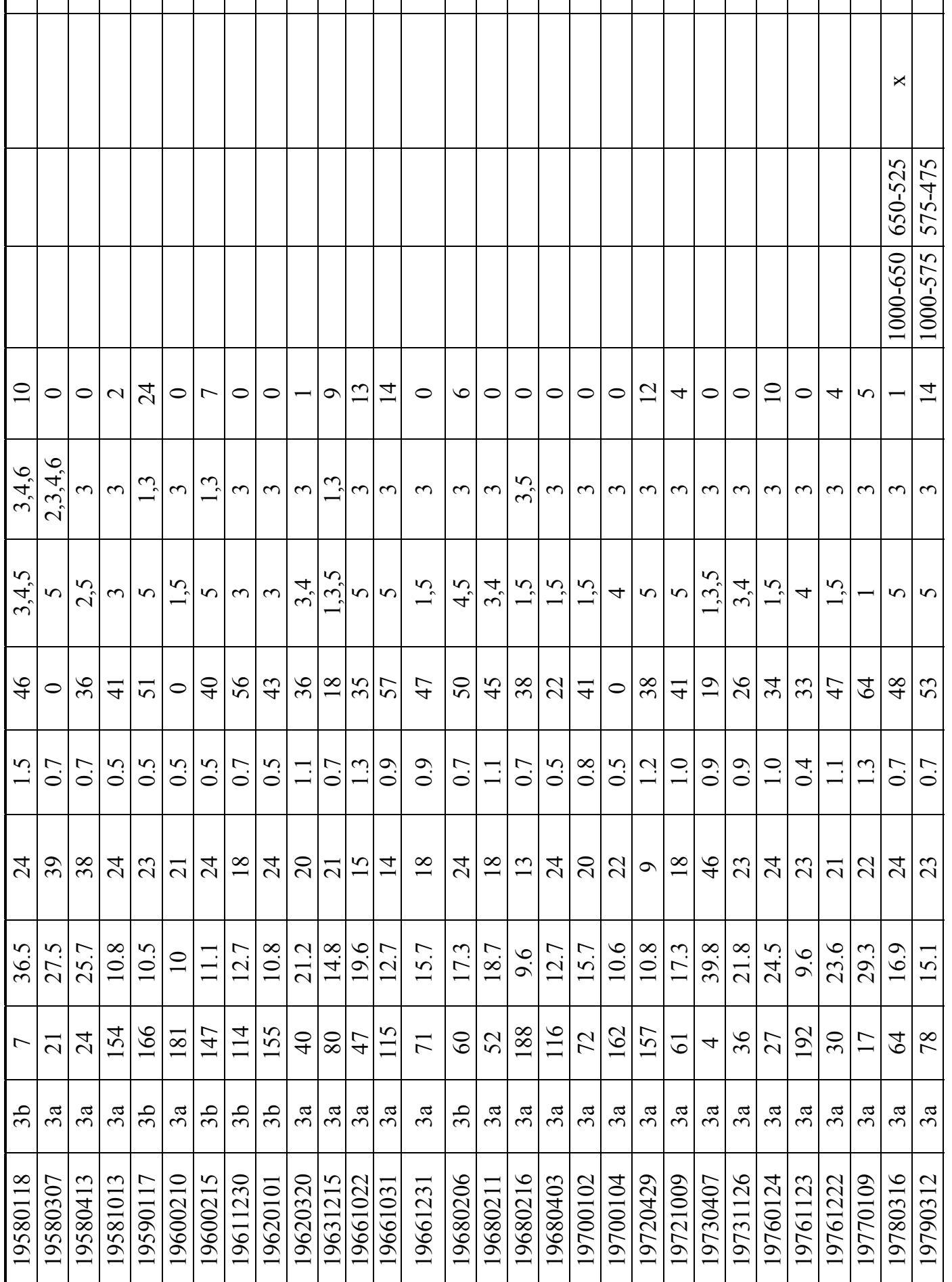




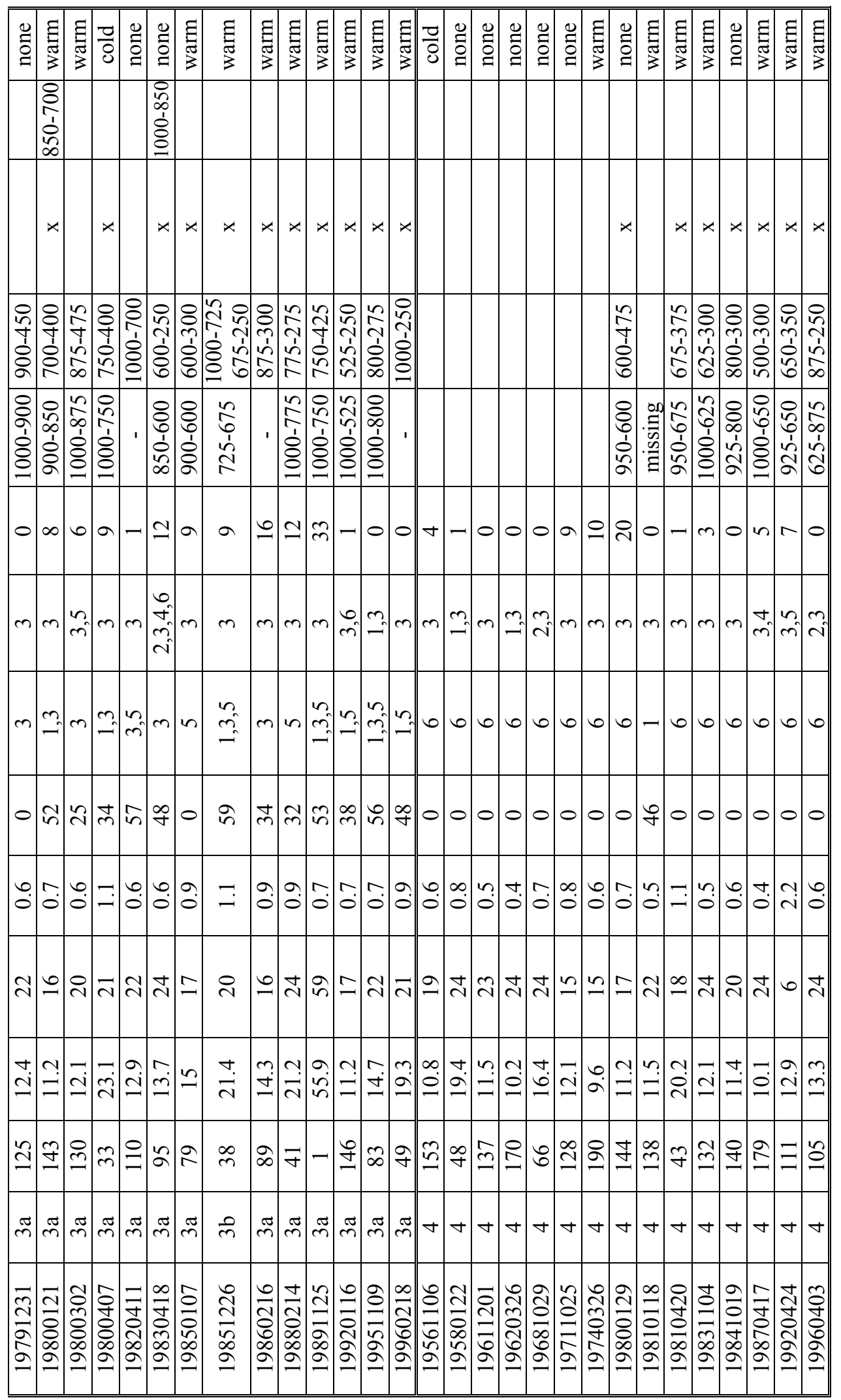




\section{Bibliography}

ACIA, 2005: Arctic Climate Impact Assessment. Cambridge University Press, 1042 pages, viewed at http://www.acia.uaf.edu, page viewed: Jan. 10, 2008.

Ahrens, C. D., November 1, 2004: Meteorology Today: An Introduction to Weather, Climate, and the Environment, Brooks Cole; 7 edition, 624 pages.

Appenzeller, C., J. Schwander, S. Sommer, and T. F. Stocker, 1998: The North Atlantic oscillation and its imprint on precipitation and ice accumulation in Greenland. Geophysical Research Letters, 25:1939-1942.

Atlas of Canada, 2008: www.atlas.gc.ca, Natural Resources Canada, page viewed on January 15, 2008.

Asuma, Y., S. Iwata, K. Kikuchi, G. W. K. Moore, R. Kimura, and K. Tsuboki, 1998: Precipitation features observed by Doppler radar at Tuktoyaktuk, Northwest Territories, Canada, during the Beaufort and Arctic storms experiment. Mon. Wea. Rev., 126:2384-2405.

Asuma, Y., Y. Inoue, K. Kikuchi, M. Kajikawa, N. Sato, and T. Hayasaka, 2000:

Wintertime precipitation behavior in the western Canadian Arctic region. Journal of Geophysical Research, 105:14927-14939.

Bell G. D., and M. S. Halpert, 1998: Climate assessment for 1997. Bull. Amer. Meteor. Soc., 79:S1-S50.

Beniston M, D. B. Stephenson, O. B. Christensen, C. A. Ferro, C. Frei, S. Goyette, K. Halsnaes, T. Holt, K. Jylh, and B. Koffi, 2007: Future extreme events in European climate: an exploration of regional climate model projections. Climatic Change, 81(s1): 71.

Bjerknes, J., 1919: On the structure of moving cyclones. Mon. Wea. Rev., 47:95-99.

Bluestein, H. B., 1992: Synoptic-dynamic meteorology in midlatitudes. Volume I. Principles of kinematics and dynamics. Oxford University Press, New York, 431 pages. 
Bosart, L. F., G. J. Hakim, K. R. Tyle, M. A. Bedrick, W. E. Bracken, M. J. Dickinson, and D. M. Schultz, 1996: Large-scale antecedent conditions associated with the 12-14 March 1993 cyclone ("Superstorm '93") over Eastern North America. Mon. Wea. Rev., 124:865-1891.

Bryazing, N. N, 1976: early mean precipitation in the Arctic region accounting for measurement errors. Proceedings: Arctic and Antarctic Research Institute, 23:40-74.

Bromwich, D. H., 1997: The atmospheric moisture budget of the Arctic and Antarctic from atmospheric numerical analyses. Proceedings of the Conference on ACSYS Polar Processes and Global Climate. Rosario, Washington: World Climate Research Program. 30-32.

Bromwich, D. H., Q. S. Chen, Y. Li, and R. L. Cullather, 1999: Precipitation over Greenland and its relation to the North Atlantic Oscillation, J. Geophys. Res., 104(22): $103-115$.

Chang, E. K. M., and Y. Fu, 2002: Interdecadal variations in Northern Hemisphere winter storm track intensity, J. Climate, 15:642-658.

Changnon, S. A., and K. E. Kunkel, 1995: Climate-related fluctuations in Midwestern floods during 1921 1985. J. Water Res. Planning Manage., 111:326-334.

Dai A., and K. E. Trenberth, 2002: Estimates of freshwater discharge from continents: Latitudinal and seasonal variations. J. of Hydrometeorology, 3:660-687.

Dalezios, N. R., A. Loukas, L. Vasiliades, and E. Liakopoulos, 2000: Severityduration-frequency analysis of droughts and wet periods in Greece. Hydrological Sciences Journal, 45:751-770.

Environment Canada, 2006: Manual of surface weather observations, Meteorological Service of Canada, Amendment No. 15, 3 April 2006, 370 pages.

Environment Canada, 2008: http:/www.climate.weatheroffice.ec.gc.ca/, page viewed: March 10, 2008. 
Fett, R. W., S. D. Burk, W. T. Thompson, and T. L. Kozo, 1994: Environmental Phenomena of the Beaufort Sea Observed during the Leads Experiment. Bull. Amer. Meteor. Soc., 75:2131-2145.

Findcisen, W., 1940: The formation of the $0^{\circ} \mathrm{C}$ isothermal layer and fractocumulus under nimbostratus, Meteorol. Zeit., 57:49-54.

Ford, J. D., B. Smit, and J. Wandel, 2006: Vulnerability to climate change in the arctic: A case study from arctic bay, Canada. Global Environmental Change, 16(2):145-160.

Førland, E. J., and I. Hanssen-Bauer, 2000: Increased precipitation in the Norwegian Arctic: True or false? Climatic Change, 46:485-509.

Frich, P., L. V. Alexander, P. Della-Marta, B. Gleason, M. Haylock, A. M. G. Klein Tank, and T. Peterson, 2002: Observed coherent changes in climatic extremes during the second half of the twentieth century, Clim. Res., 19:193-212.

Glantz S. A., and B. K. Slinker, 2000: Primer of Applied Regression and Analysis of Variance ( $2^{\text {nd }}$ ed.), New York, McGraw-Hill.

Groisman P. Y., B. Sun, R.S. Vose, J. H. Lawrimore, P. H. Whitfield, E. Førland, I. Hanssen-Bauer, M. C. Serreze, V. N. Razuvaec, and G. V. Alekseev, 2003: Contemporary climate changes in high latitudes of the northern hemisphere: daily time resolution, AMS Conference, Paper 65269.

Gryschka, M., and S. Raasch, 2005: Roll convection during a cold air outbreak: A large eddy simulation with stationary model domain. Geophys. Res. Lett., 32:L14805, doi:10.1029/2005GL022872.

Hanesiak, J., R. E. Stewart, K. Szeto, D. Hudak, and H. Leighton, 1997: The structure, water budget, and radiational features of a high-latitude warm front. Journal of the Atmospheric Sciences, 12:1553-1573.

Hanesiak, J. M., and X. L. Wang, 2005: Adverse-Weather Trends in the Canadian Arctic. Journal of Climate, 18:3140-3156.

Hanesiak, J. M., and co-authors, 2008: Storm Studies in the Arctic (STAR): Preliminary Results, International Conference on Clouds and Precipitation, Cancun, Mexico, July 7 - 13, 2008. 
Harper, J. R., R. F. Henry, and G.G. Stewart, 1988: Maximum storm surge elevations in the Tuktoyaktuk region of the Canadian Beaufort Sea. Arctic, 41:48-52.

Henson, W. L., R. E. Stewart, and B. Kochtubajda, 2007: On the precipitation and related features of the 1998 Ice Storm in the Montreal area. Atmos. Res, 83:36-54.

Hudak, D. R., R. E. Stewart, G. W. K. Moore, and E. T. Hudson, 1995: Synoptic conditions of storms in the Southern Beaufort Sea, Expectations for BASE. Proc. Conf. Polar Meteorol. Oceanogr., 4:234-237.

Hudak, D. R., and J. M. C. Young, 2002: Storm climatology of the southern Beaufort Sea. Atmosphere-Ocean, 40:145-158.

Hudson, E., D. Aihoshi, T. Gaines, G. Simard, and J., Mulluck, 2001: The weather of Nunavut and the Arctic. Nav Canada, 230 pages.

Hulme, M., 1995: Estimating Global Changes in Precipitation. Weather, 50(2):34-42.

Hurrell, J. W., 1995: Decadal trends in the North Atlantic Oscillation: Regional temperatures and precipitation. Science, 269:676-679.

Hurrell J. W., Y. Kushnir, G. Ottersen, and M. Visbeck, 2003: The North Atlantic Oscillation: climatic significance and environmental impact. Geophysical Monograph, 134: 1-35.

Intihar, M. R., and R. E. Stewart, 2005: Extratropical cyclones and precipitation within the Canadian Archipelago during the cold season. Arctic, 58: 162-174.

IPCC, 2001: Climate Change 2001: The Scientific Basis, 882 pages, viewed at http://www.grida.no/climate/ipcc_tar/index.htm, page viewed: Jan. 10, 2008.

Isaac, G., and R. Stuart, 1992: Temperature-Precipitation Relationships for Canadian Stations. Journal of Climate, 5:822-830.

Jia, X., J. Derome, and H. Lin, 2007: Comparison of the Life Cycles of the NAO Using Different Definitions. 20:5992-6011.

Johannessen, O. M., E. V., Shaline, and M. W. Miles, 1999: Satellite evidence for an Arctic sea ice cover in transformation. Science, 286:1937- 1939 . 
Jones C., 2000: Occurrence of extreme precipitation events in California and relationships with the Madden-Julian oscillation. Journal of Climate, 13:3576-3587.

Kain J. S., S. M. Goss, and M. E. Baldwin, 2000: The melting effect as a factor in precipitation-type forecasting. Wea. Forecasting, 15:700-714.

Kalnay, E., and Coauthors, 1996: The NCEP/NCAR 40-Year Reanalysis Project. Bulletin of American Meteorological Society, 77:437-471.

Kocin, P. J., P. N. Schumacher, R. F. Morales Jr., and L. W. Uccellini, 1995: Overview of the 12-14 March 1993 superstorm. Bulletin of American Meteorological Society, 76:165-182.

Koch, S. E., M. DesJardins, and P. J. Kocin, 1983: An interactive Barnes objective map analysis scheme for use with satellite and conventional data. Journal of Climate Applied Meteor., 22:1487-1503.

Konrad C. E., 2001: The most extreme precipitation events over the eastern U.S. from 1950-1996: considerations of scale. Journal of Hydrometeorology, 2:309-325.

Kotz, S., and S. Nadarajah, 2001: Extreme value distributions: Theory and applications, World Scientific Publishing Company; 1st edition, 185 pages.

Kunkel, K. E., S. A. Changnon, and J. R. Angel, 1994: Climatic aspects of the 1993 upper Mississippi River basin flood. Bulletin of American Meteorological Society, 75:811-822.

Kunkel, K. E., D. R. Easterling, K. Redmond, and K. Hubbard, 2003: Temporal variations of extreme precipitation events in the United States: 1895-2000, Geophys. Res. Lett., 30(17):1900.

Lundgren, L., 1986: Environmental Geology. Englewood Cliffs, New Jersey (Prentice-Hall), 576 pages.

Marshall J., Y. Kushnir, D. Battisti, P. Chang, A. Czaja, R. Dickson, J. Hurrell, M. McCartney, R. Saravanan, and M. Visbeck, 2001: North Atlantic climate variability: phenomena, impacts and mechanisms. International Journal of Climatology, 21(15):1863. 
Maxwell, J. B., 1981: Climatic regions of the Canadian Arctic Islands. Arctic, 34:225-240.

Mccabe, G. J., M. P. Clark, and M. C. Serreze, 2001: Trends in Northern Hemisphere surface cyclone frequency and intensity. Journal of Climate, 14:2763- 2768.

Mekis, E., and W. D. Hogg, 1999: Rehabilitation and analysis of Canadian daily precipitation time series. Atmos.-Ocean, 37:53- 85 .

Mesinger, F., and Coauthors, 2006: North American Regional Reanalysis. Bulletin of American Meteorological Society, 87:343-360.

Milbrandt J. A., and M. K. Yau, 2001: A mesoscale modeling study of the 1996 Saguenay flood. Mon. Wea. Rev., 129:1419-1440.

Mosley-Thompson, E., C. R. Readinger, P. Craigmile, L. G. Thompson, and C. A. Calder, 2005: Regional sensitivity of Greenland precipitation to NAO variability. Geophysical Research Letter, 32:L24707.

Nadeau, D., 2007: Impacts of synoptic atmospheric circulations and topographic conditions on sustained strong surface winds over Southern Nunavut, Master's thesis, McGill University, Montréal, Canada, 143 pages.

Nawri, N., and R. E. Stewart, 2006: Climatological features of orographic lowlevel jets within Frobisher Bay. Atmos.-Ocean, 44:397-413.

Newton, C., 1969: The role of extratropical disturbances in the global atmosphere in the Global Circulation of the Atmosphere. Royal Meteorological Society, $137-158$.

Nielsen, J. W., and R. M. Dole, 1992: A survey of extratropical cyclone characteristics during GALE. Monthly Weather Review, 120:1156-1167.

Perry-Castañeda Library Map Collection, 2008: http://www.lib.utexas.edu/maps/, page viewed: January 29, 2008, page last modified: January 25, 2008.

Przybylak R., 2002: Variability of total and solid precipitation in the Canadian Arctic from 1950 to 1995. International Journal of Climatology, 22(4):395.

Roberts, E. and R.E. Stewart, 2008: On the occurrence of freezing rain and ice pellets over the eastern Canadian Arctic. Atmos. Res. (In Press). 
Roberts, E., N. Nawri, and R.E. Stewart, 2008: On the Storms Passing over Southern Baffin Island during Autumn 2005. Arctic, (Accepted).

Roebber, P. J., and J. R. Gyakum, 2003: Orographic Influences on the mesoscale structure of the 1998 ice storm. Monthly Weather Review, 131:27-50.

Schultz, D. M., D. Keyser, and L. F. Bosart, 1998: The effect of large-scale flow on low-level frontal structure and evolution in midlatitude cyclones. Mon. Wea. Rev. 126:1767-1791.

Schumacher R. S., and R. H Johnson, 2006: Characteristics of U.S. Extreme Rain Events during 1999-2003. Weather and Forecasting, 21(1):69-85.

Serreze M. C., and R. Barry, 1988: Synoptic activity in the Arctic Basin, 197985. Journal of Climate, 1:1276-1295.

Serreze, M. C., J. E. Box, R. G. Barry, and J. E. Walsh, 1993: Characteristics of Arctic synoptic activity, 1952-1989. Meteorological and Atmospheric Physics, 51:147-164.

Serreze M. C., 1995: Climatological aspects of cyclone development and decay in the Arctic. Atmos.-Ocean, 33:1-23.

Serreze M. C., and C. M. Hurst, 2000: Representation of mean Arctic precipitation from NCEP-NCAR and ERA reanalyses. Journal of Climate, 13, 182-201.

Shupe, M. D., S. Y. Matrosov, and T. Uttal, 2006: Arctic mixed-phase cloud properties derived from surface-based sensors at SHEBA. Journal of the Atmospheric Sciences, 63(2):697-711.

Stewart, R. E., D. Bachand, R. R. Dunkley, A. C. Giles, B. Lawson, L. Legal, S. T. Miller, B. P. Murphy, M. N. Parker, B. J. Paruk, and M. K. Yau, 1995: Winter storms over Canada. Atmos.-Ocean, 33:223-248.

Tsukernik, M., D. N. Kindig, and M. C. Serreze, 2007: Characteristics of winter cyclone activity in the northern North Atlantic: Insights from observations and regional modeling. Journal of Geophysical. Research, 112(D3):D03101.

University of Wyoming, 2008: http://weather.uwyo.edu/upperair/sounding.html, page viewed: March 10, 2008. 
Visbeck, M., J. W. Hurrell, L. Polvani, and H. M. Cullen, 2001: The North Atlantic Oscillation: Past, present and future. Proceedings at the 12th Annual Symposium on Frontiers of Science, 98:12876-12877.

Wang, X. L., V. R. Swail, and F. W. Zwiers, 2004: Changes in extratropical storm tracks and cyclone activity as derived from two global reanalyses and the Canadian CGCM2 projections of future climate. Preprints, Eighth Int. Workshop on Wave Hindcasting and Forecasting, Oahu, HI, Environment Canada, Paper B1.

Whittaker, L. M., and L. H. Horn, 1981: Geographical and Seasonal Distribution of North American Cyclogenesis, 1958-1977. Monthly Weather Review, 109:2312-2322.

Whittaker, L. M., and L. H. Horn, 1984: Northern Hemisphere extratropical cyclone activity for four mid-season months. Journal of Climatology, 4:297-310.

Ye H., and J. R. Mather, 1997: Polar snow cover changes and global warming. International Journal of Climatology, 17: 155-162.

Yin, J.H., 2005: A consistent poleward shift in the storm tracks in simulations of $21^{\text {st }}$ century climate. Geophysical Research Letters, 32:L18701.

Zhao P., X. D. Zhang, X. J. Zhou, M. Ikeda, and Y. H. Yin, 2004: The Sea ice extent anomaly in the North Pacific and its impact on the East Asian summer monsoon rainfall. Journal of Climate, 17:3434-3447.

Zhang, X., L. A. Vincent, W. D. Hogg, and A. Niitsoo, 2000: Temperature and precipitation trends in Canada during the 20th century. Atmos.-Ocean, 38:395-429.

Zhang, X., W .D. Hogg, and E. Mekis, 2001: Spatial and temporal characteristics of heavy precipitation events over Canada. Journal of Climate, 14:19231936.

Zhang, X., J. E. Walsh, J. Zhang, U. S. Bhatt, and M. Ikeda, 2004: Climatology and interannual variability of arctic cyclone activity: 1948-2002. Journal of Climate, 17:2300-2317. 